\title{
Sedimentology of the grounding zone of the Kamb Ice Stream, Siple Coast, West Antarctica
}

by

Theo Calkin

2021

A thesis

Submitted to Victoria University of Wellington

In partial fulfilment of the requirements for the degree of Master of Science in Geology 


\begin{abstract}
The grounding line of the Siple Coast incorporates six major ice streams, which together drain around a third of the West Antarctic Ice Sheet. Previously, the $2000 \mathrm{~km}$-long feature had only been sampled and directly observed at Whillans Ice Stream. This thesis examines glaciomarine sediment and processes operating at the presently stagnant Kamb Ice Stream (KIS) grounding zone $\sim 3.3 \mathrm{~km}$ seaward of the modern grounding line (Lat. -82.78, Long. -155.16), where the ice is $590 \mathrm{~m}$ thick and overlies a $30 \mathrm{~m}$ thick water column. KIS-GZ is the planned site for a deep drilling project in 2023.
\end{abstract}

The sea floor was accessed using a hot water drill in the 2019/20 Antarctic field season. A remotely operated submersible ('Icefin') was deployed under the ice shelf, which provided $800 \mathrm{~m}$ of sea floor video toward the grounding line. A small number of short $(\sim 0.6 \mathrm{~m})$ gravity cores were collected from the seafloor, one of which was examined in this study.

The Icefin video imagery was processed using Structure-from-Motion (SfM) software, enabling the identification of two previously unrecognised sea floor sedimentary facies. One is defined by ubiquitous cm-scale ripples in fine-medium sand, where the ripples are aligned with the prevailing tidal currents flowing parallel to the grounding line. Observed current speeds are too low for the ripples to be generated under the modern oceanographic regime. The second facies is defined by abundant dropstones in mediumcoarse sand. A transition zone separates the two facies. Previously unidentified decimetre-scale bedforms are present in the transition zone and near the borehole.

The lithological, geochemical, and microfossil properties of the gravity core were analysed. The core sediment is sandy diamicton with weak stratification defined by decimetre-scale changes in clast abundance. Mineral counts, zircon ages, Nd/Sr isotopes, and an immature composition indicate this sediment is sourced within the Kamb catchment. The core also contains reworked late Oligocene-late Miocene diatoms. Quaternary diatoms are absent. Ramped pyrolysis radiocarbon dating was attempted on 19 carbon fractions obtained from samples at four depths. Two pyrolysis fractions yielded ages of 31.5-33.2 ka, while the rest did not contain measurable radiocarbon. This likely reflects the reworking of radiocarbon-dead material into the sediment and can only be considered a maximum age for deposition.

Together, the sediment and video data suggest deposition of the sea floor sediment at the core site occurred subsequent to the stagnation of KIS 160 years ago. I assume that sediment concentrations are relatively uniform along the length of the ice stream and calculate that up to $\sim 2.7 \mathrm{~m}$ of diamicton was rapidly deposited at the core site as the grounding line retreated and englacial sediment melted out and settled through the water column. Accumulation in recent decades has been comparatively low. During the period of reduced sedimentation, the sea floor diamicton has been reworked to varying degrees to form ripples and winnowed lag deposits, resulting in a textural patchwork at $\mathrm{km}$ scale. 


\section{Acknowledgements}

What a ride.

An immense thank you to Antarctica New Zealand, New Zealand Post, the Antarctic Science Platform (ANTA1801), and the Antarctic Research Centre and SGEES at Victoria University of Wellington for financially supporting this thesis, and to the Antarctic Science Platform, Antarctica New Zealand, and participants in Event K862 for field and logistical support in the 2019/20 field season.

I'd like to acknowledge the input of my collaborators. The cooperation of the Icefin team, particularly Justin Lawrence and Britney Schmidt, significantly broadened the scope of this thesis in an exciting way. Thank you. Dave Harwood - an apology for all of the emails, and a big thank you for the work you put into this thesis. Craig Stevens another target of my communications - thank you for sharing your data and answering my questions promptly and with good humour. Adam Martin, Cathy Ginnane, Jocelyn Turnbull - your expertise and input on this project was invaluable.

Gavin, Cliff; this thesis really wouldn't be half the piece of science that it is without you. I really cannot thank either of you enough. Gavin, you're the engine that has kept this thesis moving. The breadth of your knowledge of Antarctic science is ridiculous! And always an obscure paper from the 80s or a quote from a Greek philosopher to back it up. From you l've learned a lot about this topic (as you would hope) but also a lot about how to approach science, integrity, and squeezing every last bit of information you can from the data you have. It's been a pleasure to work with you so closely. Cliff(y), your passion and enthusiasm for geology is infectious and has kept me connected to this thesis, even when the eyes, brain, and typing fingers were ready to give out! Your lectures in first year drew me down the geology path, and the opportunity to work with you over the years - Te Muna, Geotrips, and now on this thesis - has driven home what I love about geology.

Thank you to my parents for an amazing upbringing that has given me the confidence to shoot for the stars (or the sea floor beneath $\sim 600 \mathrm{~m}$ of ice). To all iterations of $\mathrm{my}$ flatmates at Todman Street, for being my home and family away from home. To the friends I've made through geology, some for life and some for just a few semesters - it really has been a pleasure. 
$\underline{0: \text { Acknowledgements }}$

\section{Table of Contents}

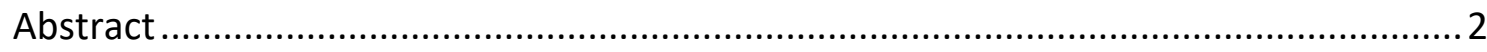

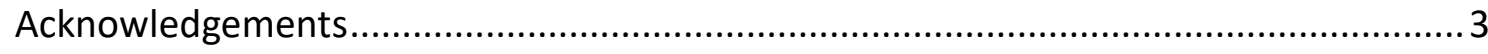

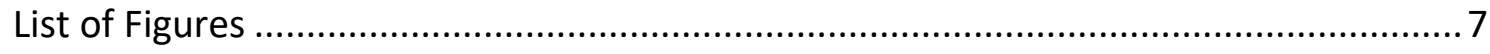

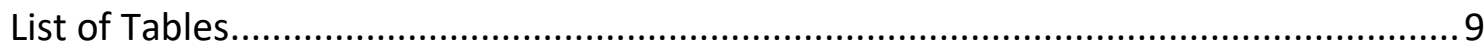

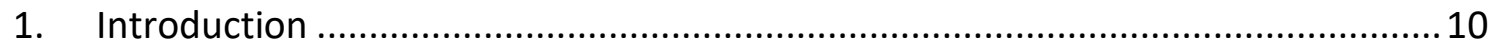

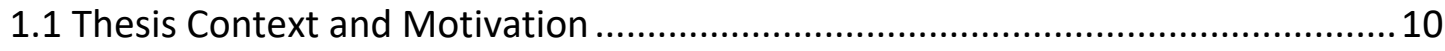

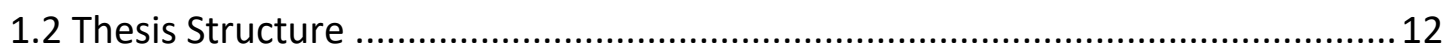

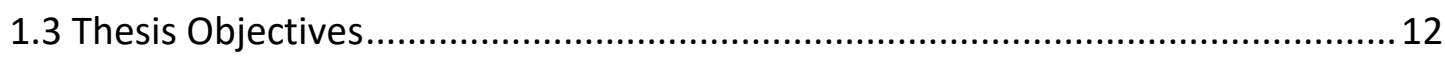

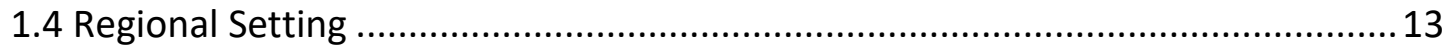

1.4.1 Geography/Glaciology ................................................................... 13

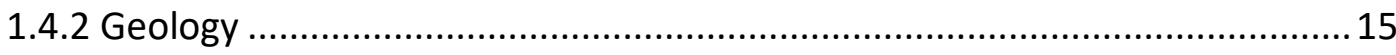

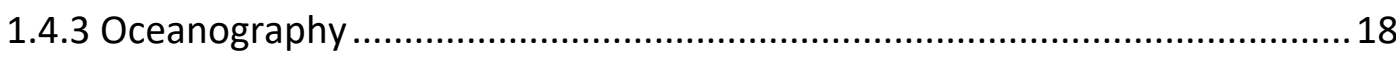

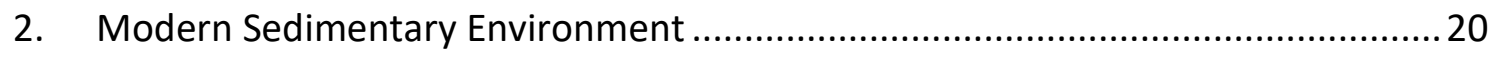

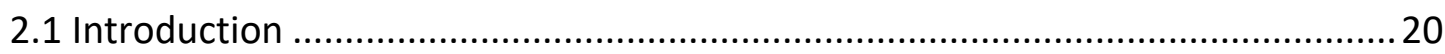

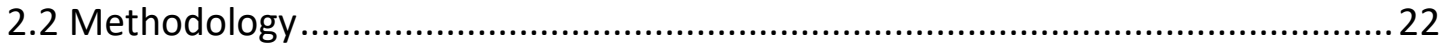

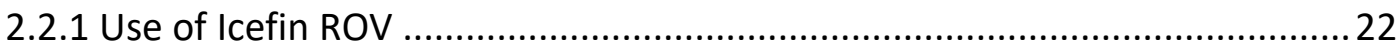

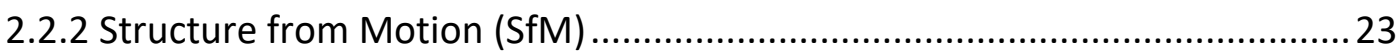

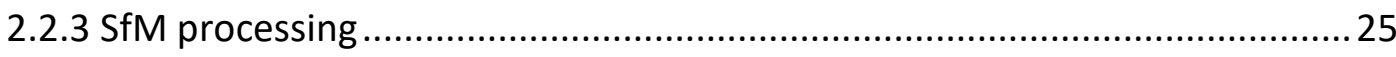

2.2.4 Coverage and accuracy of SfM products ............................................... 30

2.2.5 Extracting quantitative sea floor sediment and morphology data................ 31

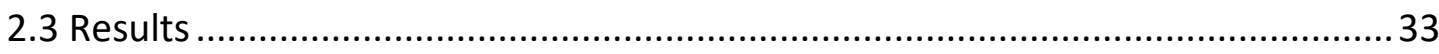

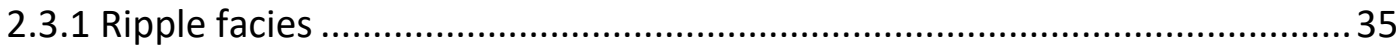

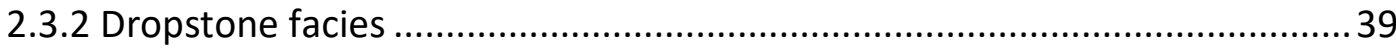

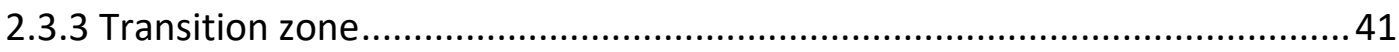

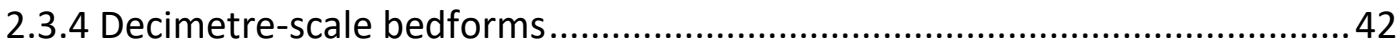

2.3.5 Biological traces on the sea floor ......................................................... 44

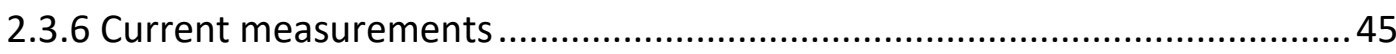

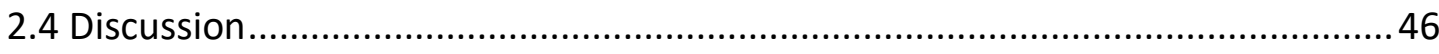

2.4.1 Processes influencing the modern sea floor ............................................. 46 
2.4.2 Methodological improvements.......................................................... 51

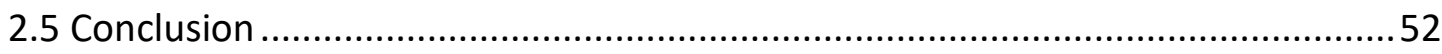

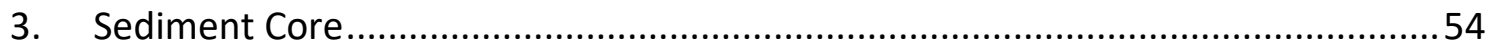

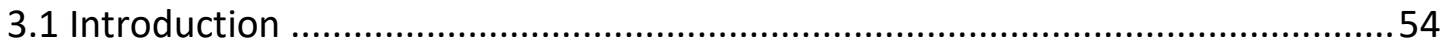

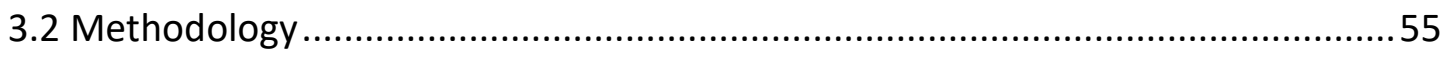

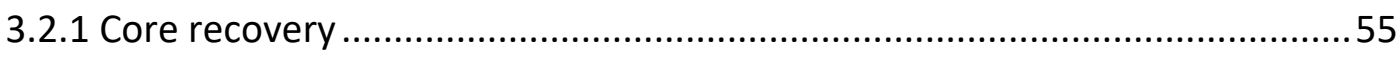

3.2.2 Computed tomography (CT) scanning and analysis................................56

3.2.3 Measurement of Geothermal Properties ................................................. 58

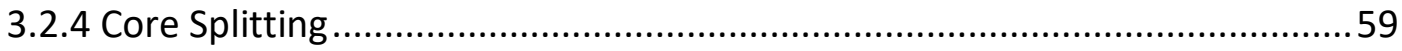

3.2.5 Ramped Pyrolysis radiocarbon dating .....................................................59

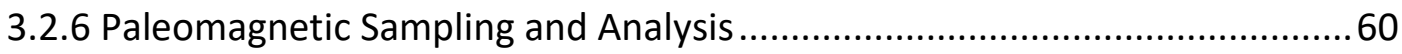

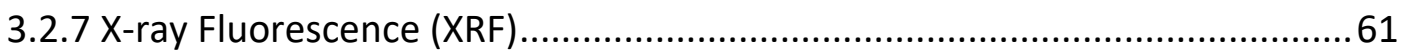

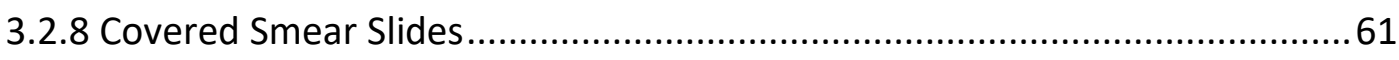

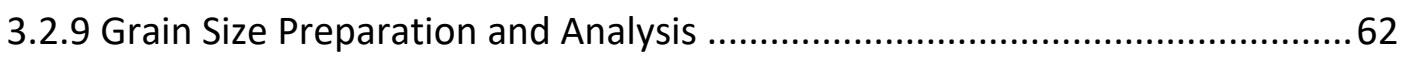

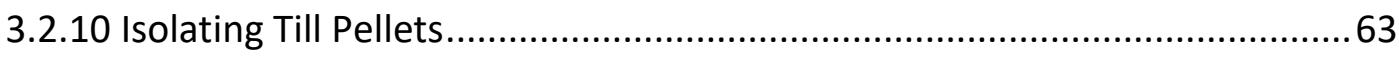

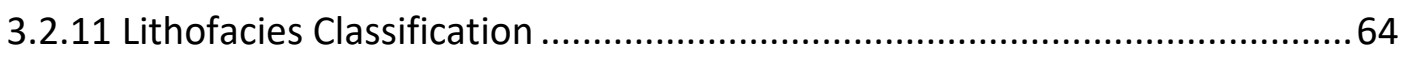

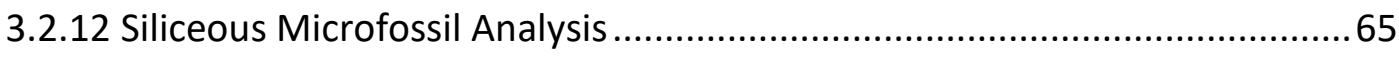

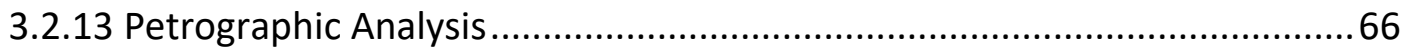

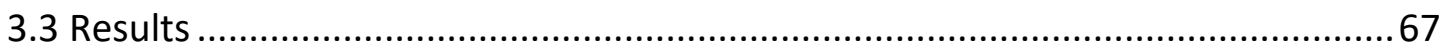

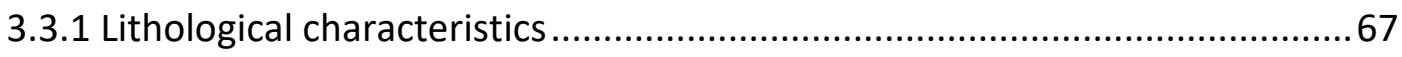

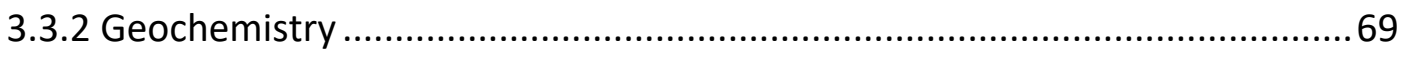

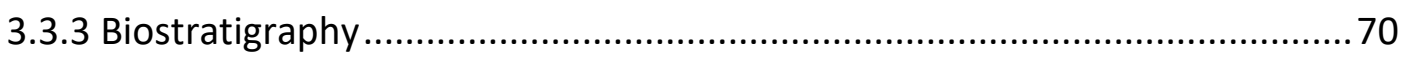

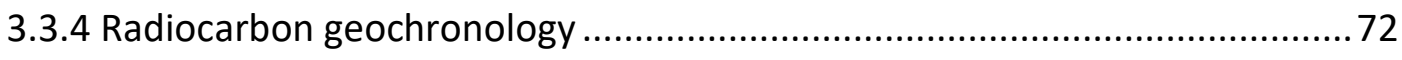

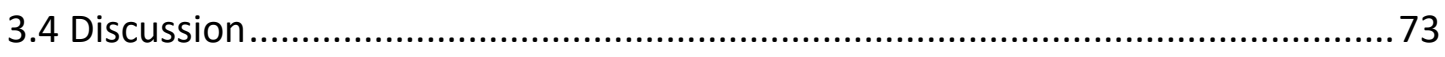

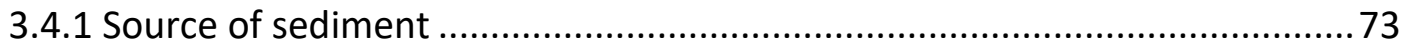

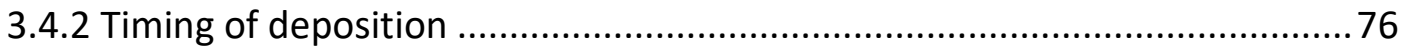

3.4.3 Relationship between KIS-GZ core and sedimentary facies models..............79 
$\underline{0: \text { Acknowledgements }}$

3.4.4 Assessment of the evidence for and against sub-glacial deposition .81

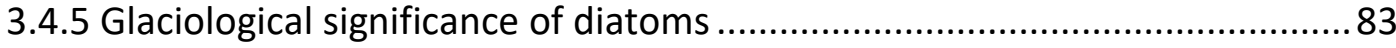

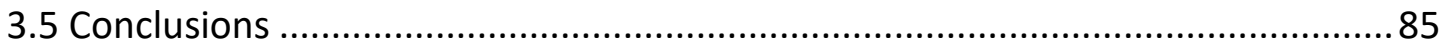

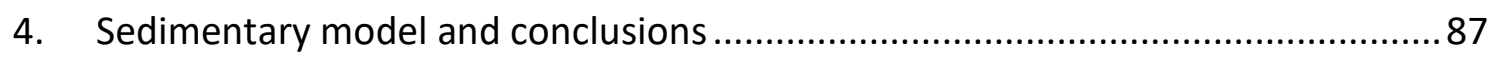

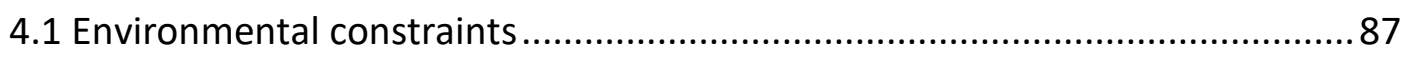

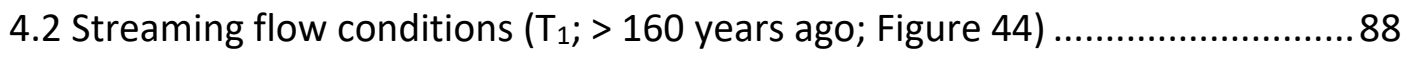

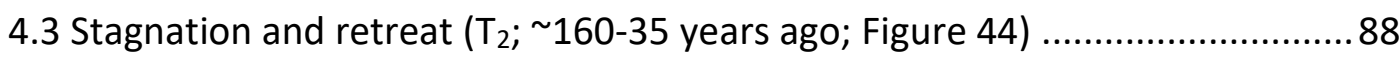

4.4 Static grounding line $\left(T_{3},<35\right.$ years ago; Figure 44$)$..................................90

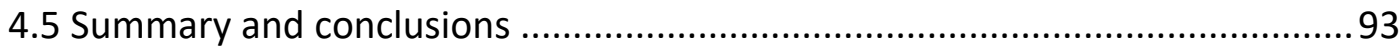

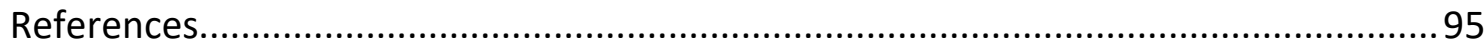

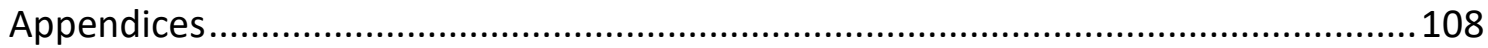

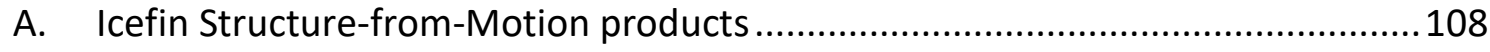

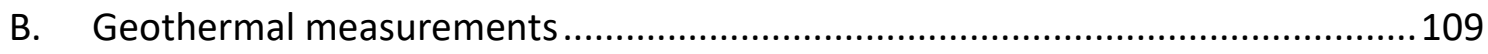

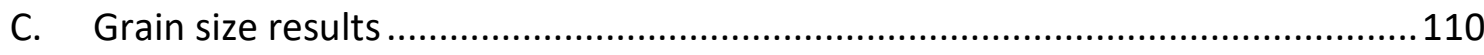

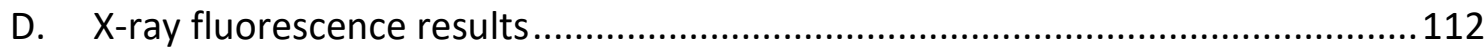




\section{List of Figures}

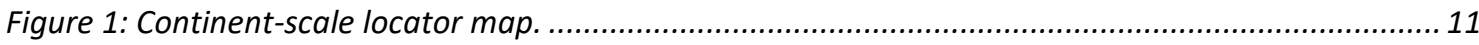

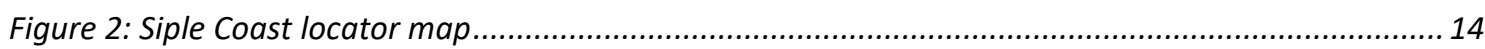

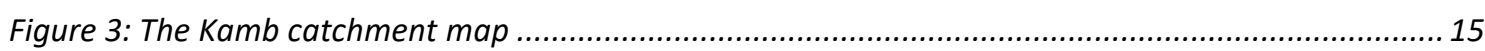

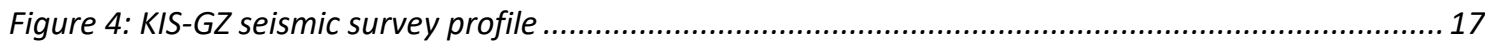

Figure 5 (duplicated from Chapter 1): Siple Coast locator map .....................................................2 20

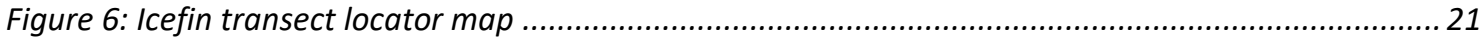

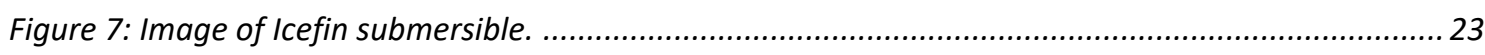

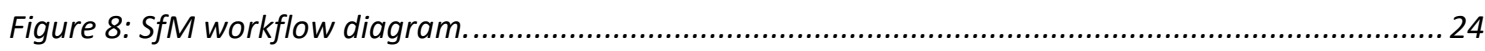

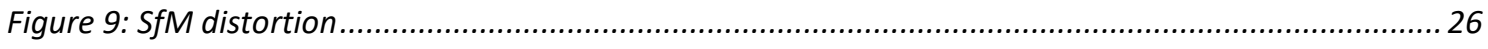

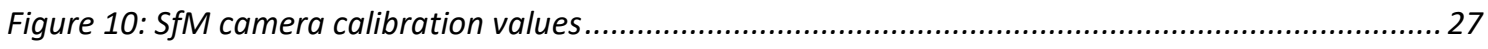

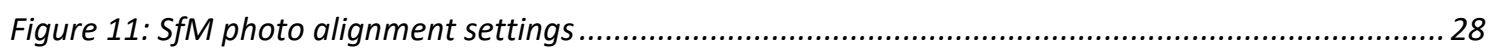

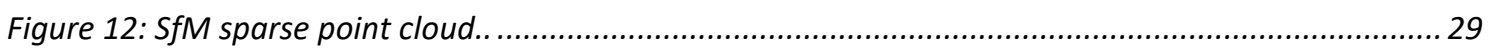

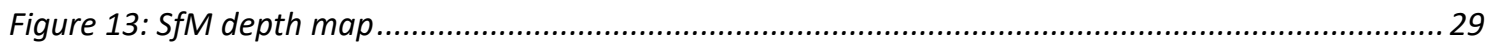

Figure 14: Image of ice shelf base and percentage coverage charts................................................. 33

Figure 15: Schematic for spatial relationship between borehole and facies..................................... 35

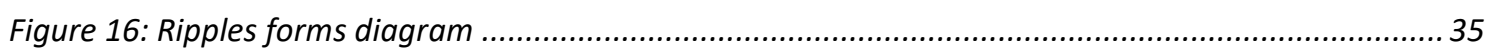

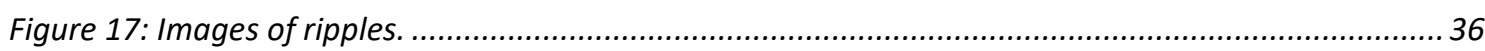

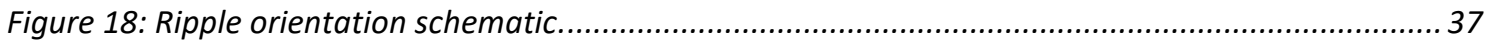

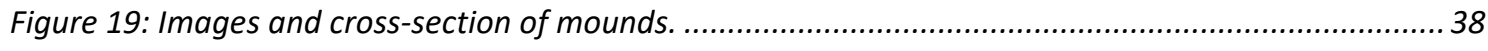

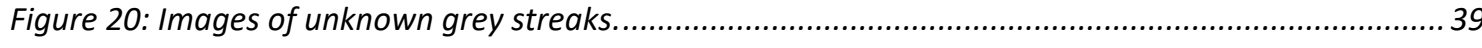

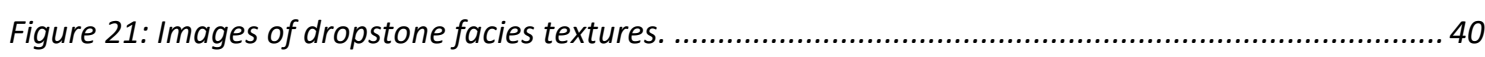

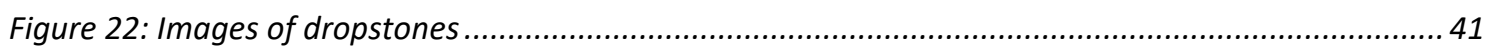

Figure 23: Images of decimetre-scale bedforms around borehole .................................................... 43

Figure 24: DEM of decimetre-scale bedforms in the transition zone. ...........................................4 44

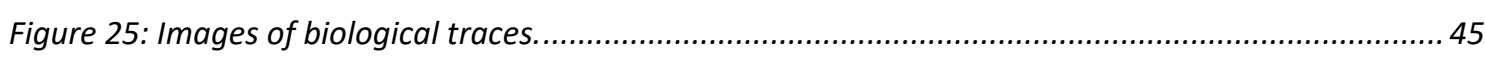

Figure 26: Radial graph of current speeds measured at KIS-GZ borehole...............................................46

Figure 27: Bedform-velocity diagram modified from Stow et al. (2009).............................................49

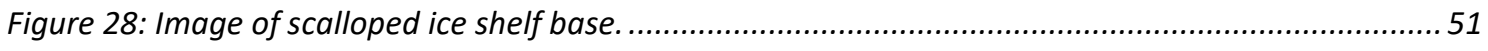

Figure 29: Schematic of an optimal dive plan for collecting data for SfM. .........................................52

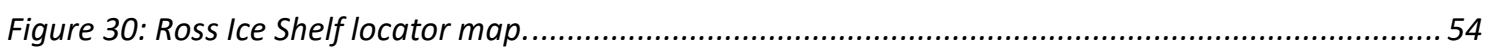

Figure 31: Trainable Weka Segmentation workflow diagram ..............................................................5 58

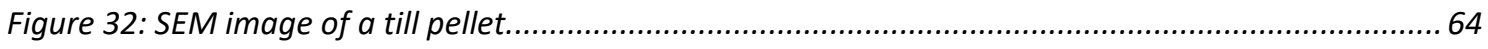

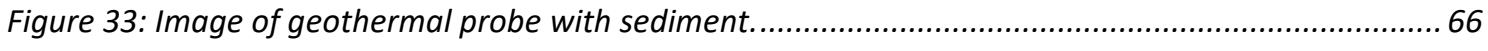

Figure 34: Compiled lithological characteristics of the KIS-GZ core ................................................6 68

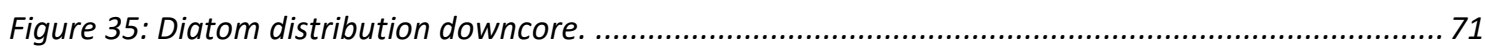

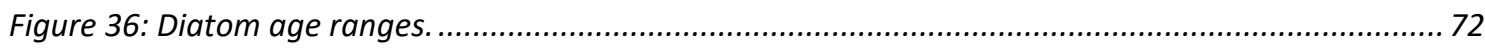




\section{$\underline{0: \text { List of Figures }}$}

Figure 37: Kamb catchment map with upstream sediment cores. ...................................................75

Figure 38: Ice transport pathways through the Ross embayment from 19.8 ka to present .....................78

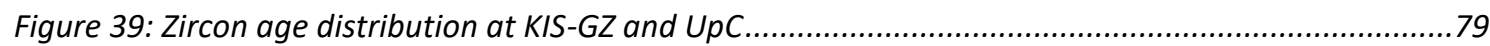

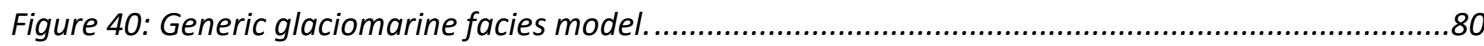

Figure 41: Distribution of Quaternary diatoms in Ross embaymen sediments.....................................84

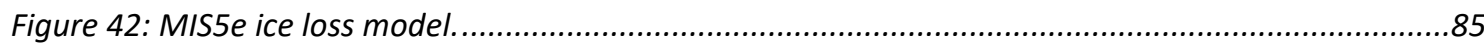

Figure 43: Schematic of sediment distribution in ice stream base ....................................................90

Figure 44: Schematic sedimentary model for time evolution of KIS-GZ depositional environment...........92 


\section{List of Tables}

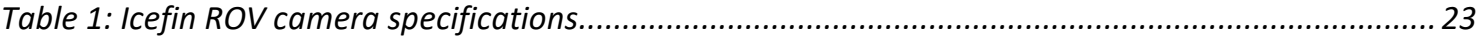

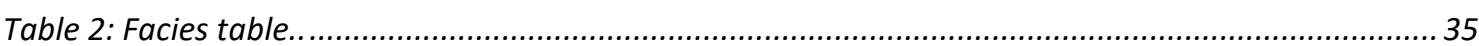

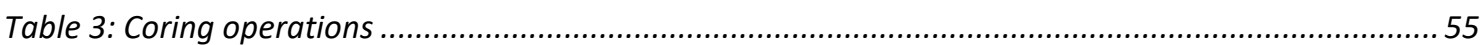

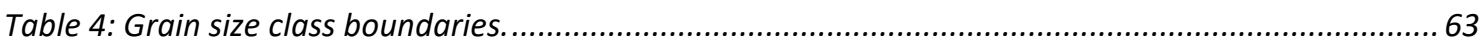

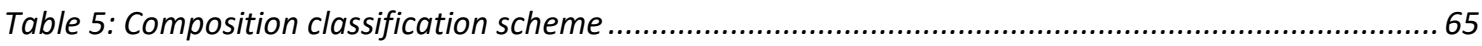

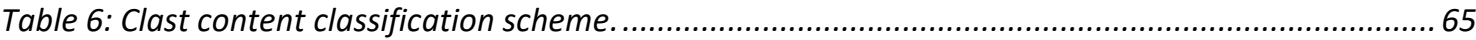

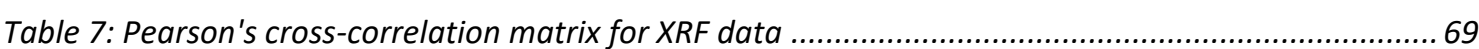

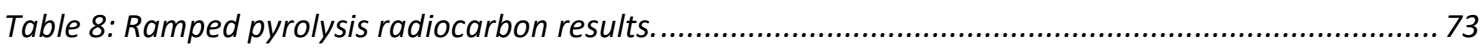




\section{1: Introduction}

\section{Introduction}

\subsection{Thesis Context and Motivation}

Antarctica presently contains around 27 million $\mathrm{km}^{3}$ of ice, distributed roughly 15:1 between the East and West Antarctic Ice Sheets (EAIS and WAIS respectively; Fretwell et al., 2013). In the past, naturally-occurring changes to the Earth's orbit have triggered cyclical episodes of climatic warming, which resulted in global eustatic sea level increases of up to $22 \mathrm{~m}$ when Earth was only $3^{\circ} \mathrm{C}$ warmer than present (Miller et al., 2012), with major related effects for global oceanic, atmospheric, and climatic systems. Melt of the West Antarctic Ice Sheet alone, which is predisposed to instability due to its landward sloping sub-ice sheet bed of which much is grounded below sea level (Joughin \& Alley, 2011; Weertman, 1974), has been associated with significant episodes of past sea level rise (Naish et al., 2009). The human consequences of similar changes today would be catastrophic (Bosello et al., 2012; Nicholls et al., 2011; Tol et al., 2006). Anthropogenic warming of Earth's climate beyond the bounds of natural system variability is already underway, and is expected to increase rates of Antarctic ice loss in future (Deconto \& Pollard, 2016; Dutton et al., 2015). However, limitations in our understanding of the dynamics of the Antarctic ice sheets mean that the true impacts of these changes - how much, how fast, and where sea levels will rise - are, as yet, not fully known.

Computer simulations of ice sheet behaviour are the primary tool used to predict how Antarctica will respond to a warming climate. However, our ability to model ice sheet dynamics is only as good as our understanding of the mechanics of these complex systems, which is constructed from a combination of empirical knowledge, theoretical ideas, and direct observations used to verify and tune ice sheet simulations (Dutton et al., 2015). Glaciomarine environments produce characteristic sediment based on a site's location relative to key glacial features (Alley et al., 1989; Domack \& Harris, 1998; Smith et al., 2019). The recovery of sediment which has been eroded, transported, or deposited by ice can provide quantitative records of ice sheet dynamics over timeseries orders of magnitude larger than timeseries provided by the instrumental record (Stocker, 2014). 
Moreover, where the timing of sediment deposition is well-constrained, sedimentary cores can be correlated with paleoclimate records to interpret how past climate conditions affected the behaviour of the ice sheets that were present at the time (Hambrey et al., 2002; Naish et al., 2009; Passchier et al., 2011). Understanding the potentially highly localised interactions between oceans, ice, and sediment, which occur over hours, days, and weeks, and underpin these continental-scale behaviours, is also critical. Observations at both scales along the ice sheet-ice shelf grounding zones of West Antarctica are particularly important due to the region's role in the stability of the broader West Antarctic Ice Sheet (Horgan \& Anandakrishnan, 2006; Schoof, 2007) and to date are very rare. This thesis presents the first direct observation of glaciomarine processes near the Kamb grounding line and is the second time the sea floor has been accessed along the Siple Coast after Whillans Ice Stream grounding zone (Figure 1; Horgan et al., 2013).

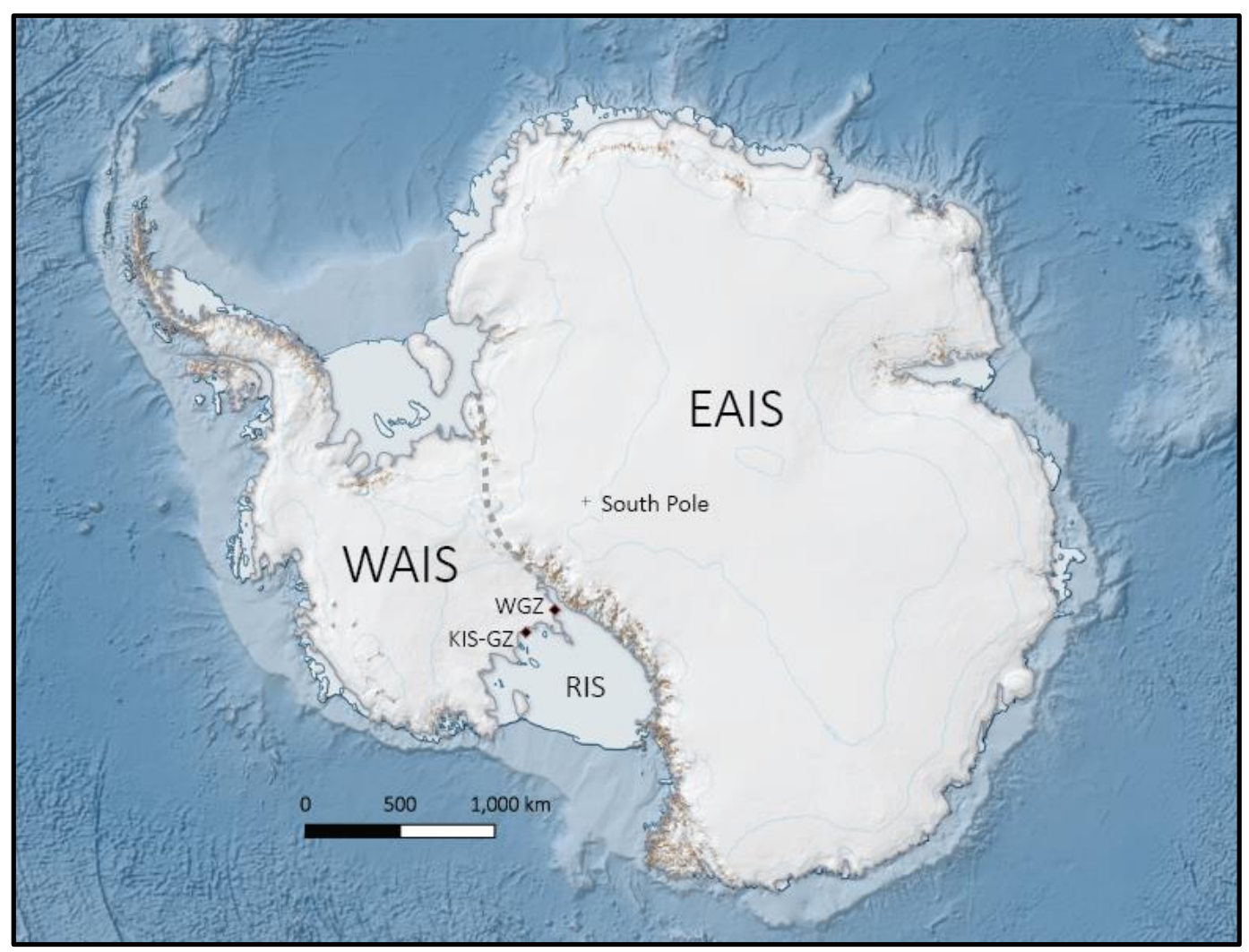

Figure 1: Antarctica contains around $65 \mathrm{~m}$ of SLE ice distributed 10:1 between the East Antarctic Ice Sheet (EAIS) and West Antarctic Ice Sheet WAIS, respectively. The WAIS flows into the Ross Ice Shelf (RIS) across the grounding line of six ice streams, of which only two have been sampled; the Whillans Ice Stream (at site WGZ), and the Kamb Ice Stream (at site KIS-GZ, examined in this thesis). 


\section{1: Introduction}

The thesis utilises sample material and observations collected from the sea floor at the Kamb Ice Stream (KIS) grounding zone hot water drill site (Lat. -82.7841, Long. 155.2626 ) in the $2019 / 20$ austral summer (Figure 1). The primary datasets are derived from the upper $49 \mathrm{~cm}$ of a short $(0.6 \mathrm{~m})$ gravity core and high-resolution video captured by a remote submersible. The site lies $\sim 3.3 \mathrm{~km}$ seaward of the present Kamb Ice Stream grounding line on West Antarctica's Siple Coast (measured to Antarctic Surface Accumulation and Ice Discharge (ASAID) grounding line position). The core site is henceforth referred to in this thesis as KIS-GZ (grounding zone). Other operational names were KIS-1 and Hot Water Drill (site) 1 (HWD-1). Where "the grounding zone of KIS" is discussed, I refer to the studied area immediately adjacent to the borehole and up to one kilometre seaward of the borehole. The fieldwork was undertaken as part of site survey work for a deeper ( $200 \mathrm{~m}$ below sea floor) drilling effort planned for a nearby site in the 2022/23 season. KIS is presently stagnant (Retzlaff \& Bentley, 1993), which reduces logistical difficulties associated with deep drilling through flowing ice and provides a unique opportunity to collect a potentially long-ranging record from a grounding-line proximal site.

\subsection{Thesis Structure}

This thesis is presented as the basis for two journal manuscripts. Accordingly, there is some duplication of figures and introductory material. Additional explanation is included in places to increase the accessibility of this work in its thesis form. The first manuscript assesses the modern sedimentary regime at the grounding zone of the Kamb Ice Stream using video imagery of the sea floor accompanied by data from an oceanographic mooring. The second manuscript examines the upper $49 \mathrm{~cm}$ of a $60 \mathrm{~cm}$-long sedimentary core recovered through the KIS-GZ borehole to interpret the recent geological history of the Kamb Ice Stream. The concluding chapter synthesizes the two manuscripts and presents a sedimentary model for the KIS-GZ site for the period of time covered by the core.

\subsection{Thesis Objectives}

1. Develop an understanding of the processes responsible for generating the texture and bedforms of the modern sea floor near the grounding zone of the Kamb Ice Stream 
2. Develop a recent geological history of the grounding zone of the Kamb Ice Stream consistent with lithology, chronology, oceanography and glaciology of the KIS-GZ site

3. Consider the 'modern' processes observed in this thesis in the context of generic glaciomarine sedimentation models

\subsection{Regional Setting}

\subsubsection{Geography/Glaciology}

The Siple Coast ice streams are a series of six major ice streams which flow west off the West Antarctic Ice Sheet and coalesce to form the eastern Ross Ice Shelf (Figure 2). The streams are a critical conduit between the relatively stable, slow-moving ice of the ice sheet's interior, and the more quickly moving, relatively unstable ice at the coastal margins of the ice sheet (Conway et al., 2002; Joughin et al., 2002; Ng \& Conway, 2004). The Siple Coast system is highly dynamic, with the six ice streams together responsible for exporting between 30 and $40 \%$ of West Antarctica's ice (Horgan \& Anandakrishnan, 2006; Price et al., 2001). Pressurised water and weak glacial diamicton (till) lubricate the base of the ice streams, allowing them to rapidly transport large volumes of ice (Kamb, 2001; Van Der Wel et al., 2013). Quasi-cyclical changes in ice stream flow occur on geologically short (years to centuries) timescales and range from variations in flow rate to complete stagnation and re-initiation events (Catania et al., 2012). These changes appear to be driven by variability in ice stream basal conditions and in some cases interactions with adjacent ice and the re-routing of the subglacial water which lubricates flow of the ice streams (Anandakrishnan et al., 2001; Catania et al., 2012). 


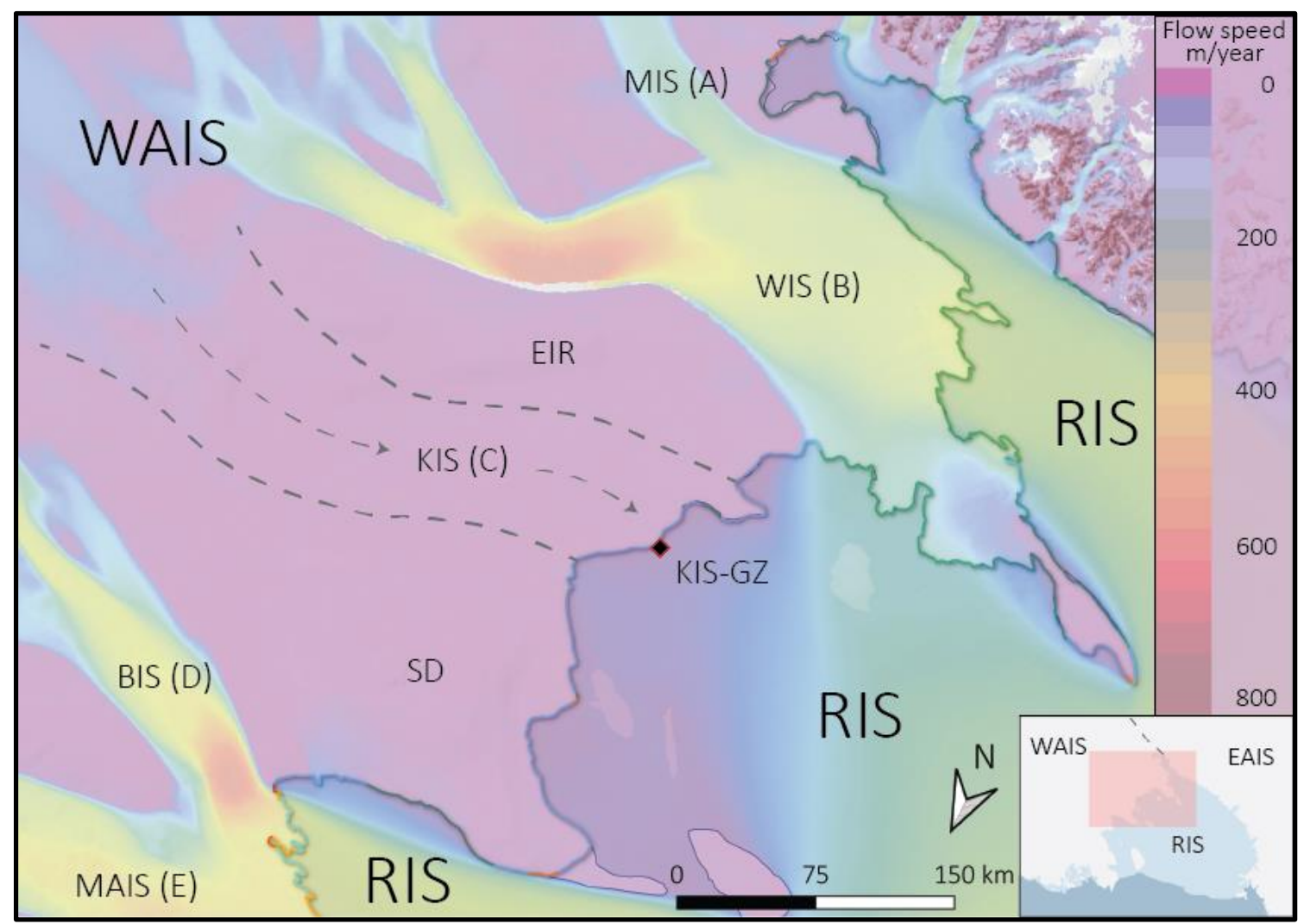

Figure 2: The Siple Coast with ice streams flowing off the West Antarctic Ice Sheet (WAIS) into the Ross Ice Shelf (RIS). These are the Siple Coast ice streams. The Kamb Ice Stream (KIS) itself is stagnant and has been for the past 160 years for reasons not well understood. MIS = Mercer Ice Stream, WIS = Whillans Ice Stream, BIS = Bindschadler Ice Stream, MAIS = MacAyeal Ice Stream, EIR = Engelhardt ice Ridge, $S D=$ Siple Dome, $W G Z=$ Whillans Grounding Zone core location, KIS-GZ = Kamb Ice Stream Grounding Zone core location. Bracketed letters refer to old ice stream identification scheme. The colour scale on this map highlights different ice flow speed, from MEaSUREs programme 2013-2017 data.

The Kamb Ice Stream (KIS; previously called Ice Stream C) is bordered by the Engelhardt Ice Ridge to the south and Siple Dome to the north (Joughin \& Tulaczyk, 2002). Its thickness varies between 600 and 2000 m over its $\sim 700 \mathrm{~km}$ extent. KIS is unique in that it is the only ice stream that is stagnant in the present configuration of the Siple Coast system; flow at the Kamb Ice Stream stagnated approximately 160 years ago ( AD 1863; Retzlaff \& Bentley, 1993). Radar surveys indicate that stagnation of KIS initiated in the lower reaches over a period of less than 30 years, before advancing to the head of the flow over a period of less than 70 years, slowing as it went (Retzlaff \& Bentley, 1993). Basal freeze-on and subglacial drainage changes are postulated as likely stagnation mechanisms (Anandakrishnan et al., 2001). At present, flow in the trunk of the Kamb Ice Stream ranges between complete stagnation up to $\sim 15 \mathrm{~m} /$ year, while the upper sections of the ice stream continue to flow at rates of 60-70 m/year, and as a result continue to thicken (Joughin \& Tulaczyk, 2002; see Figure 2). Active Siple Coast ice streams are 
typified by flows of around $400 \mathrm{~m} /$ year (Whillans \& Van Der Veen, 1993). The grounding line of KIS likely retreated to its current position following stagnation, and since then has either remained stable or advanced slightly (Horgan et al., 2017; Horgan \& Anandakrishnan, 2006). Geophysical surveys indicate that most of the Siple Coast grounding line has remained stable in its present position since the mid-1980s, including at Kamb (Horgan \& Anandakrishnan, 2006).

\subsubsection{Geology}

Thick ice coverage inhibits precise estimation of lithological boundaries across most of West Antarctica. Much of what is known about the region's geology is derived from a limited number of visible outcrops, which are mostly confined to coastal areas, and inferred from geophysical surveys. The sole outcrop in the Kamb catchment is the Whitmore Mountains, approximately $700 \mathrm{~km}$ inland of KIS-GZ, (Figure 3), which comprise Jurassic granites (Craddock et al., 2017) and calcareous Cambrian sedimentary rocks (Cox \& Lyttle, 2019). Provenance indicators collected from sediment under WAIS ice streams and elsewhere indicate a distinct difference in zircon age profile for WAIS compared to EAIS-derived sediment (Licht et al., 2014). Additional analysis may enable further discrimination between individual ice streams.

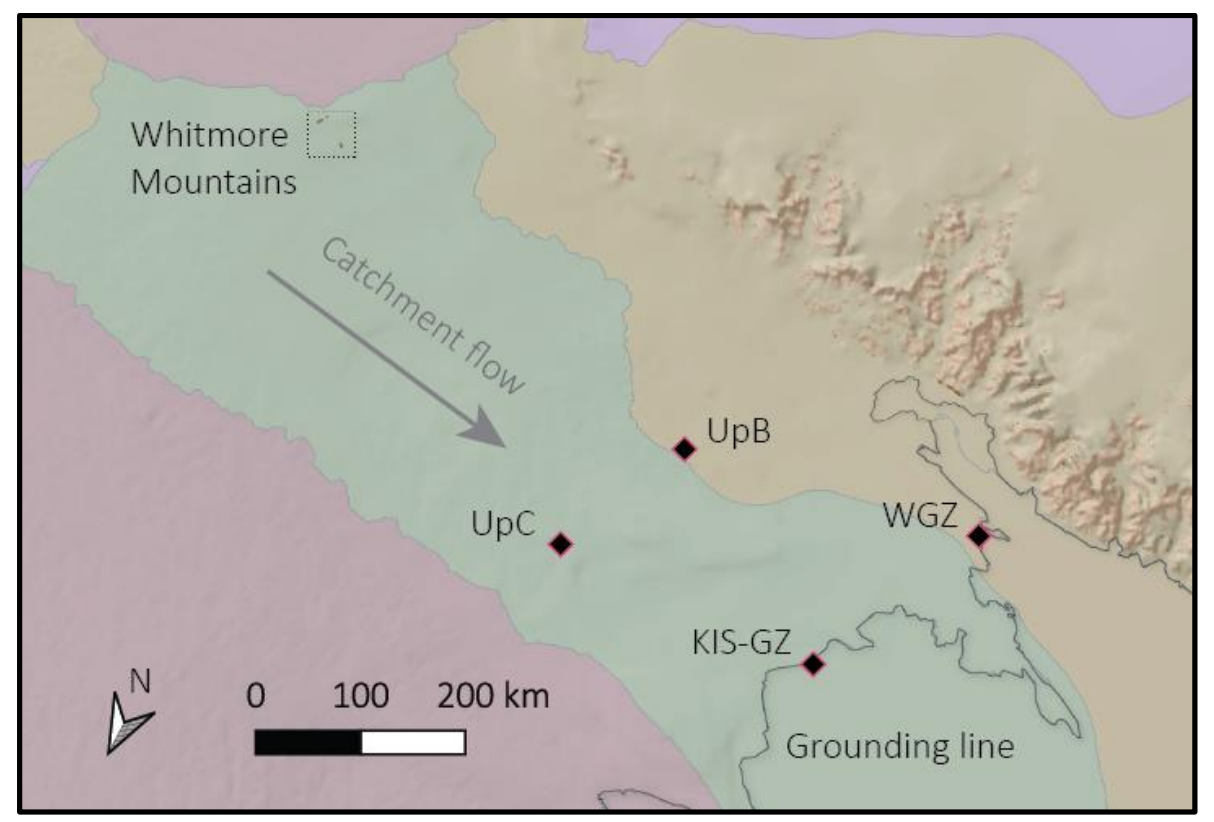

Figure 3: The Kamb catchment (green, approximate boundaries). The Whitmore Mountains, $\sim 700 \mathrm{~km}$ up-catchment from KIS-GZ, are the only outcropping rocks in the KIS catchment, while UpC, $270 \mathrm{~km}$ up-catchment, is the only subglacial sampling site. WGZ, $200 \mathrm{~km}$ south of KIS-GZ, 


\section{1: Introduction}

exhibits a grounding zone wedge (GZW) of similar composition to subglacial samples recovered from higher in that catchment at UpB.

The modern Siple Coast is underlain by thin crustal rocks formed during the development of the West Antarctic Rift System, which began in the late Cretaceous and continued throughout the Cenozoic (Jordan et al., 2020). Volcanism associated with the rifting has been dominantly confined to Marie Byrd Land and the Antarctic Peninsula (Jordan et al., 2020), though there is evidence of active subglacial volcanism within several hundred kilometres of the Siple Coast (Blankenship et al., 1993). Tephra deposits from trachytic volcanoes in Marie Byrd Land are also evident in ice cores recovered from Siple Dome, around 160 km north of the Kamb Ice Stream (Kyle et al., 1978, 1981; Wilch et al., 1999).

During paleo-marine inundation events, grabens formed during crustal extension developed into a series of discontinuous marine basins (Rooney et al., 1991; Studinger et al., 2001). The present position of the Siple Coast ice streams appear to be confined by the boundaries of these fault-bounded sedimentary basins (Peters et al., 2006; Rooney et al., 1991; Studinger et al., 2001). Packages of hundreds of metres of late Neogene to Quaternary marine sediments, likely derived from the glaciomarine Ross Sea sequence (Kamb, 2001; Tulaczyk et al., 1998), are common throughout the basins (Studinger et al., 2001); the grounding zone of the Kamb Ice Stream itself is underlain by approximately $130-180 \mathrm{~m}$ of sub-horizontal inferred marine sediment overlying a shallow-angle unconformity ('Event D') of Horgan et al. (2017; Figure 4). 


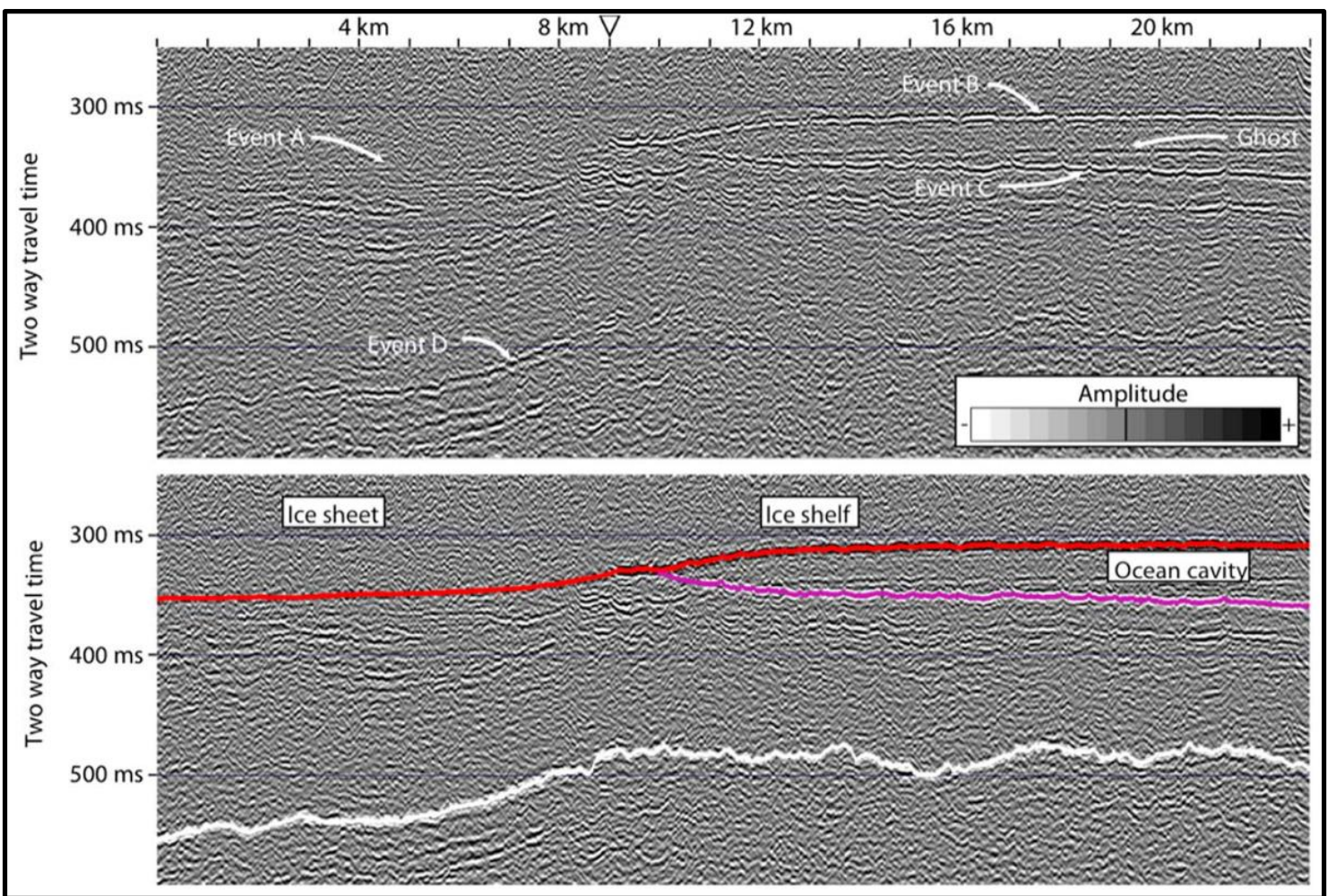

Figure 4: Horgan et al. (2017)'s seismic survey over the KIS grounding line shows the presence of a shallow-angle unconformity 130-180 m below the sea floor. The red line is the underside of the ice sheet/shelf; the pink line is the sea floor. The white line is the unconformity.

The Siple Coast ice streams are underlain by a $\sim 5-10 \mathrm{~m}$ thick layer of water-saturated deformable till (Atre \& Bentley, 1993; Blankenship et al., 1987), which unconformably overlies the marine sediment (Rooney et al., 1987; Rooney et al., 1988) and lubricates the surface between the sedimentary deposits and the overlying ice stream (Tulaczyk et al., 1998). Physical samples of the material reveal unfrozen, structureless, clay-rich, unsorted glacial till (Kamb, 2001; Tulaczyk et al., 1998). At Whillans Ice Stream, around $200 \mathrm{~km}$ south of the Kamb Ice Stream, clasts in the till are dominated by crystalline lithologies including gneiss, schist, granite, and other plutonics, though sedimentary clasts, volcanics, and coal are also present (Kamb, 2001; Tulaczyk et al., 1998). The till also contains diatoms and other marine microfossils dating from the Miocene to late Pleistocene (Scherer, 1991). At the Kamb Ice Stream, quartz and plagioclase grains, along with felsic and sedimentary lithic fragments, are present throughout the sand fraction of the till (Licht et al., 2005). Petrographic analysis of subglacial sediment recovered upstream of KIS-GZ, at UPC, shows most lie in the Transitional Crust or less commonly in the dissected arc fields in a traditional "QFL" plot of sand composition (Vogel, 2004). 


\section{1: Introduction}

The presence of a depositional wedge at the grounding zone of the adjacent Whillans Ice Stream (WGZ, Figure 3) derived from the erosion of up-catchment source rocks (Anandakrishnan et al., 2007; Christianson et al., 2016) suggests that sediment recovered from the grounding zone of the Kamb Ice Stream may also reflect characteristics of the lithologies found upstream in the Kamb catchment.

\subsubsection{Oceanography}

The stability of ice sheet grounding zones is significantly influenced by the oceanic processes occurring in sub-ice shelf ocean cavities (Begeman et al., 2018; Holland, 2008). However, the practical limitations of oceanographic monitoring in these areas means that the retrieval of empirical data from these areas is in its infancy; observational data for Ross Ice Shelf grounding zones are limited to two sites (Begeman et al., 2018; Craig Stevens \& Natalie Robinson (NIWA), pers. comm, 2020). Theoretical models propose a circulation dominated by tidal signatures (Holland, 2008), with little influence from dynamic ocean processes like storms due to their distance from the open ocean. Most oceanographic models predict a mixed water column near ice sheet grounding lines (Holland, 2008; MacAyeal, 1984). Recent observations from the grounding zone of the Whillans Ice Stream reveal a tri-stratified water column and weak currents velocities of around $1.5 \mathrm{~cm} . \mathrm{s}^{-1}$ in the sub-ice shelf ocean cavity (Begeman et al., 2018). The stratification of the water column near the grounding line slowed melt of the underside of the ice shelf to less than $10 \mathrm{~cm} /$ year, around half of that observed across the Ross Ice Shelf as a whole (Begeman et al., 2018). A continuous record from an oceanographic mooring emplaced at the grounding zone of the Kamb Ice Stream in late 2019 showed similar trends in stratification, though current speeds were higher (Stevens \& Robinson, pers. comm., 2020). The water column is stratified into an upper and lower body of water. Currents are bi-directional, flow approximately parallel to the grounding line, and rarely exceed $10 \mathrm{~cm} \cdot \mathrm{s}^{-1}$. The record shows little variability, as expected due to the site's distance from the dynamic processes of the open ocean. A mooring from the central Ross Ice Shelf (HWD-2: Lat. -80.65767, Long. 174.46263), beginning in 2017, shows evidence of short-term increases in current velocity several times each year driven by large internal waves propagating through the ocean cavity (Stevens, pers. comm., 2020). These events have been attributed to large-scale iceberg calving events and seismic 
sources. While this signature has not yet been recorded at the Kamb grounding zone, it is possible that a similar phenomenon may occur there (Stevens, pers. comm., 2020). 


\section{Modern Sedimentary Environment}

\subsection{Introduction}

The Siple Coast grounding line is the nexus between the grounded interior ice of the West Antarctic Ice Sheet (WAIS) and the floating ice of the Ross Ice Shelf (RIS). Following decades of geophysical surveys (e.g. Anandakrishnan et al., 2007; Horgan et al., 2013), a 2015 drill programme targeting a site several kilometres seaward of the grounding line at Whillans Ice Stream (WGZ) offered the first direct look at the sedimentary environment and processes of an ice stream grounding zone on the Siple Coast (Scherer et al., 2015; Figure 5). However, observations here were restricted to the area immediately adjacent to the bottom of the borehole.

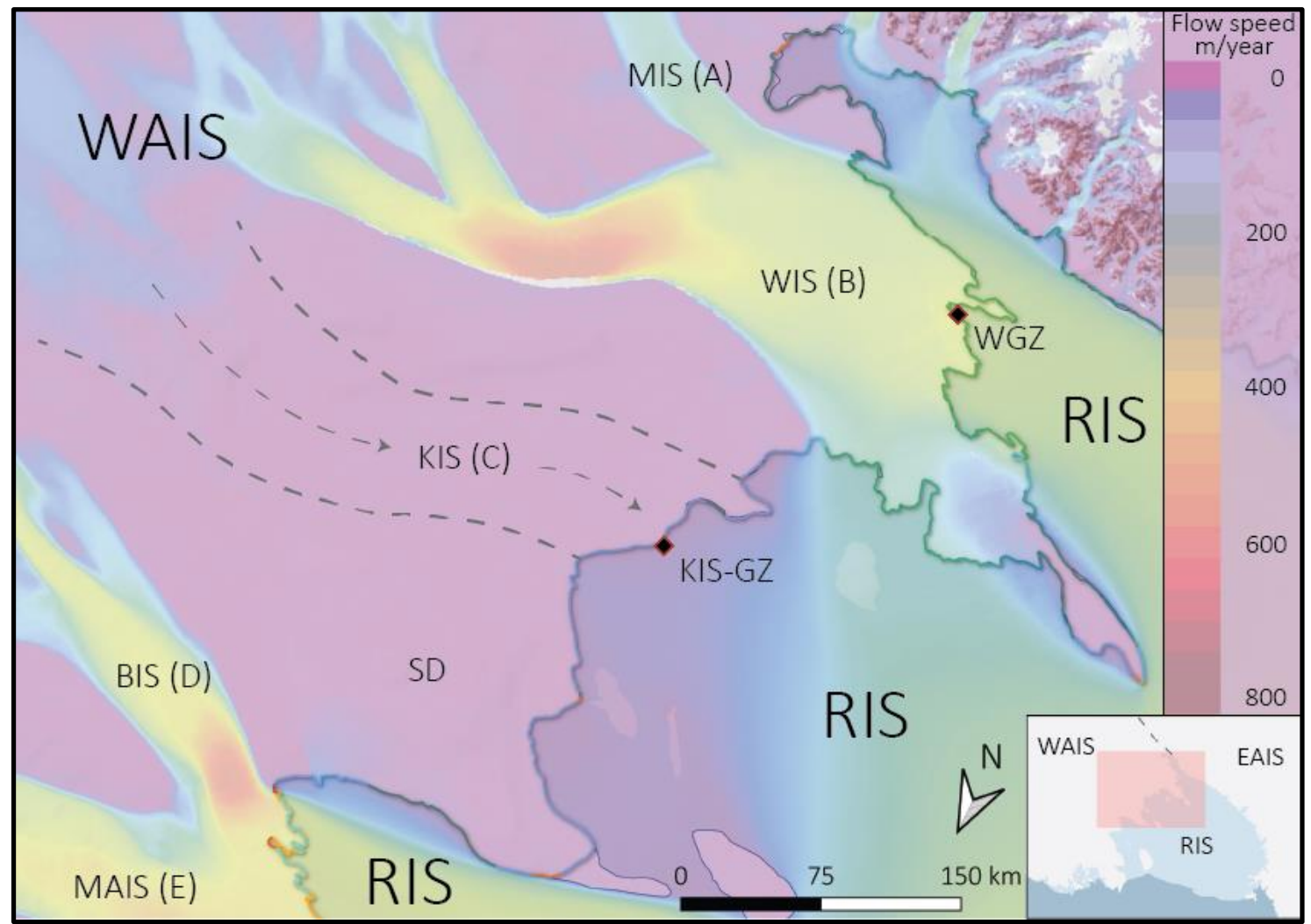

Figure 5 (duplicated from Chapter 1): The Siple Coast with ice streams flowing off the West Antarctic Ice Sheet (WAIS) into the Ross Ice Shelf (RIS). These are the Siple Coast ice streams. The Kamb Ice Stream (KIS) itself is stagnant and has been for the past 160 years for reasons not well understood. MIS = Mercer Ice Stream, WIS = Whillans Ice Stream, BIS = Bindschadler Ice Stream, MAIS = MacAyeal Ice Stream, EIR = Engelhardt Ice Ridge, $S D=$ Siple Dome, $W G Z=$ Whillans Grounding Zone core location, KIS-GZ = Kamb Ice Stream Grounding Zone core location. Bracketed letters refer to the old ice stream identification scheme. The colour scale on this map highlights different ice flow velocities. 
This chapter presents observational data of the sea floor at the grounding zone of the Kamb Ice Stream (KIS), approximately $200 \mathrm{~km}$ north of the WIS grounding zone. HD video footage captured by the 'Icefin' ROV spans an $800 \mathrm{~m}$ transect which runs approximately perpendicular to the modern KIS grounding line, beginning $2.3 \mathrm{~km}$ and ending $3.1 \mathrm{~km}$ away from the grounding line (Figure 6). The imagery documents the sedimentary texture of the sea floor around the borehole and captures the presence of centimetrescale ripples, previously unknown decimetre-scale bedforms, dropstones, and rare biological surface traces. The surveyed sea floor was divided into two characteristic facies, which provide additional detail to existing facies schemes for grounding-line proximal sub-ice shelf environments (e.g. Domack \& Harris, 1998; Smith et al., 2019). Combined with findings from the $49 \mathrm{~cm}$ section of gravity core assessed in Chapter 3 and current velocity data from the NIWA oceanographic mooring installed through the KIS-GZ borehole, the Icefin imagery is used to interpret and constrain the processes influencing the modern KIS grounding zone.

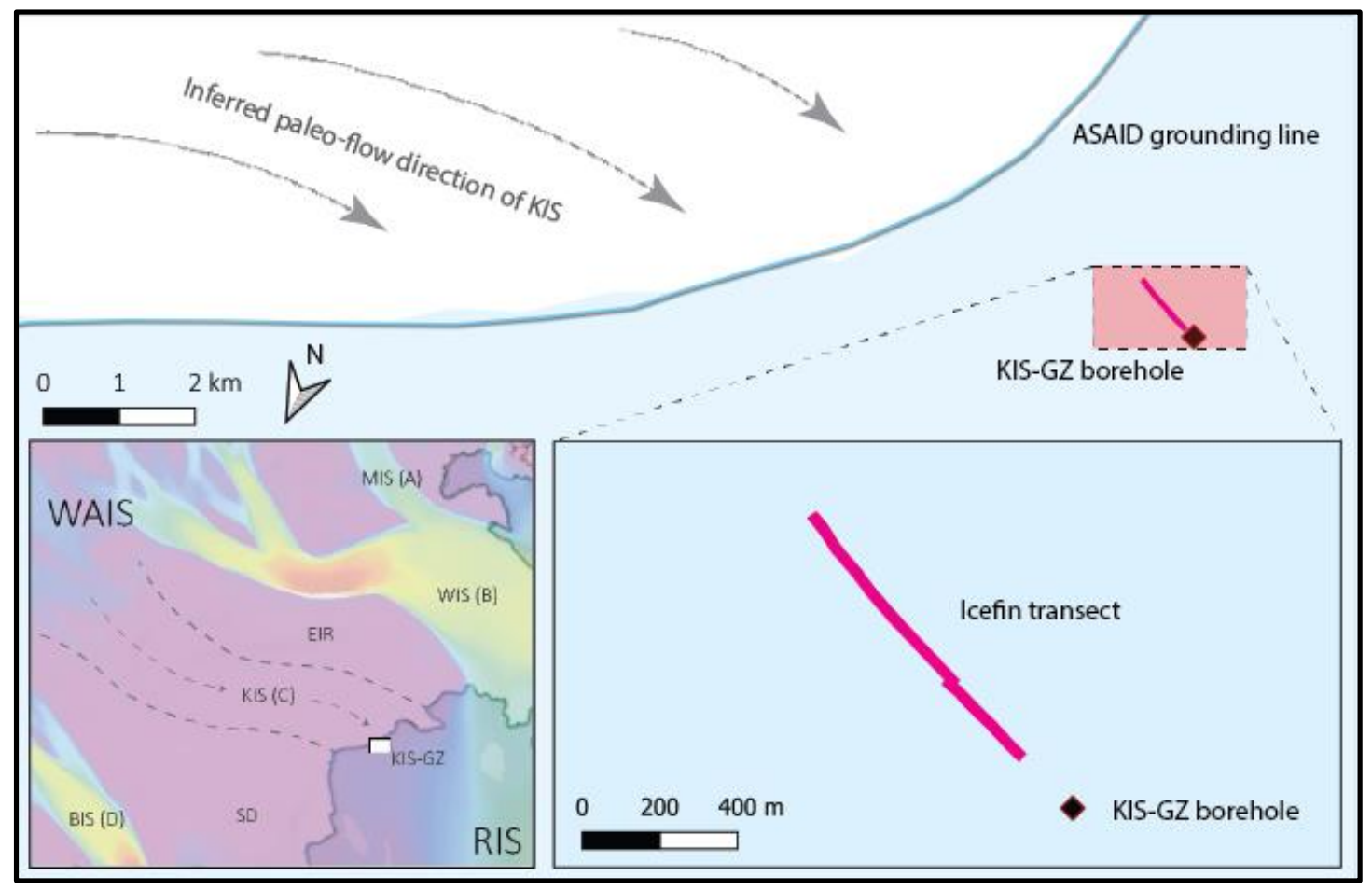

Figure 6: The $800 \mathrm{~m}$ Icefin transect that captured images of the seafloor begins $\sim 2.3 \mathrm{~km}$ from the grounding line (shortest distance) and extends $800 \mathrm{~m}$ seaward, approximately parallel with the paleo-flow direction of KIS. Antarctic Surface Accumulation and Ice Discharge (ASAID) project grounding line used. 


\section{2: Modern Sedimentary Environment}

Video footage was processed using Structure-from-Motion (SfM) software. Orthomosaics and digital elevation models (DEMs) were developed to simplify characterisation of sea floor texture variations and to enable the geometry of bedforms to be examined, respectively. Dive plans prioritised oceanographic profiling, ice shelf imaging, and sonar (backscatter) collection alongside imaging of the sea floor; the video data were not originally collected with SfM analysis in mind. Accordingly, there are no overlapping flight paths and the lighting conditions are sub-optimal, resulting in some compromises in processing and ultimately interpreting the data. Nonetheless, it was felt that the SfM approach was the best available means of providing a semi-quantified geological analysis of the sea floor. Moreover, applying the SfM approach here as a pilot study may yield useful guidance for processing similar video data in future. Recommendations for improving the SfM approach to sea floor analysis are provided at the end of this Chapter's discussion.

\subsection{Methodology}

\subsubsection{Use of Icefin ROV}

This was the first sub-shelf deployment of a submersible at the Siple Coast. The Icefin ROV is a $3.5 \times 0.23 \mathrm{~m}$ cylindrical submersible designed to be deployed through narrow boreholes into sub-ice environments (Figure 7). The submersible is tethered to and controlled from the ice surface and at KIS-1 could travel up to $1 \mathrm{~km}$ from the point of entry. The vehicle has a modular design and can deploy with an array of cameras, sonar, and oceanographic sensors appropriate for the dive goals (https://schmidt.eas.gatech.edu/icefin). During deployments at KIS-GZ, 1080p resolution video at 30 frames per second (fps) was captured by a downward-facing WIP HDMSC-3085-F-SUBCXBH6-CS fisheye camera (Table 1) mounted on the underside of the submersible. Light was provided by a single, constantly illuminated light positioned $\sim 1 \mathrm{~m}$ aft of the camera and tilted $\sim 30$ degrees from vertical in the forward direction. $\mathrm{A}$ pair of fixed-position laser pointers spaced at $5 \mathrm{~cm}$ provided scale. The mean altitude of the ROV above the sea floor during sections of video that could be converted to SfM products was $1.26 \mathrm{~m}$ (std. dev. $0.55 \mathrm{~m}$ ). At this altitude, the camera's field of view (FoV) 
encompasses approximately $1.16 \mathrm{~m}^{2}$, though shadow from the oblique light source reduced the usable FoV.

\section{0}

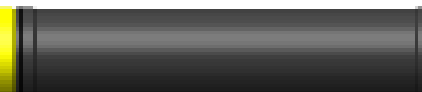

Figure 7: The Icefin submersible is $3.5 \mathrm{~m}$ long $\times 23 \mathrm{~cm}$ diameter and is tethered to and operated from the surface.

Table 1: Camera specifications (WIP HDMSC-3085-F-SUBCXBH6-CS from https://www.deepsea.com/portfolio-items/hd-multi-seacam)

\begin{tabular}{|c|c|}
\hline Lens & $\begin{array}{c}2.5 \mathrm{~mm}, \mathrm{f} / 2.8 \\
\text { Low Distortion }\end{array}$ \\
\hline Focus & Fixed \\
\hline $\begin{array}{c}\text { Field of View (FoV) in } \\
\text { water }\end{array}$ & $85^{\circ} \mathrm{H} \times 50^{\circ} \mathrm{V} \times 95^{\circ} \mathrm{D}$ \\
\hline Image sensor & $1 / 3 \mathrm{inch} 2.2 \mathrm{MP} \mathrm{CMOS}$ \\
$16: 9 @ 0.1 \mathrm{Lux}$ \\
\hline Resolution & $1920 \mathrm{H} \times 1080 \mathrm{~V}$ \\
\hline
\end{tabular}

\subsubsection{Structure from Motion (SfM)}

Structure from Motion ( $\mathrm{SfM}$ ) is a photogrammetry technique that reconstructs geometrically accurate 3-D scenes using 2-D images. Common features are identified in overlapping photographs, with changes in the relative position of matched pixels used to triangulate the image sensor's position and orientation and the position and orientation of the detected features. Automated workflows within SfM software are used to combine spatial data calculated from multiple photos into 3-D reconstructions of objects or scenes - in this case, the sea floor beneath the ice shelf.

SfM is fundamentally different from other 'scene modelling' techniques such as terrestrial laser scanning (TLS) because the only required inputs are overlapping, highdefinition images of the area in question that contain spatial context (such as a scale bar). SfM was used for this analysis because it allowed Digital Elevation Models (DEMs) and composite images (orthomosaics) to be generated from the Icefin footage, making 


\section{2: Modern Sedimentary Environment}

it possible to display, compare, and quantify differences in the sea floor along the submersible's transect. Agisoft Limited's 'Metashape' Structure from Motion software package (previously called 'Agisoft Photoscan'; https://www.agisoft.com/features/professional-edition) was used to produce the composite images (orthomosaics) and associated Digital Elevation Models (DEMs) examined in this thesis. Metashape is a commercial SfM package used for geographic and geomorphic applications (Smith et al., 2016). It provides automated workflows for SfM operations from importing images through to the generation of DEMs and orthomosaics. The workflow provided in the Agisoft Metashape User Manual (Professional Edition, Version 1.7) outlines the basic process used to develop the Icefin imagery into DEMs and orthomosaics, with some changes to suit the characteristics of the Icefin imagery (Figure 8). Key steps and departures from the standard workflow are outlined below. For more detail on SfM in geoscience, refer to Smith et al., 2016; van Scheltinga et al., 2020; Westoby et al., 2012; Woodget et al., 2015.

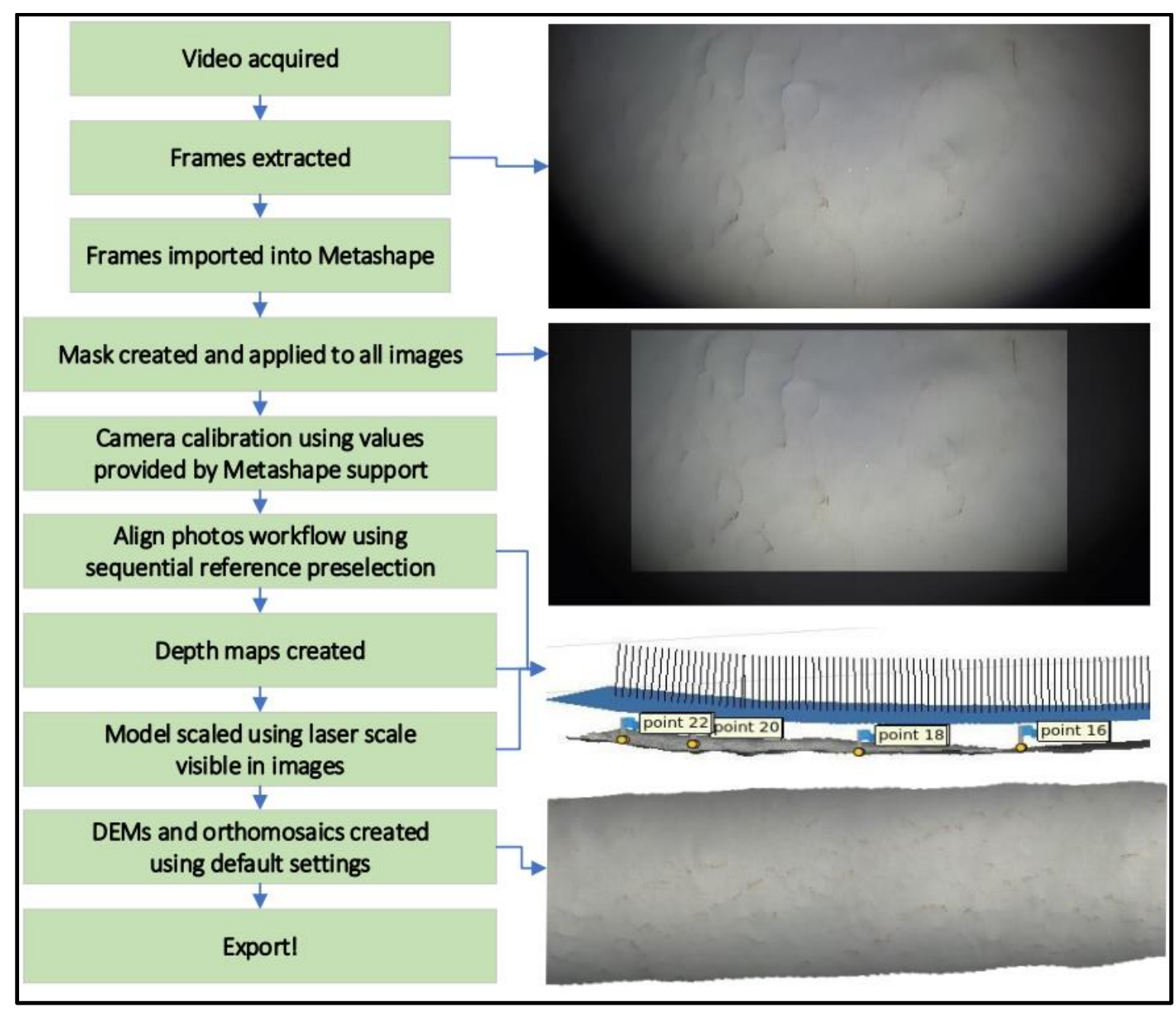

Figure 8: The SfM workflow applied to the Icefin video footage. Third screenshot shows camera locations (in blue) as detected by Metashape. These cameras are detected as relatively flat, so 
accurately reflecting the flat seafloor, in contrast to Figure 9 where the seafloor is highly distorted.

\subsubsection{SfM processing}

Videos were initially loaded into Metashape and still frames extracted using Metashape's automated workflow. However, this process produced blurry frames and was computationally intense and time-consuming. Still frames were instead extracted from the native $30 \mathrm{fps}$ videos at $5 \mathrm{fps}$ using a bash script [ffmpeg -ss 00:01:10 -i IceFin_sea floor.mov -t 00:00:18 -vf $\mathrm{fps}=5$ out\%d.png] prior to importation into Metashape. Metashape recommends $80 \%$ forward overlap between sequential photos for maximum image alignment (Metashape User Manual, Prof. Ed., v1.7); 5 fps was selected as a compromise between reducing processing time and maintaining sufficient overlap (approximately 85\%). Extracted frames were imported to Metashape and processed in batches of 200 images (equating to 40-second clips of the original video). All processing was carried out on Agisoft Metashape Professional, V1.6.4 build 10928 (64 bit).

Up to $60 \%$ of the field of view of each raw image was unable to be processed due to poor illumination and the shadowing caused by the oblique light source. A mask was therefore created to obscure highly shadowed areas of the images and applied to all images in each batch. Unique masks were made for each batch of images because the poorly illuminated areas of the imagery varied based on the altitude of the submersible above the sea floor. This step increased the density of matched points between linked images and reduced computational demand by reducing the size of the images. Continuing without masking resulted in pervasive distortion of the SfM scene (e.g. Figure 9), likely due to uneven shadowing in the images. 


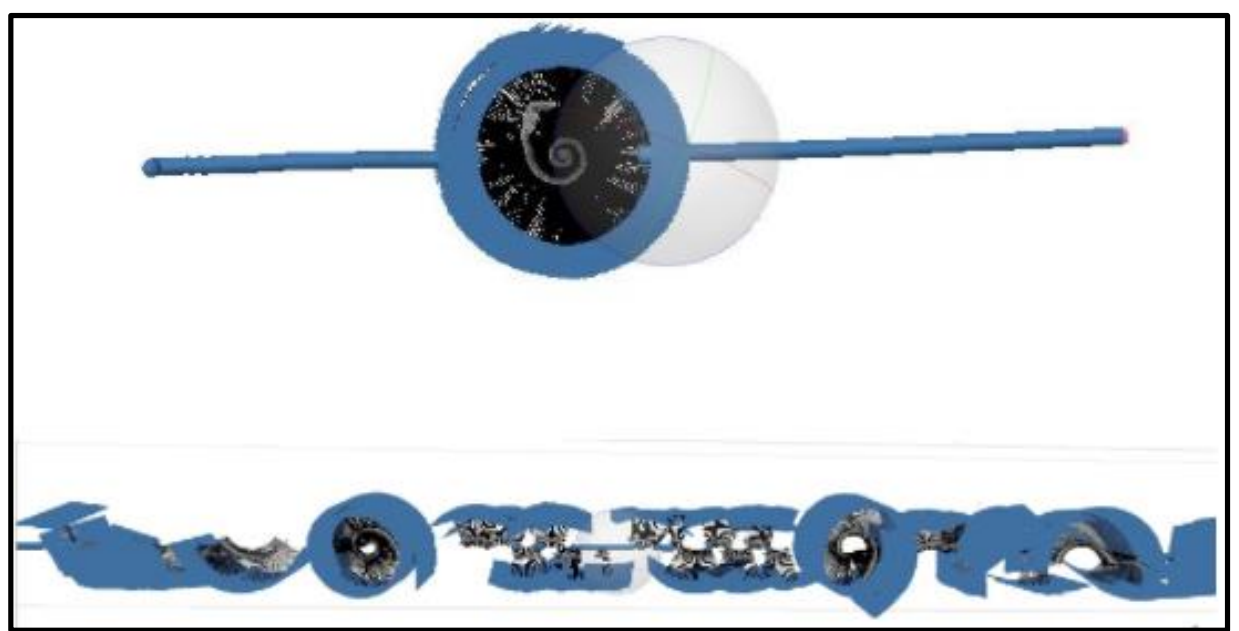

Figure 9: Distortion of the SfM scene when masking is not applied. The blue areas show camera positions reconstructed by Metashape. The Icefin ROV flew at a constant height above the sea floor, which was relatively flat. The blue shapes in the above images should therefore also be flat. The spirals and curves in the figure indicate that Metashape's automated processes think that the Icefin ROV flew in spirals and curves, which results in major distortion of the sea floor if not corrected.

As per the recommended workflow outlined in the Metashape manual, the imported frames were calibrated to reflect the internal orientation parameters of the camera. Independently measured camera parameters provided by Icefin were tested. They were found to reduce the quality of SfM products, possibly because the video assessed in this analysis was recorded in water, but the parameters provided by Icefin were not measured in water (Lawrence, pers. comm., 2020). Following discussion with Metashape support, the camera type was set to fisheye, the focal length to $1500 \mathrm{~mm}$, and all other calibration parameters were fixed for all processing (Figure 10). 


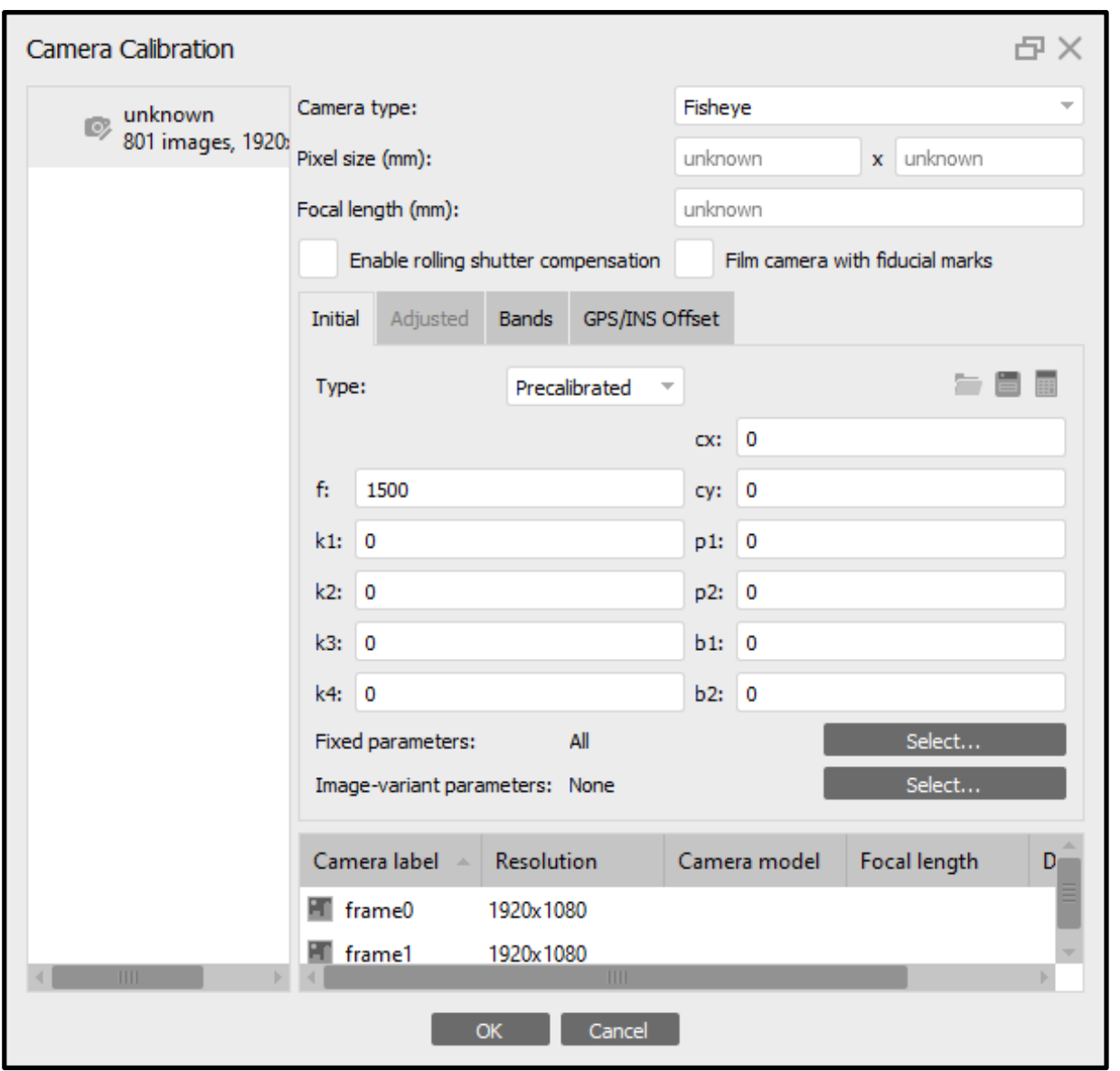

Figure 10: Camera calibration values for all processing completed in this thesis

Metashape's automated photo-alignment process was applied to the masked, calibrated images to determine identical points between images and estimate the camera's location when each image was captured. Sequential reference preselection and default key and tie point limits were used (Figure 11). Where cameras failed to align, those sections of images were realigned following the Metashape User Manual (Prof. Ed., v1.7). Camera locations determined by Icefin's onboard Inertial Measurement Unit (IMU) and linked to the GPS-measured location of the borehole were applied to each image but were found to reduce the quality of the SfM products compared to camera locations automatically estimated during image alignment. 


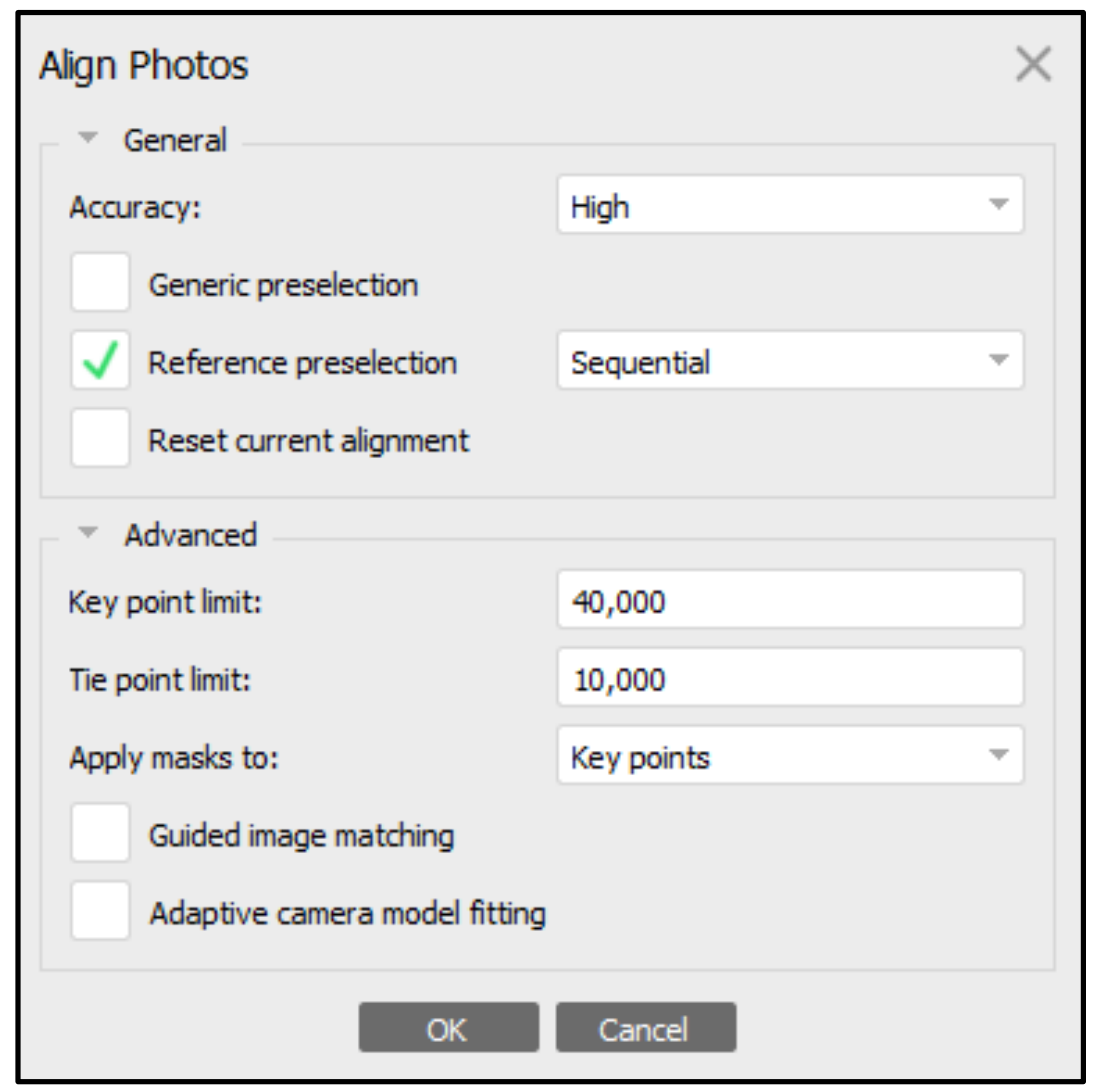

Figure 11: Photo alignment settings for all processing completed in this thesis

Automated image alignment produces a sparse point cloud representing the triangulated positions of matched points between images (Figure 12). While sparse point clouds can be used to develop dense point clouds, testing showed little difference in the final SfM products between using sparse and dense point clouds for this dataset. Accordingly, further processing was completed using sparse point clouds to reduce computational demand. 


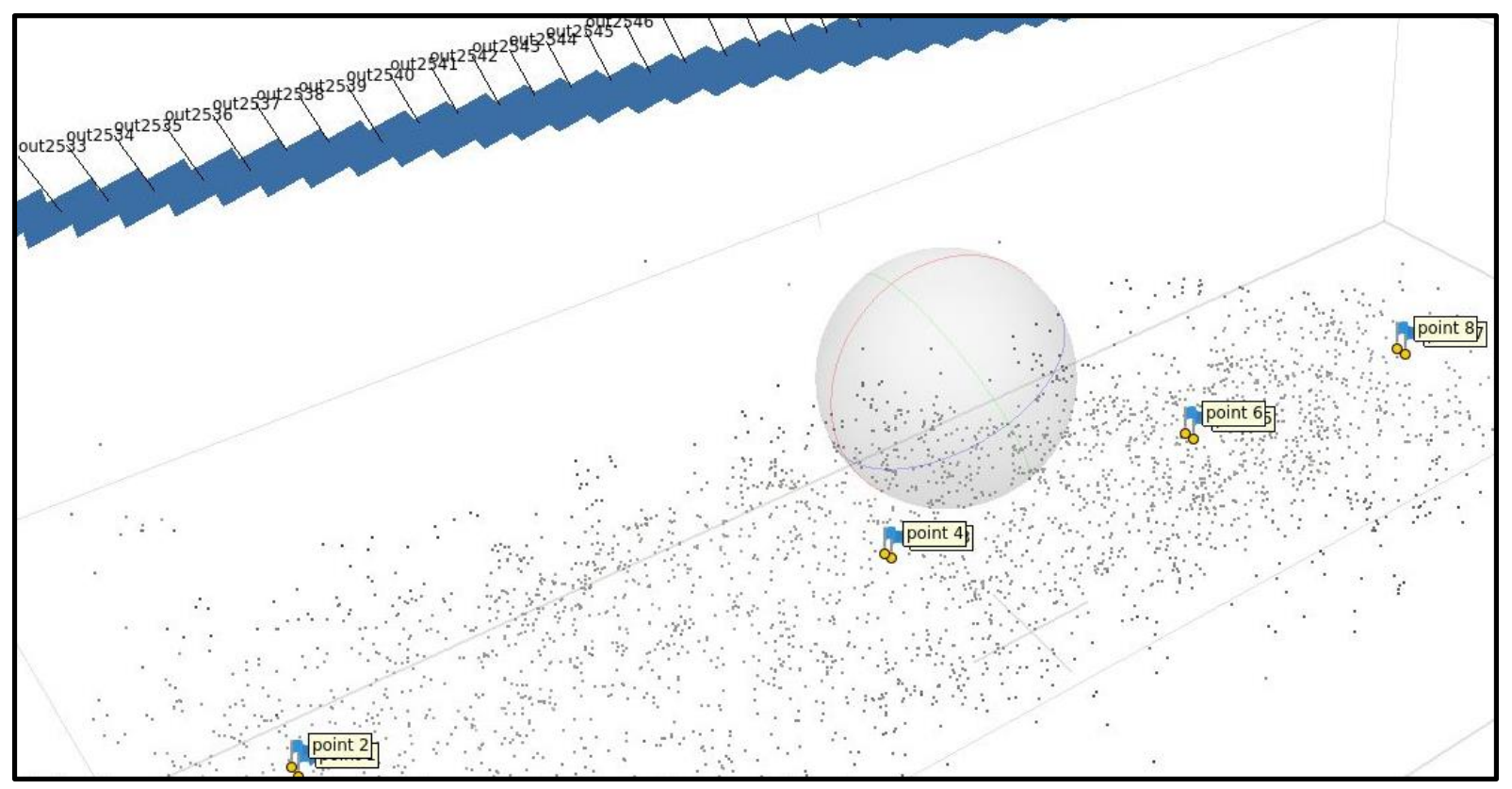

Figure 12: A sparse point cloud. Blue oblongs are camera positions estimated by Metashape; Light grey points indicate matched pixels between photos; yellow and blue flags represent the position of the paired laser points used to scale the SFM.

Metashape's automated workflow was applied to the sparse point cloud to produce 3D models using depth maps generated using high-quality settings (Figure 13). A laser scale visible in the imagery and separated by a constant distance of $50 \mathrm{~mm}$ allowed the images to be scaled using the 'Create scale bar' function. The scaled depth maps were then used to create digital elevation models (DEMs) and orthomosaics using the automated Metashape workflows using default settings.

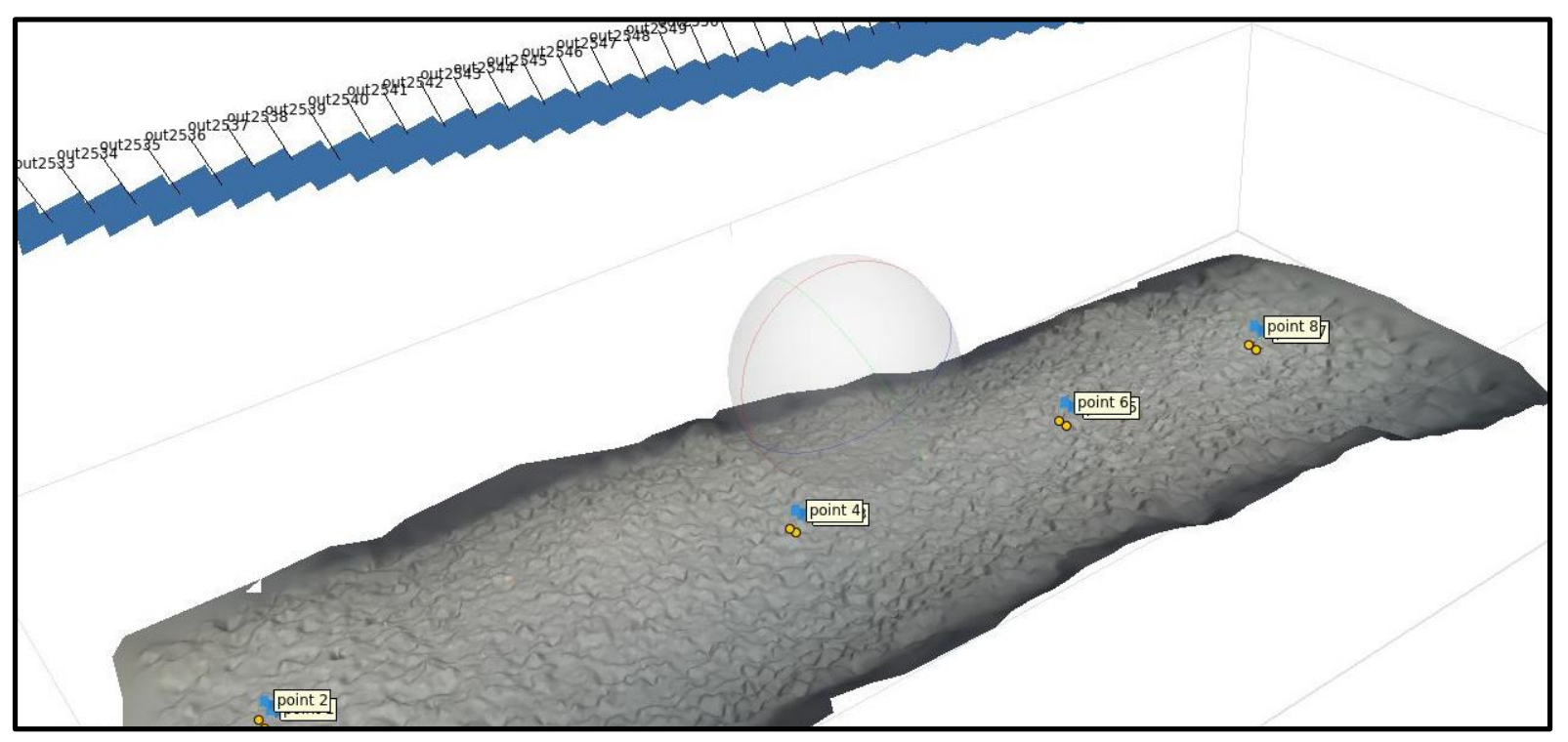

Figure 13: Depth map created using Metashape's default workflow under high-quality settings. 


\subsubsection{Coverage and accuracy of SFM products}

In addition to the dual goals of capturing imagery of the sea floor and the base of the overlying ice shelf, characterisation of the oceanographic properties of the water column was a key objective during the dive. The resulting flight path exhibits a high degree of variability in the submersible's altitude above the sea floor. During the full 60 minute video, the mean altitude in the 30-metre ocean cavity was approximately $9.4 \mathrm{~m}$, with a standard deviation of $8.8 \mathrm{~m}$. However, the mean and standard deviation in altitude for sections of video which were successfully converted to SfM products is 1.26 $\mathrm{m}$ and $0.55 \mathrm{~m}$, respectively. The significantly lower altitude and relatively low variance for SfM-appropriate video indicate a narrow range in the camera's elevation above the sea floor that can be successfully processed using SfM. This relationship illustrates the fundamental challenge of this dataset; quantitative analysis of the sea floor was not a mission objective, which limits the quality of information able to be extracted from the video footage. An additional limitation was the single-pass flight line over which the imagery was captured; an idealised SFM scenario would see areas of interest imaged from several different angles. As a result, of the 60 minutes of video footage, only 9:41 minutes could be converted to orthomosaics and DEMs of the sea floor. Suggestions for future workers to make data more useful for SFM applications are outlined in the discussion.

Agreement between DEMs and orthomosaics is variable. In some cases, bedforms that were evident in video footage and on the corresponding orthomosaics were unable to be distinguished from DEMs of the same area. In other areas, video footage, orthomosaics, and DEMs showed good agreement. These differences are likely a consequence of developing SfM products from input data of varying quality (i.e. imagery captured during high speed and high-altitude portions of the dive is more blurred, so the SfM products are lower quality).

These inconsistencies translate to variable accuracy of the SfM products. Horizontal uncertainty was determined by measuring the distance between the laser pointers on the orthomosaics using the QGIS measure tool and comparing the measured distance to the known distance $(5 \mathrm{~cm})$. Typical horizontal uncertainty on orthomosaics was $<10 \%$, but in some instances, the horizontal uncertainty is as high as $20 \%$. Vertical uncertainty was unable to be quantified because there are no objects at any point in the video 
footage for which the dimensions in the vertical plane are known. To constrain the vertical accuracy of the SFM products, clasts that appeared approximately spherical were measured in the horizontal and vertical plane using the QGIS measure and profile tools, respectively. A vertically accurate model should reflect spherical clasts as having similar vertical and horizontal dimensions. Vertical dimensions were typically measured to be 1-3 x smaller than the measured horizontal dimension, or the clasts were not detected at all. These tests indicate that confidence in measurements in the vertical plane from these SfM products is low.

\subsubsection{Extracting quantitative sea floor sediment and morphology data}

Orthomosaics and DEMs were assessed to quantify the distribution and geometry of bedforms, the size and concentration of dropstones, and variations in the grain size and sediment sorting at the sea floor surface. The sea floor was classified into facies based on textural characteristics and the presence and absence of bedforms. Unprocessed video footage was used to clarify the continuity of facies across areas not covered by orthomosaics or DEMs (detail in the Results section). Examples of biological surface traces were also recorded.

Two classes of bedforms were identified, one being $\mathrm{cm}$-scale ripples and the second $\mathrm{dm}$ to $\mathrm{m}$-scale large bedforms. The centimetre-scale ripples are evident in the original Icefin video, the orthomosaics, and to a limited extent in the DEMs. Orthomosaics were imported into QGIS, with ridge-to-ridge wavelengths measured using the QGIS profile tool. $\mathrm{Cm}$-scale ripples visible in DEMs were transected using the profile tool to estimate bedform amplitude on the order of a few $\mathrm{cm}$. However, uncertainty with the vertical scale is high due to the lack of scaling objects in the vertical plane. Bedform symmetry (an indicator of current direction) was unable to be determined from the DEMs, and is unclear in the orthomosaics and video footage because each section of the sea floor was only imaged from one angle relative to the orientation of the bedforms. The geographic orientation of the bedforms was determined by measuring the angle of the bedforms relative to the long axis of the orthomosaics using the QGIS 'profile' plugin tool and correcting the measured angle to the bearing of the Icefin track recorded by the ROV's IMU. 


\section{2: Modern Sedimentary Environment}

The large bedforms are not distinguishable in orthomosaics and were not immediately apparent in the original video. Accordingly, their distribution was only able to be determined for areas where DEMs had been generated. Their presence was initially identified via Icefin's onboard sonar (Lawrence, pers. comm., 2020) and was highlighted by conducting an aspect analysis on the DEMs produced for this thesis using QGIS. Wavelength and orientation were determined using the same methodology employed for the centimetre-scale bedforms. Amplitude was unable to be accurately measured from the DEMs using the QGIS profile tool, so it was visually estimated. Symmetry was unable to be determined. Additional evidence for these bedforms also comes from the oblique video footage collected at the sea floor directly under the KIS-GZ hole by NIWA (Stevens, pers. comm., 2020).

Grain size was visually estimated from orthomosaics using the scaling lasers where they are visible and the measurement tool in QGIS otherwise. Lonestone size was measured using the QGIS measurement tool. Lonestone abundance was estimated by measuring the spatial coverage of representative sections of orthomosaics and manually counting the lonestones within that area. Here the term "lonestones" describes outsized clasts lying on the sea floor among finer-grained sediment and measure more than $15 \mathrm{~mm}$ along their longest axis (Brink et al., 1998). Because melting from overlying ice is the only credible source of the outsized clasts (Bennett et al., 1996), they are hereafter referred to as 'dropstones'. Where biological traces were identified, the location and type was recorded.

The sediment concentration in the bottom of the ice shelf was investigated but was unable to be quantified. A scanner deployed through the borehole failed to accurately detect the presence of sediment due to excess light reflection off the walls of the borehole. Visual estimates of sediment content were made by comparing images of the bottom of the ice shelf to charts for estimating the percentage clast coverage in core cross-sections (Figure 14). However, the basal ice at KIS-GZ is mostly transparent, and as a result, has low reflectivity. The sediment which is entrained in the ice has high reflectivity, so even sediment which is several metres into the ice is still visible at the ice surface. These differences in reflectivity cause the appearance of a higher concentration of sediment at the ice surface than is actually present. Comparing against percentage clast coverage charts can provide information about changes in the relative 
concentration of sediment but is unsuitable for estimating the absolute concentration of sediment in ice in this setting.

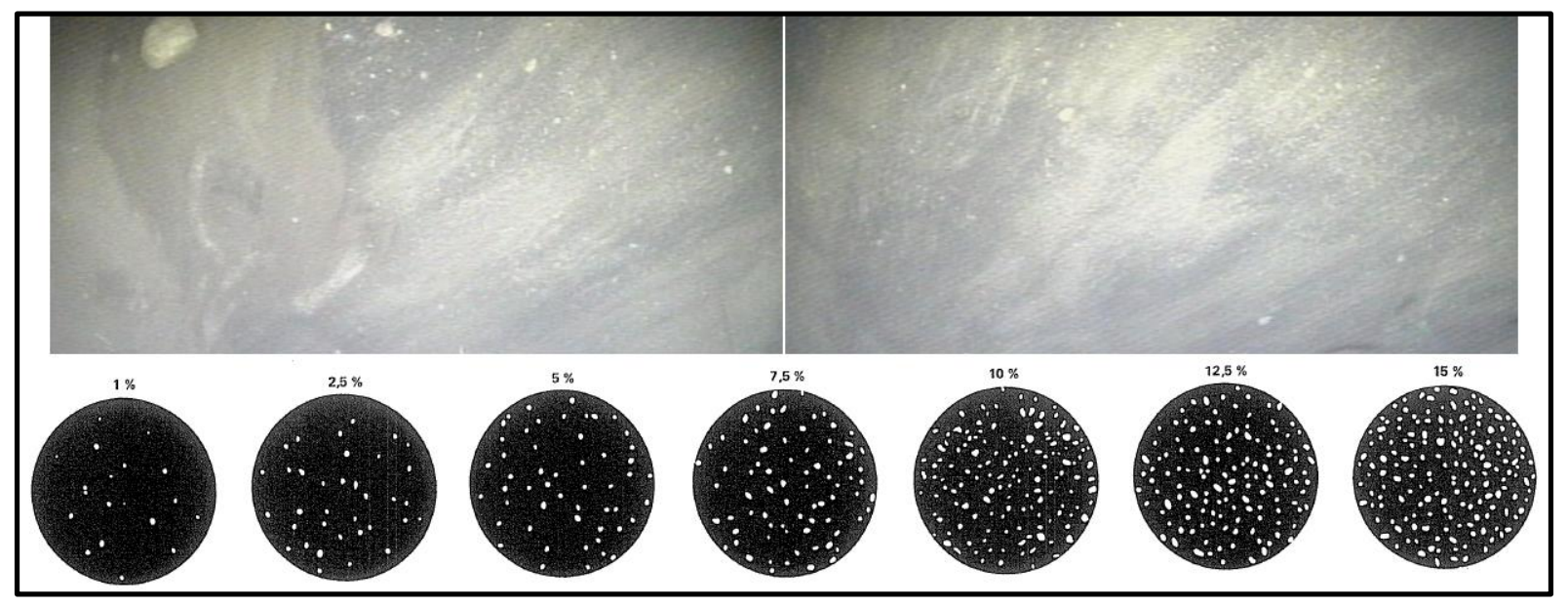

Figure 14: Estimating sediment abundance in basal ice. Percentage coverage charts from CRP Core Logging Manual (after Flugel 1978 and Bacelle and Bosellini 1988). The sediment concentration in the pictured ice appears higher than what is actually present due to the high reflectivity of the sediment. Light-coloured parts of the image are sediment, not bubbles. Note the range of particle sizes present.

\subsection{Results}

Video footage was recorded along an $800 \mathrm{~m}$ transect, with $550 \mathrm{~m}$ capturing the seafloor. Orthomosaics and DEMs were successfully constructed for approximately $220 \mathrm{~m}$ of that distance. The mean width of the orthomosaics/DEMs was $\sim 1 \mathrm{~m}$, giving spatial coverage of $217 \mathrm{~m}^{2}$ for the SfM products. Results outlined here are interpreted from the SfM products and the original video footage; all SfM products are attached in Appendix A.

The sea floor at KIS-GZ is heterogeneous and is classified into three types based on its most prominent visual characteristics; a 'ripple facies', a transition zone, and a 'dropstone facies' (Figure 15, Table 2). The ripple facies is the dominant facies over the surveyed transect, extending for $312 \mathrm{~m}$ at the grounding line end of the transect, while the dropstone facies is observed over $119 \mathrm{~m}$ at the seaward end of the transect. A transition zone that exhibits characteristics of both facies stretches over $114 \mathrm{~m}$ between the areas occupied by the two facies. The seafloor near the borehole appears superficially similar to the dropstone facies, but limited video precluded detailed analysis of the area. Based on grain size analysis of the core (Chapter 3 ), there is more fine sediment near the borehole than what is present in the dropstone facies. 


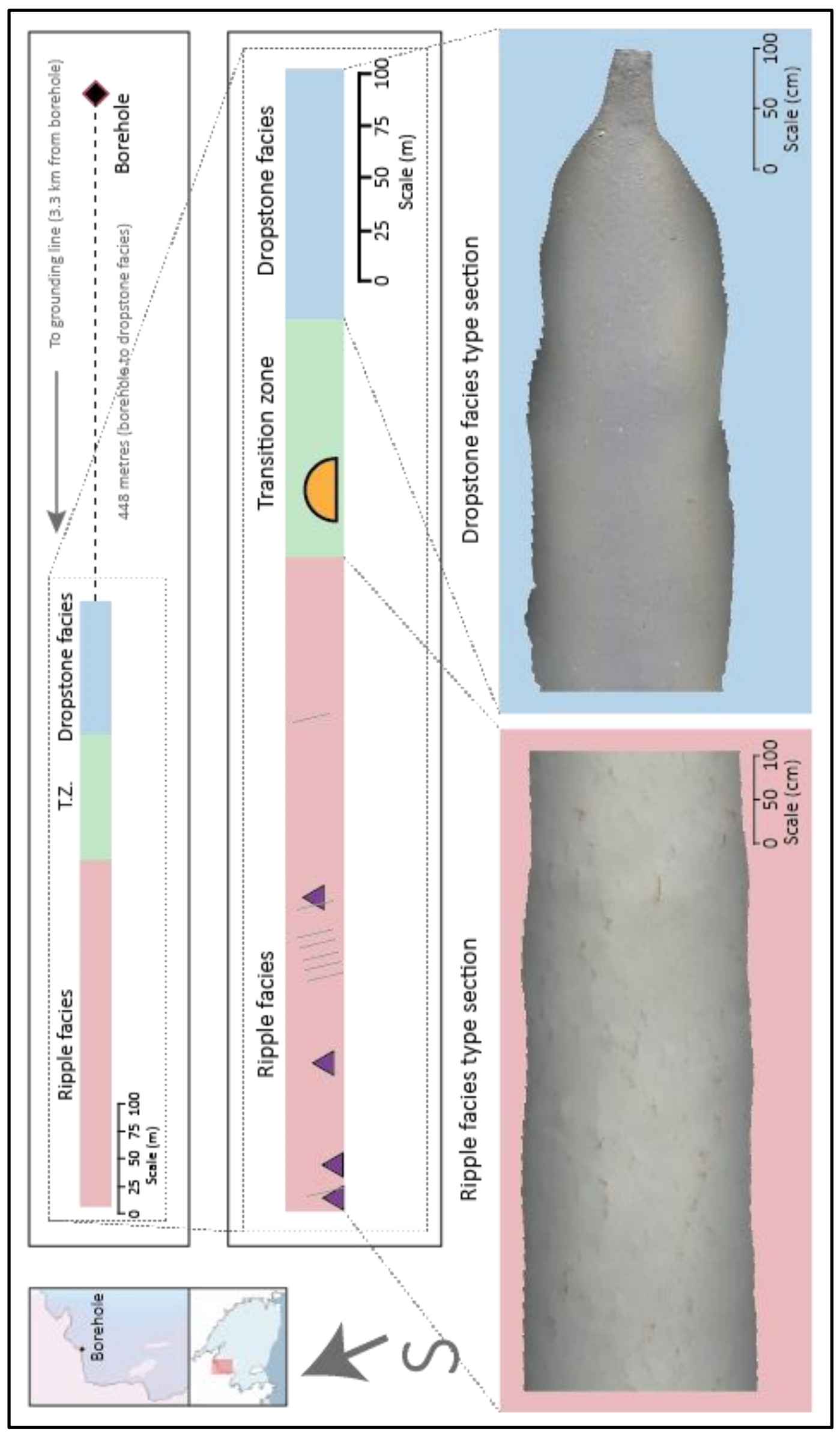


Figure 15: Schematic showing the relative extent of the dropstone facies $(119 \mathrm{~m})$, transition zone $(114 \mathrm{~m})$ and ripple facies (312 m). Decimetre-scale bedforms (yellow half-circle), grey streaks (grey lines), and biological surface traces (purple triangles) are positioned along the flight path to scale. Type sections of the dropstone and ripple facies are provided for reference.

Table 2: Characteristics of different seafloor types observed at KIS.

\begin{tabular}{|c|c|c|c|c|}
\hline & Ripple facies & Transition zone & Dropstone facies & Borehole \\
\hline Grain size & Fine-medium sand & $========>$ & Medium-coarse sand & Silt-medium sand \\
\hline Sorting & Moderate & $========>$ & Moderate-poor & Poor \\
\hline $\begin{array}{c}\text { Mean dropstone } \\
\text { abundance }\end{array}$ & 0.2 clasts $/ \mathrm{m}^{2}$ & $========>$ & 12.1 clasts $/ \mathrm{m}^{2}$ & $\sim 8$ clasts $/ \mathrm{m}^{2}$ \\
\hline Dropstone size & $\begin{array}{c}\text { Range }=1.5-5.5 \mathrm{~cm} \\
\text { Mean }=2 \mathrm{~cm}\end{array}$ & $\begin{array}{c}\text { Range }=1.5-12 \mathrm{~cm} \\
\text { Mean }=2 \mathrm{~cm}\end{array}$ & $\begin{array}{c}\text { Range }=1.5-40 \mathrm{~cm} \\
\text { Mean }=2.2 \mathrm{~cm}\end{array}$ & $\begin{array}{c}\text { Range }=2-7 \mathrm{~cm} \\
\text { Mean }=3 \mathrm{~cm}\end{array}$ \\
\hline Biological traces & Rare movement trails & Not observed & Not observed & Not observed \\
\hline Ripples & $\begin{array}{c}\text { Wavelength } 5-25 \mathrm{~cm} \\
\text { - Amplitude } 0.5-2 \mathrm{~cm} \\
\text { - Ripple index }=\sim 10 \\
\text { - Out-of-phase } \\
\text { sinuous/catenary form* } \\
\text {-Symmetry uncertain } \\
\end{array}$ & Not observed & Not observed & Not observed \\
\hline Dm-scale bedforms & Not observed & $\begin{array}{c}\text { - Wavelength } 0.5-1 \mathrm{~m} \\
\cdot \text { Amplitude } 10-40 \mathrm{~cm} \\
\cdot \text { Ripple index }=\sim 5 \\
\text {-Straight/sinuous form* } \\
\text { Asymmetrical } \\
\end{array}$ & Not observed & $\begin{array}{c}\cdot \text { Wavelength } 0.5-1 \mathrm{~m} \\
\cdot \text { Amplitude } 10-40 \mathrm{~cm} \\
\cdot \text { Ripple index }=\sim 5 \\
\text {-Straight/sinuous form* } \\
\text { Asymmetrical } \\
\end{array}$ \\
\hline Mounds & $\begin{array}{c}\text { Present (up to } 1 \mathrm{~m} \\
\text { diameter, } 30 \mathrm{~cm} \text { + height) }\end{array}$ & $\begin{array}{l}\text { Present (up to } 20 \mathrm{~cm} \\
\text { diameter, } 5 \mathrm{~cm} \text { height) }\end{array}$ & $\begin{array}{l}\text { Present (up to } 20 \mathrm{~cm} \\
\text { diameter, } 5 \mathrm{~cm} \text { height) }\end{array}$ & Not observed \\
\hline Craters & $\begin{array}{c}\text { Present (up to } 30 \mathrm{~cm} \\
\text { diameter) }\end{array}$ & $\begin{array}{c}\text { Present (up to } 20 \mathrm{~cm} \\
\text { diameter) }\end{array}$ & $\begin{array}{c}\text { Present (up to } 20 \mathrm{~cm} \\
\text { diameter) }\end{array}$ & Not observed \\
\hline
\end{tabular}

*See Figure 16

\subsubsection{Ripple facies}

The ripple facies is characterised by the widespread presence of sets of centimetre-scale bedforms (Figure 17). The ripples are discontinuous, often ending after less than $20 \mathrm{~cm}$. Crests which extend further than $50 \mathrm{~cm}$ are rare. Following the nomenclature of Blatt et al. (1972), the ripples switch between out-of-phase sinuous and catenary shapes (Figure 16). The ripples are observed in semiparallel sets with a uniform orientation of approximately 095 degrees along-crest over $\sim 380 \mathrm{~m}^{2}$ (Figure 18). Ripple coverage varies through the facies. Where bedforms are abundant, the ridge-to-ridge spacing (wavelength) consistently lies between 5 and $25 \mathrm{~cm}$, most commonly falling between $10-15 \mathrm{~cm}$. The amplitude of the ripples could not be measured with high

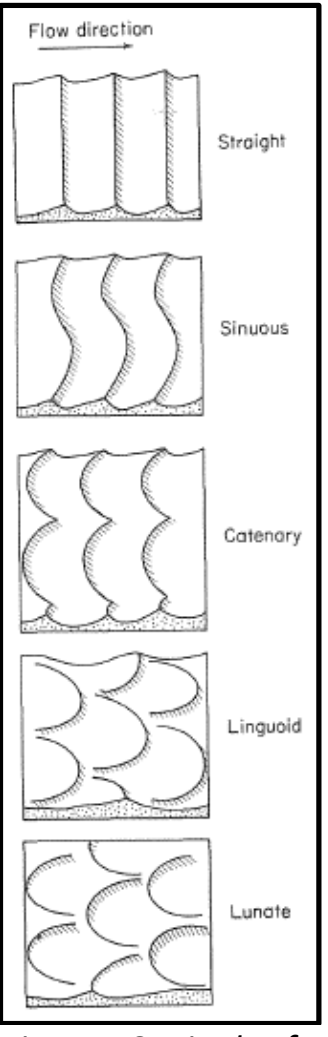

Figure 16: Ripples forms from Blatt et al. (1972) 


\section{2: Modern Sedimentary Environment}

confidence but is estimated at $0.5-2 \mathrm{~cm}$, yielding a ripple index (wavelength/amplitude) of $\sim 10$. The degree of ripple symmetry was unable to be determined from the available data. The crests of the ripples are often but not always delineated by the presence of brown sediment, which is easily disturbed by currents produced by the Icefin ROV's thrusters (Figure 17B).

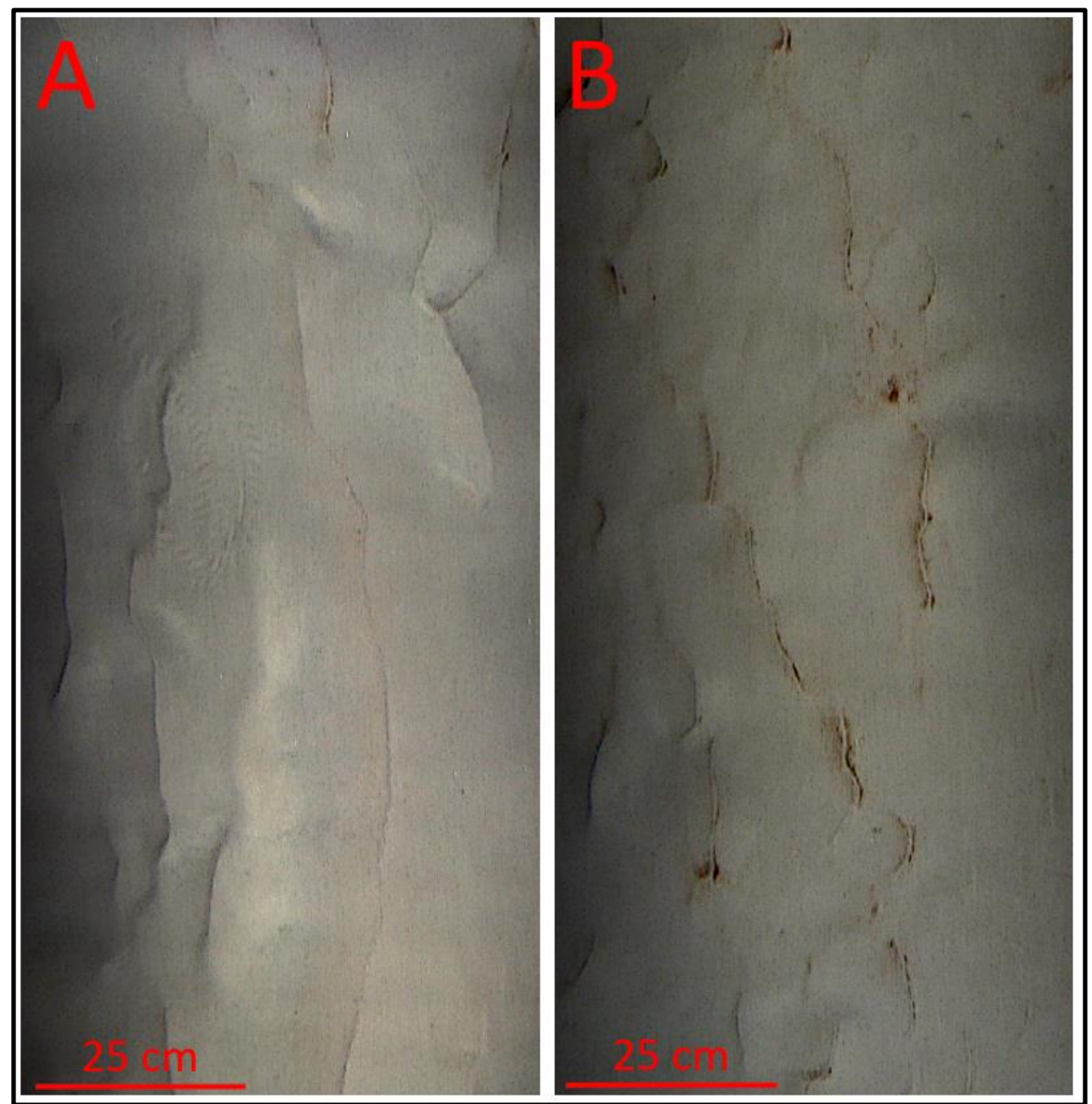

Figure 17: Centimetre-scale ripples on the sea floor. Note biological traces in A, brown sediment lining ridges in $B$. 


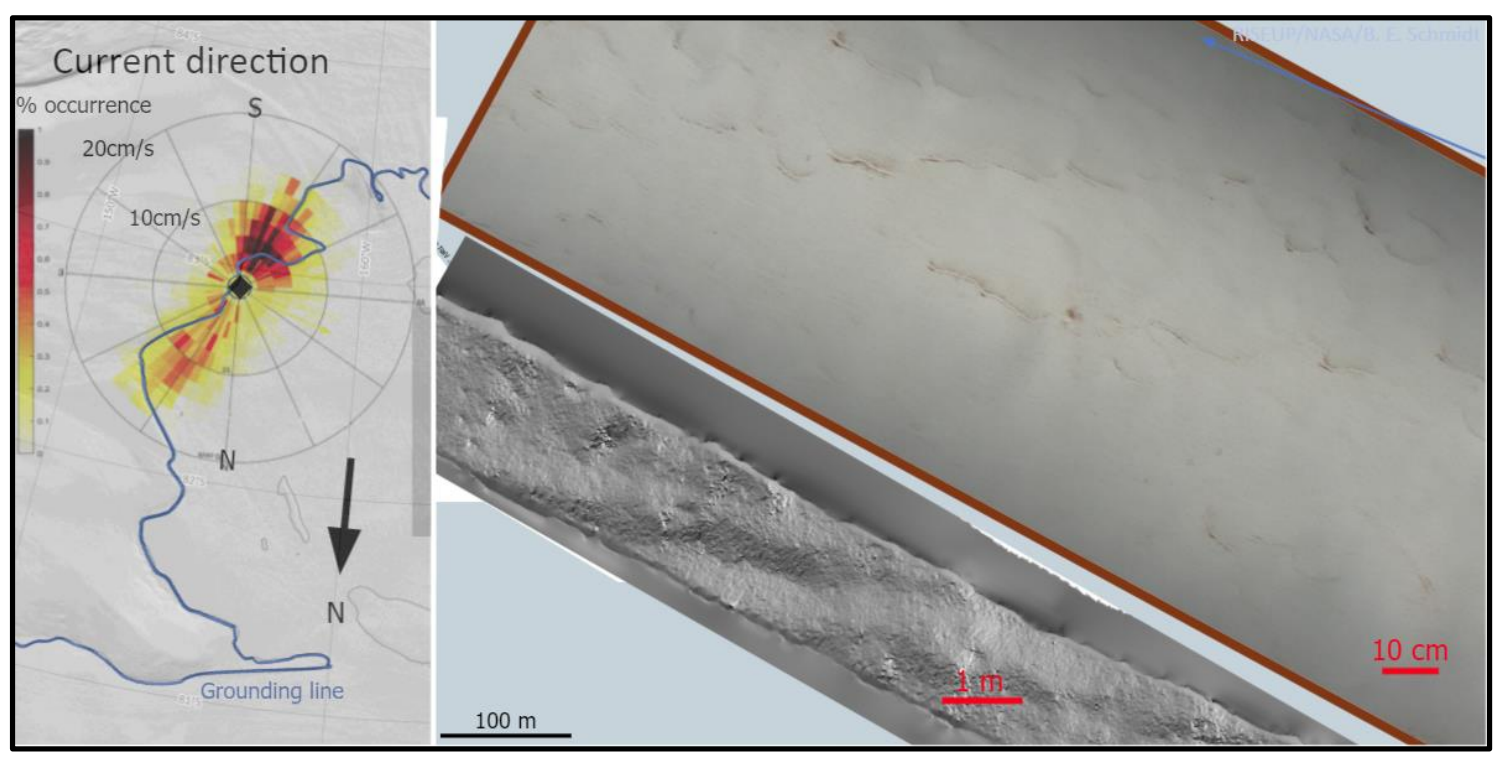

Figure 18: Where present, ripples are orientated along a mean bearing of 071 degrees (upper image), approximately perpendicular to the tidal flows recorded by the oceanographic mooring. Decimetre-scale bedforms in the transition zone (lower DEM) are orientated along a mean bearing of 060 degrees, though the orientation of the dm-scale bedforms near the borehole was unable to be determined.

Surface texture throughout the ripple facies is primarily moderately sorted fine to medium sand, though patches of poorly sorted sediment are present. Quantifying the sorting and grain size of sediment in the sand size class is difficult due to the resolution of the video footage and associated orthomosaics. Grains finer than fine sand were unable to be visually distinguished, but the presence of low quantities of silt are inferred from the settling time of sediment disturbed by the Icefin ROV's thrusters. Dropstones $>1.5 \mathrm{~cm}$ in diameter are present in the ripple facies but are rare, with a maximum abundance of 8 clasts $/ \mathrm{m}^{2}$ and a mean abundance of 0.2 clasts $/ \mathrm{m}^{2}$. Typical dropstones are $\sim 2 \mathrm{~cm}$ in diameter and subrounded-angular in shape. The colour and shape of the clasts vary significantly, indicating significant compositional variation. The largest observed clast in the ripple facies measured $5.5 \mathrm{~cm}$ along its longest axis. No preferred clast orientation is evident. Over most of the transect, the ripple facies is devoid of any dropstones. Where higher concentrations of dropstones are present, ripples tend to be less abundant.

Several steep-sided mounds are present throughout the ripple facies and are seemingly randomly distributed (e.g. Figure 19). The mounds range in height from 5 to $>30 \mathrm{~cm}$. 


\section{2: Modern Sedimentary Environment}

The minimum base diameter is $25 \mathrm{~cm}$. The largest mounds extend beyond the camera's field of view, with a minimum measured diameter of more than $80 \mathrm{~cm}$. Some smaller mounds ( $>20 \mathrm{~cm}$ base diameter) are encircled by craters or depressions in the sea floor up to $5 \mathrm{~cm}$ deep (low certainty). Similar semi-circular craters without mounds are also present and range in diameter from $3-20 \mathrm{~cm}$. $\mathrm{Cm}$-scale ripples aligned with surrounding sets are often present on the sides and top of the mounds. The internal sediment and structure of the mounds are unable to be determined from the data available, but the surface is moderately- to well-sorted fine to medium sand. In one instance, something dark, possibly a protruding clast, is evident near the peak of the mound and appears to be protruding through the sand (Figure 19C).

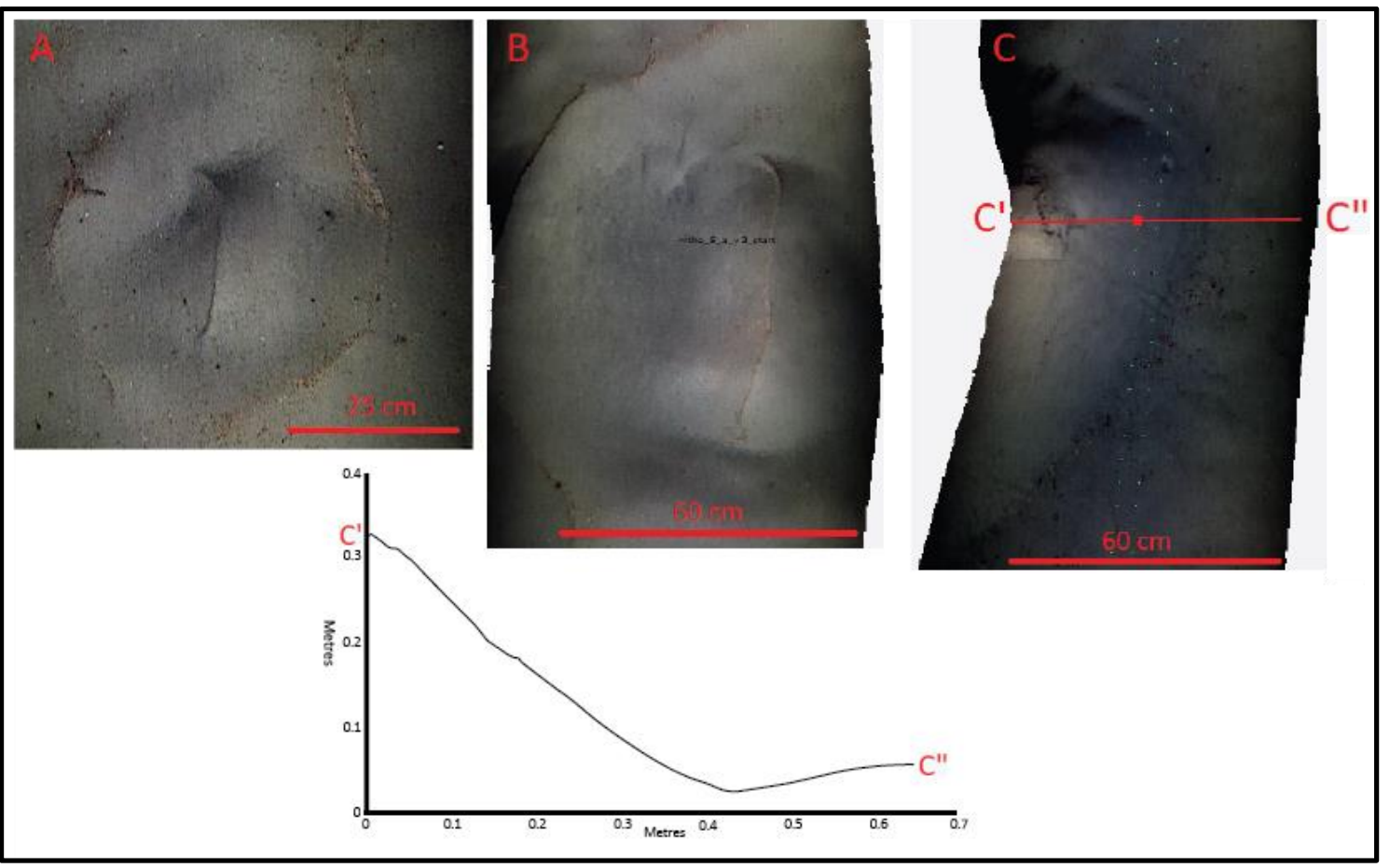

Figure 19: Three examples of mounds; $A$ and $B$ are surrounded by craters. Note ripples atop the mounds. $C$ is a large, steep mound with no surrounding crater, no bedforms, and an amplitude of approx. $30 \mathrm{~cm}$. Note black mottled appearance near the top of mound $C$.

Additionally, a series of eight semi-sinuous light grey-dark grey streaks crosscut the sets of centimetre-scale bedforms at orthogonal or sub-orthogonal angles (Figure 20). Six of the eight streaks occur over a $\sim 40 \mathrm{~m}$ stretch in the middle of the area covered by the ripple facies, with the remaining two streaks positioned 104 and $90 \mathrm{~m}$ landward and seaward of the larger cluster of streaks, respectively. All streaks are orientated within 35 degrees of each other, parallel-sub-parallel to the grounding line. The streaks range in width between $3-5 \mathrm{~cm}$ and do not appear to have any significant relief relative to the surrounding terrain. 


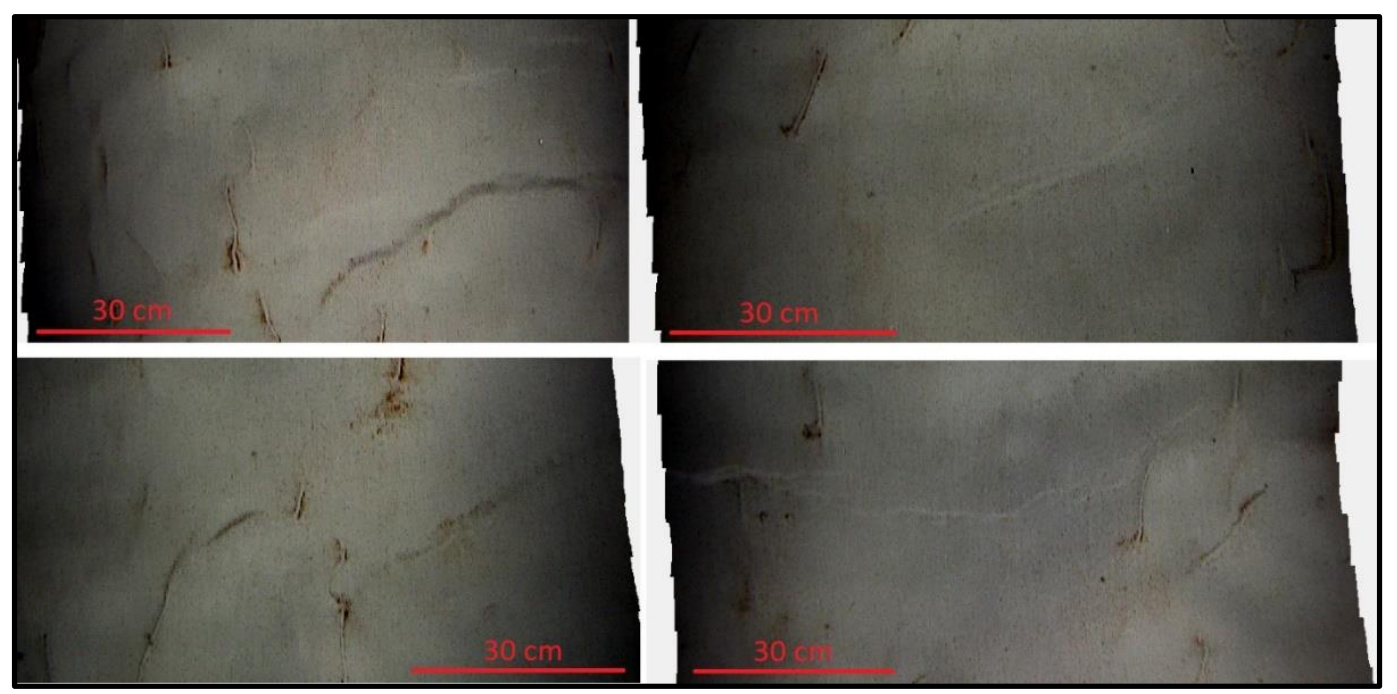

Figure 20: Rare grey streaks intersect ripples at normal-sub-normal angles.

\subsubsection{Dropstone facies}

Throughout the dropstone facies grain size at the surface ranges from fine sand to very coarse sand with abundant granules but is typically poorly sorted medium-coarse sand (Figure 21). The surface texture coarsens and becomes more poorly sorted seaward. More than 30 clasts $/ \mathrm{m}^{2}$ are present in some areas, with a mean dropstone abundance of $\sim 12$ clasts $/ \mathrm{m}^{2}$. The dropstones range in size between 1.5 and $40 \mathrm{~cm}$, with an average clast size of $\sim 2.2 \mathrm{~cm}$. The dropstones are subrounded-angular and have variable colouring (Figure 22). Small indents are occasionally observed surrounding dropstones. There is no evidence of a preferred orientation of the long axis of clasts. A 'pimply' appearance is common, where the otherwise smooth sea floor displays randomly distributed, low gradient mounds up to approximately $10 \mathrm{~cm}$ in diameter and an estimated $5 \mathrm{~cm}$ in height, especially toward the transition zone. These mounds are similar to those in the ripples facies, but smaller. Exposed clasts are sometimes present on the pimply textured sea floor and sometimes not. In places, clasts are partially covered by finer-grained sediment (Figures 21B, 22D). Craters $(<5 \mathrm{~cm}$ diameter) are rare. The ripples and streaky grey sediment distributed throughout the ripple facies were not observed in the dropstone facies. 


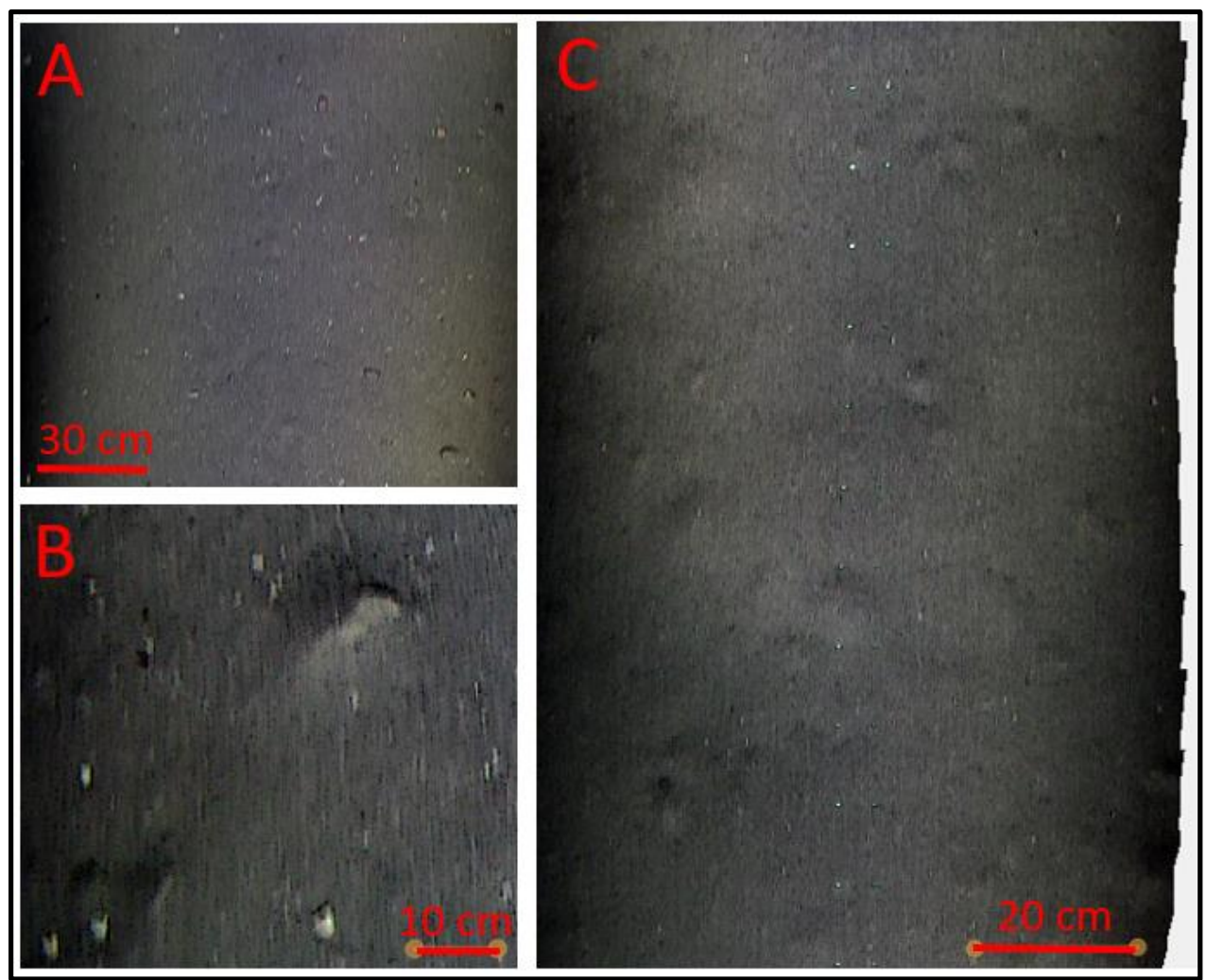

Figure 21: Textural variation in the dropstone facies. A) Dropstone density exceeds $30 \mathrm{clast} / \mathrm{m}^{2}$ in places; B) Dropstones partially covered by sand occur alongside fully exposed dropstones; $C$ ) An area with a 'pimply' appearance. Parallel tracks of green dots are from the Icefin ROV's laser pointers. Dots are $5 \mathrm{~cm}$ apart in the horizontal direction. 


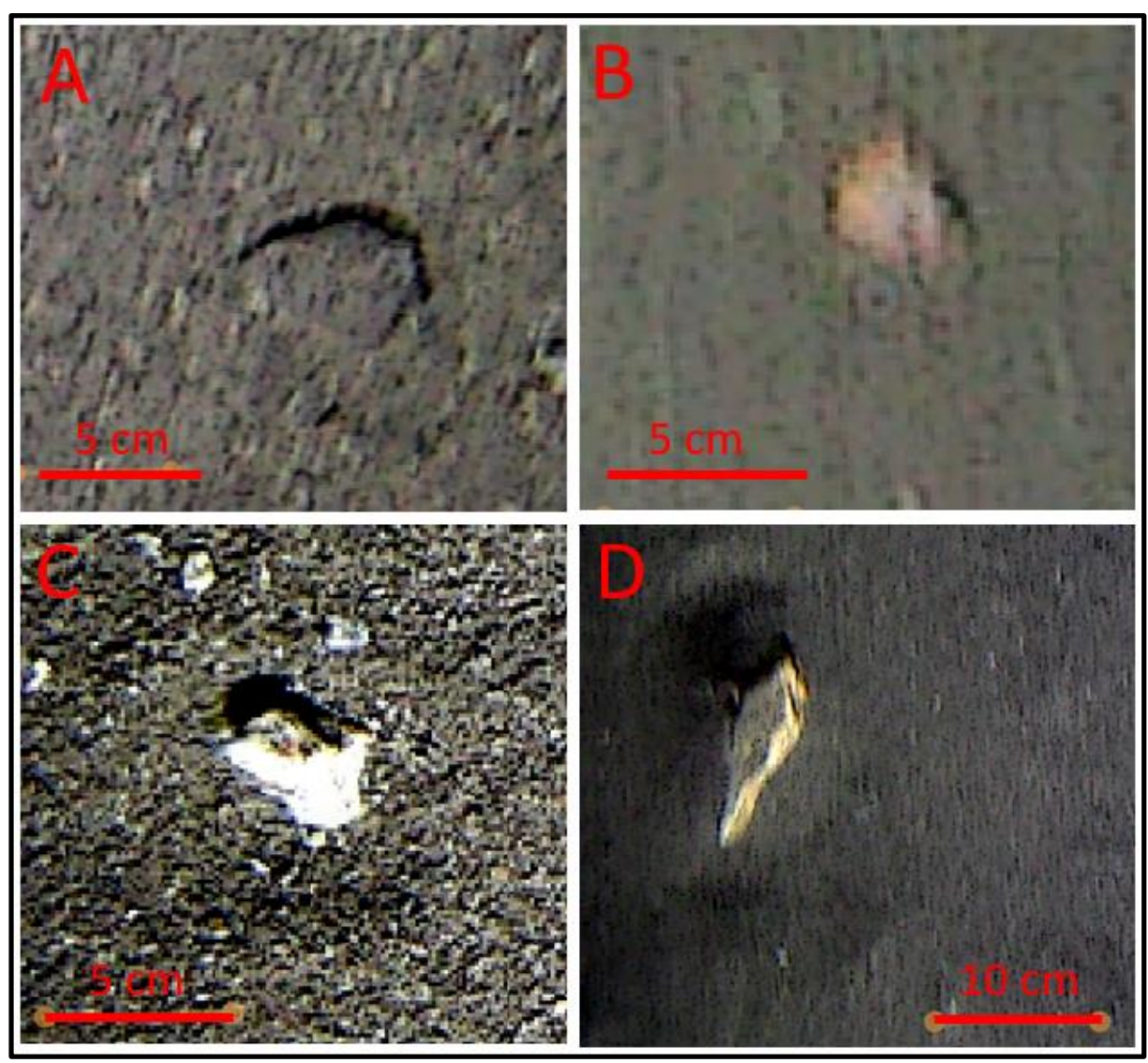

Figure 22: Dropstones exhibit a wide range of shapes and colours. Note the indentations surrounding the large dropstones in $C$ and $D$; also note that the large clast in $D$ is semi-covered by sand.

\subsubsection{Transition zone}

A length of sea floor exhibiting attributes of both the ripple and dropstone facies extends $\sim 114 \mathrm{~m}$ between the two facies. This sea floor has features of both the ripple facies and dropstone facies and, accordingly, is described here as a "transition zone" rather than a unique facies.

The transition zone can be characterised as the ripple facies with a higher concentration of dropstones. Ripples are more abundant toward the end of the transition zone that connects to the ripple facies. The surface texture is that of medium-sized moderately sorted sand. In many places, the sea floor exhibits a "pimply" appearance like that described for the dropstone facies. Counting these as clasts covered by sediment, the concentration of dropstones ranges from 0-10 clasts $/ \mathrm{m}^{2}$. Dropstones become more abundant toward the dropstone facies. The largest exposed dropstone measured $\sim 5 \mathrm{~cm}$ 


\section{2: Modern Sedimentary Environment}

along its longest axis. The mounds, craters, grey streaks and biological traces evident in the ripple facies was not observed in the transition zone.

\subsubsection{Decimetre-scale bedforms}

Decimetre-scale bedforms are present in the transition zone (Figure 15) and near the borehole (Figure 23). Their existence was initially inferred from oblique sea floor imagery captured by a camera fixed to an oceanographic instrument lowered down the borehole (Figure 23), and was also recognised in sonar imaging conducted and processed by Icefin (Lawrence, pers. comm., 2020). The bedforms were observed in the transition zone between the ripple and dropstone facies but are otherwise difficult to identify in the Icefin video footage and orthomosaics or may be absent from this area. Geometric analysis of the bedforms in the transition zone indicate that they are asymmetric, have a typical wavelength of 0.5-1 m, and amplitudes of $10-15 \mathrm{~cm}$ (Figure 24), but uncertainty on these numbers is high for reasons outlined in the methods section. The bedforms near the borehole appear to have an amplitude of up to $40 \mathrm{~cm}$, but there is no means of quantifying their geometry. The estimated ripple index is approximately 5, but again uncertainty is high. The bedforms have a consistent overall orientation but are often subparallel within sets, sometimes diverging and converging (Lawrence, pers. comm., 2021). The long axes of the bedforms are orientated at $\sim 060$ degrees, approximately perpendicular to the orientation of the grounding line and parallel to the direction of inferred past ice flow from the Kamb Ice Stream (Figure 18). 


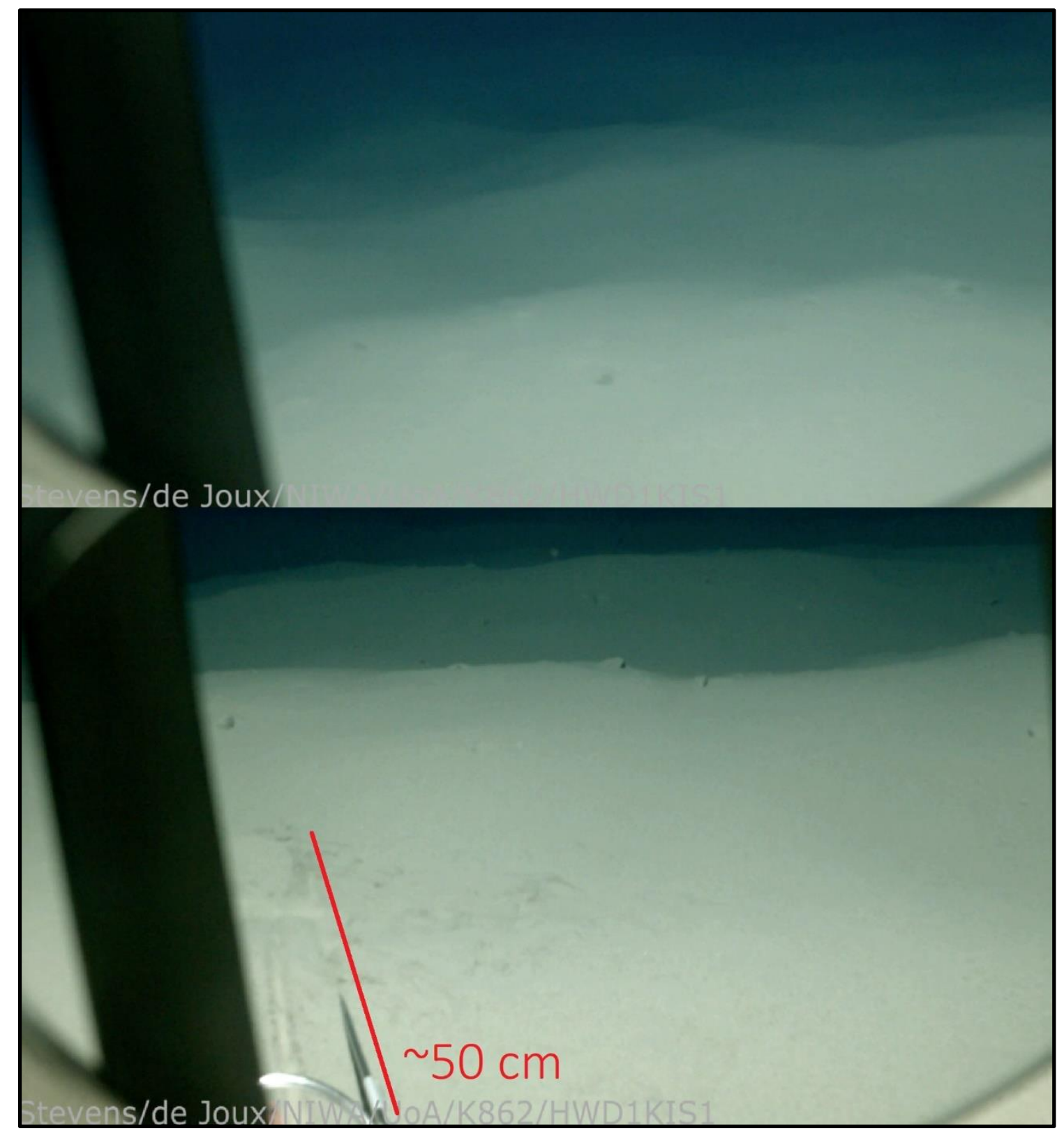

Figure 23: Decimetre-scale bedforms on the sea floor around the borehole. The scale is visually estimated. Images courtesy of Craig Stevens, NIWA. 


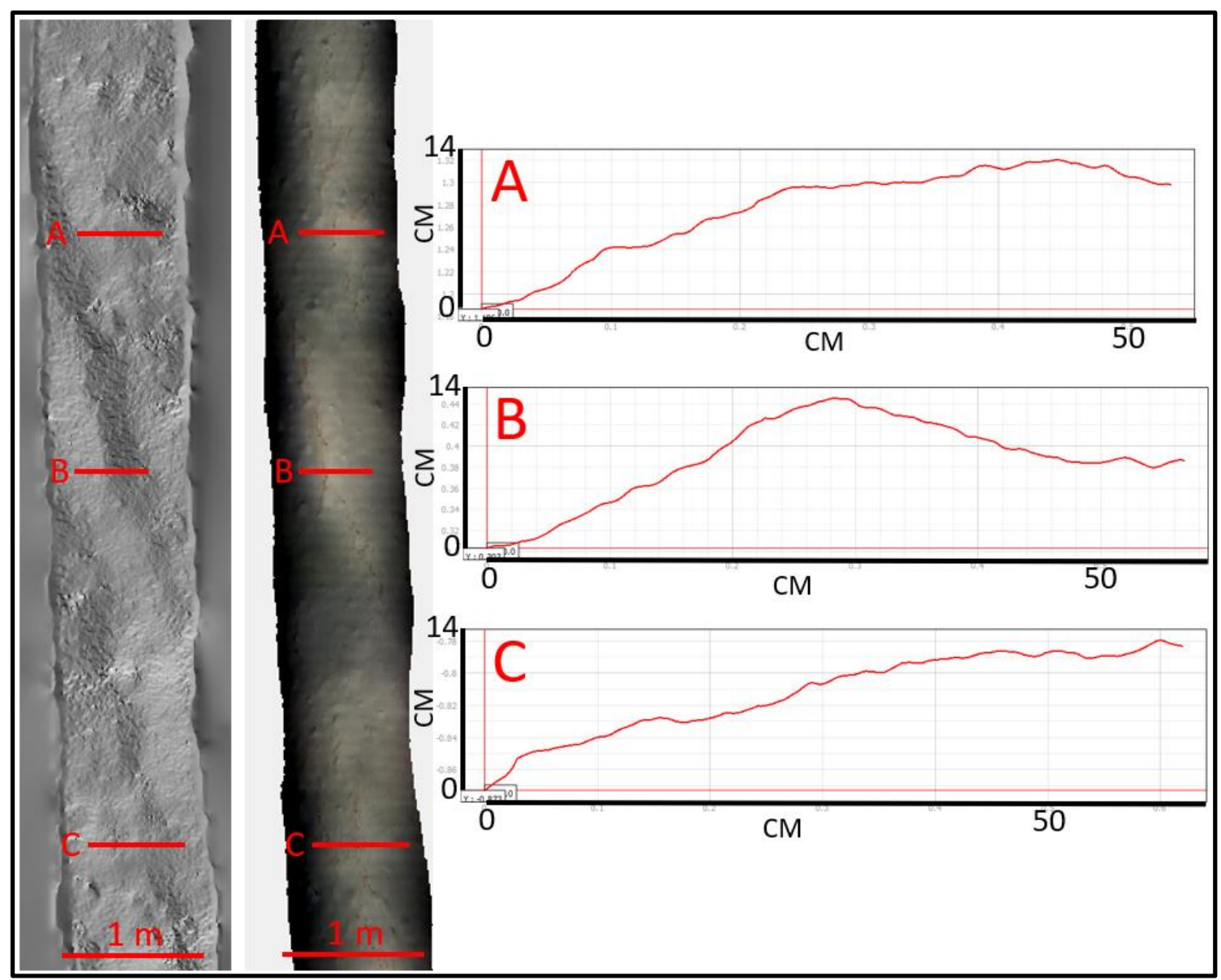

Figure 24: Decimetre-scale bedforms in the transition zone viewed after aspect analysis of the sea floor DEM. Bedform morphology is irregular and typically asymmetric.

\subsubsection{Biological traces on the sea floor}

Biological traces are rare and occur only in the ripple facies (Figure 25). Following the nomenclature outlined by Lindholm (2012), two main forms were identified. Simple meandering trails of dark brown-black sediment are evident in six locations and occupy between 70 and $250 \mathrm{~cm}^{2}$. Additionally, one example of meandering elongate tracks with twin sets of scratch marks (Diplichnites) is present and spans approximately $750 \mathrm{~cm}^{2}$. There is no evidence of vertical burrowing. Nothing that could be unequivocally identified as a living organism was observed in any video footage. Further interpretation of the biotic features identified here is beyond the scope of this thesis. 


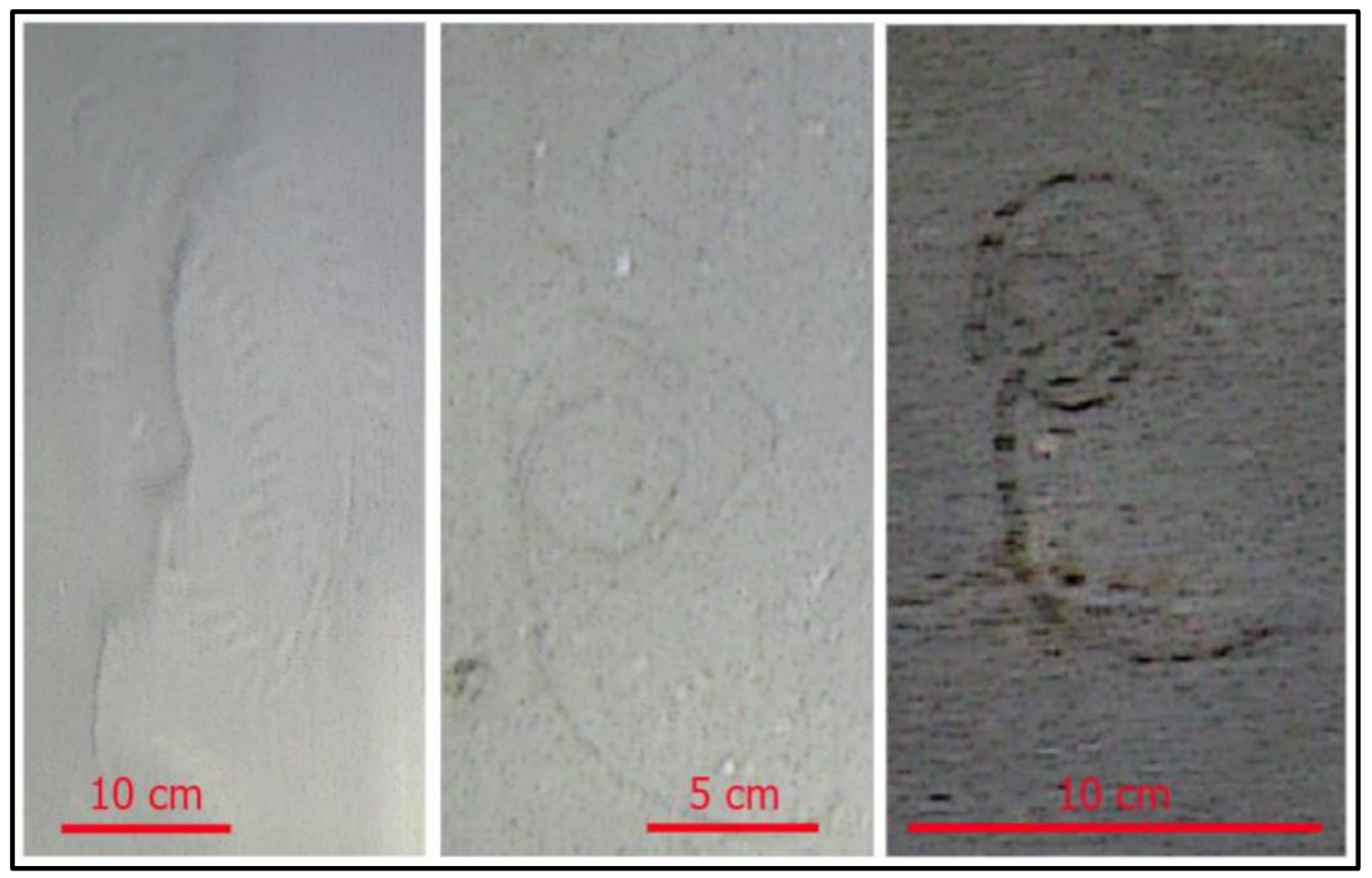

Figure 25: Rare biological traces are present in the ripple facies.

\subsubsection{Current measurements}

*All current data collected by Dr. Craig Stevens and processed by Drs. Craig Stevens and Natalie Robinson (NIWA).*

Current velocities for a two-month period in early 2020 were recorded by an oceanographic mooring in the $\sim 30 \mathrm{~m}$ thick water column under the KIS-GZ borehole. The current meter was positioned approximately 12 metres above the sea floor near the boundary layer between two stratified bodies of water. The measurements therefore probably reflect a lower bound for current velocity at the sea floor-water interface (Stevens, pers. comm., 2021). Measured currents are strongly bi-directional in response to tidal flow into and out of the ice shelf cavity at respective bearings of $200 / 040$ (Stevens, pers. comm., 2021). The velocity of these tidal currents rarely exceeded 10 $\mathrm{cm} . \mathrm{s}^{-1}$ /second and never exceeded $20 \mathrm{~cm} . \mathrm{s}^{-1}$ (Figure 26; Stevens and Robinson, pers. comm., 2021). No major perturbations to the system were recorded. 


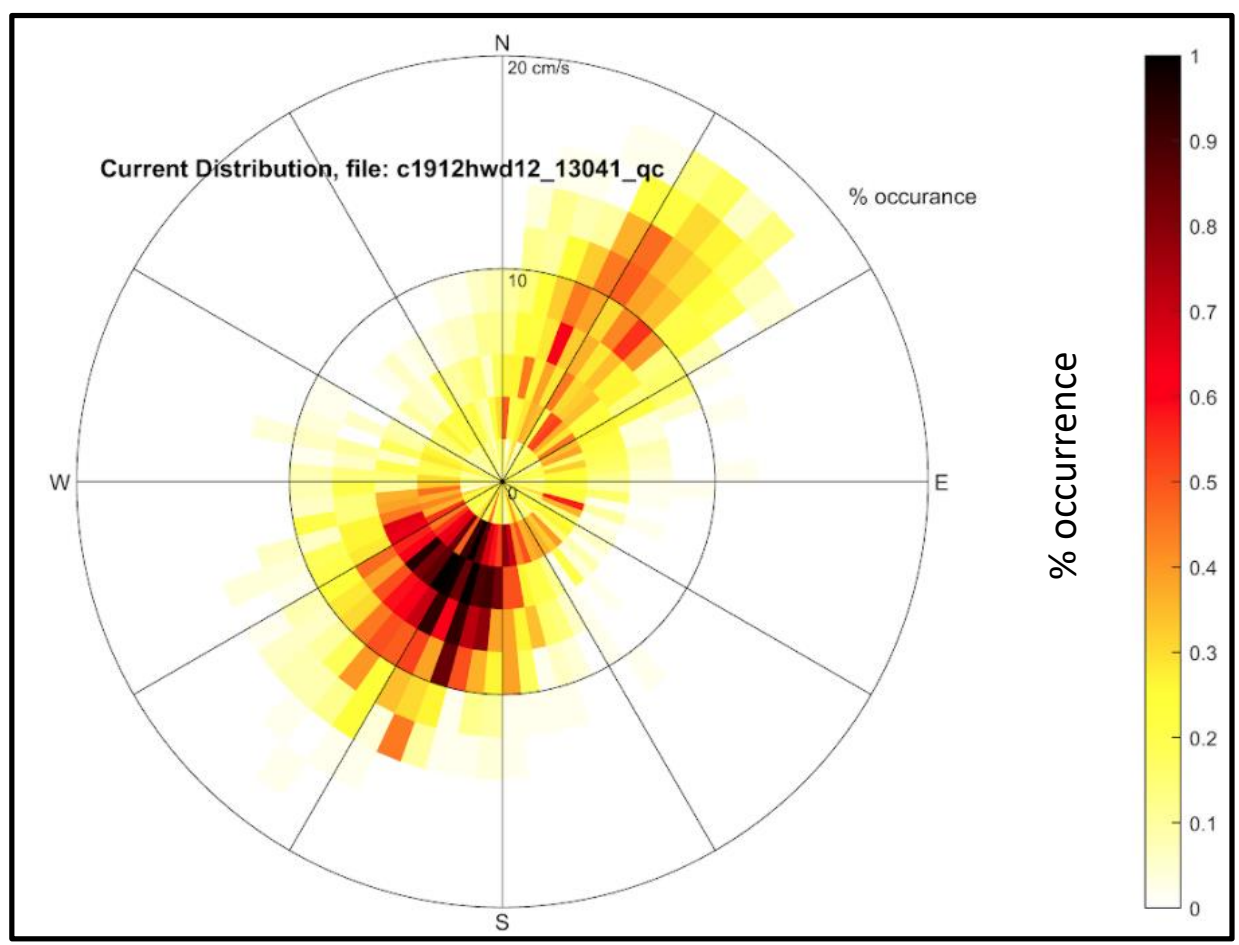

Figure 26: Current speed (radial scale) and direction at KIS-GZ measured by an oceanographic mooring under the borehole. Data and figure courtesy of Stevens and Robinson, NIWA, 2021.

\subsection{Discussion}

\subsubsection{Processes influencing the modern sea floor}

Two end-member sea floor facies at the KIS grounding zone are identified and defined by variations in sediment texture and the presence or absence of different bedform morphologies (Table 2). The facies are separated by a transition zone which exhibits attributes of both facies. 
Table 2 (reproduced): Characteristics of different seafloor types observed at KIS

\begin{tabular}{|c|c|c|c|c|}
\hline & Ripple facies & Transition zone & Dropstone facies & Borehole \\
\hline Grain size & Fine-medium sand & $========>$ & Medium-coarse sand & Silt-medium sand \\
\hline Sorting & Moderate & $========>$ & Moderate-poor & Poor \\
\hline $\begin{array}{l}\text { Mean dropstone } \\
\text { abundance }\end{array}$ & 0.2 clasts $/ \mathrm{m}^{2}$ & $=======>$ & 12.1 clasts $/ \mathrm{m}^{2}$ & $\sim 8$ clasts $/ \mathrm{m}^{2}$ \\
\hline Dropstone size & $\begin{array}{c}\text { Range }=1.5-5.5 \mathrm{~cm} \\
\text { Mean }=2 \mathrm{~cm}\end{array}$ & $\begin{array}{c}\text { Range }=1.5-12 \mathrm{~cm} \\
\text { Mean }=2 \mathrm{~cm}\end{array}$ & $\begin{array}{c}\text { Range }=1.5-40 \mathrm{~cm} \\
\text { Mean }=2.2 \mathrm{~cm}\end{array}$ & $\begin{array}{c}\text { Range }=2-7 \mathrm{~cm} \\
\text { Mean }=3 \mathrm{~cm}\end{array}$ \\
\hline Biological traces & Rare movement trails & Not observed & Not observed & Not observed \\
\hline Ripples & $\begin{array}{c}\cdot \text { Wavelength } 5-25 \mathrm{~cm} \\
\text { - Amplitude } 0.5-2 \mathrm{~cm} \\
\text { - Ripple index }=\sim 10 \\
\text { · Out-of-phase } \\
\text { sinuous/catenary form* } \\
\text { - Symmetry uncertain }\end{array}$ & Not observed & Not observed & Not observed \\
\hline Dm-scale bedforms & Not observed & $\begin{array}{c}\cdot \text { Wavelength } 0.5-1 \mathrm{~m} \\
\cdot \text { Amplitude } 10-40 \mathrm{~cm} \\
\cdot \text { Ripple index }=\sim 5 \\
\text {-Straight/sinuous form* } \\
\text { Asymmetrical }\end{array}$ & Not observed & $\begin{array}{c}\cdot \text { Wavelength } 0.5-1 \mathrm{~m} \\
\cdot \text { Amplitude } 10-40 \mathrm{~cm} \\
\cdot \text { Ripple index }=\sim 5 \\
\text {-Straight/sinuous form* } \\
\text { Asymmetrical }\end{array}$ \\
\hline Mounds & $\begin{array}{c}\text { Present (up to } 1 \mathrm{~m} \\
\text { diameter, } 30 \mathrm{~cm}+\text { height) }\end{array}$ & $\begin{array}{l}\text { Present (up to } 20 \mathrm{~cm} \\
\text { diameter, } 5 \mathrm{~cm} \text { height) }\end{array}$ & $\begin{array}{l}\text { Present (up to } 20 \mathrm{~cm} \\
\text { diameter, } 5 \mathrm{~cm} \text { height) }\end{array}$ & Not observed \\
\hline Craters & $\begin{array}{c}\text { Present (up to } 30 \mathrm{~cm} \\
\text { diameter) }\end{array}$ & $\begin{array}{c}\text { Present (up to } 20 \mathrm{~cm} \\
\text { diameter) }\end{array}$ & $\begin{array}{c}\text { Present (up to } 20 \mathrm{~cm} \\
\text { diameter) }\end{array}$ & Not observed \\
\hline
\end{tabular}

\section{*See Figure 16}

Basal melt of the overlying ice shelf and the resultant rainout of entrained sediment is the dominant sediment delivery mechanism throughout the study area (see Chapters 3, 4). Rainout sedimentation is evidenced by the widespread occurrence of dropstone craters on the sea floor (e.g. Bronikowska et al., 2021; Figure 19). Some dropstones are partially covered by finer sediment (Figure 21, Figure 22). Mounds of varying scales are ubiquitous and are interpreted to be dropstones that are fully covered by finer sediment (Figure 19Figure 21C).

Sediment texture is frequently used as the basis for environmental interpretation, given the often-narrow range of conditions under which sediment of a given size, sorting, and composition can be generated. Imagery of the ice shelf base reveals a complete spectrum of particle sizes from clay through to cobble (see Figure 14), which is consistent with observations of extremely poorly sorted sediment entrained in the basal ice at UpC (Christoffersen et al., 2010).

Since ice itself does not sort sediment in transit, I assume the texture of the sediment released to the sea floor from melting of the overlying ice is uniformly poorly sorted. Any variation in the texture of the sea floor therefore indicates that the sediment has 


\section{2: Modern Sedimentary Environment}

been reworked following initial rainout deposition. The most likely mechanism for sorting sediment in a sub-ice shelf environment is ocean currents.

The ability of a current to transport sediment and generate bedforms is a function of the size of the sediment grains and the velocity of the current (e.g. Baas, 1994 and references therein). These relationships are well-established (e.g. Costello \& Southard, 1981; Inman, 1949; Stow et al., 2009). The sinuous-catenary shaped ripples that populate the sea floor's fine-medium sand areas require a minimum current velocity of $\sim 0.2 \mathrm{~m} . \mathrm{s}^{-1}$ to develop (Figure 27). The presence of fine sand constrains the upper

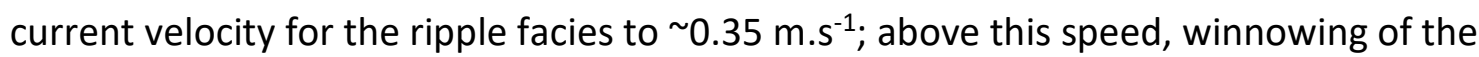
finer-grained sediment would have occurred (Figure 27). The absence of sediment finer than fine sand in the dropstone facies, along with relatively abundant dropstones, is indicative of fine-fraction winnowing associated with current velocities in excess of $\sim 0.35 \mathrm{~m} . \mathrm{s}^{-1}$ (Figure 27). The absence of bedforms in the medium-coarse sand suggests an upper flow velocity of no more than $\sim 0.5 \mathrm{~m} . \mathrm{s}^{-1}$ (Figure 27). While the orientation of the ripples is consistent with generation by the tidal flows measured at the KIS-GZ borehole, the velocities observed over a 2-month period are either insufficient to generate bedforms in the particle sizes observed on the sea floor or effectively winnow sea floor sediment (Figure 27). Therefore, the textures and bedforms on the sea floor must be relict (i.e. formed in the past under different current regimes). 


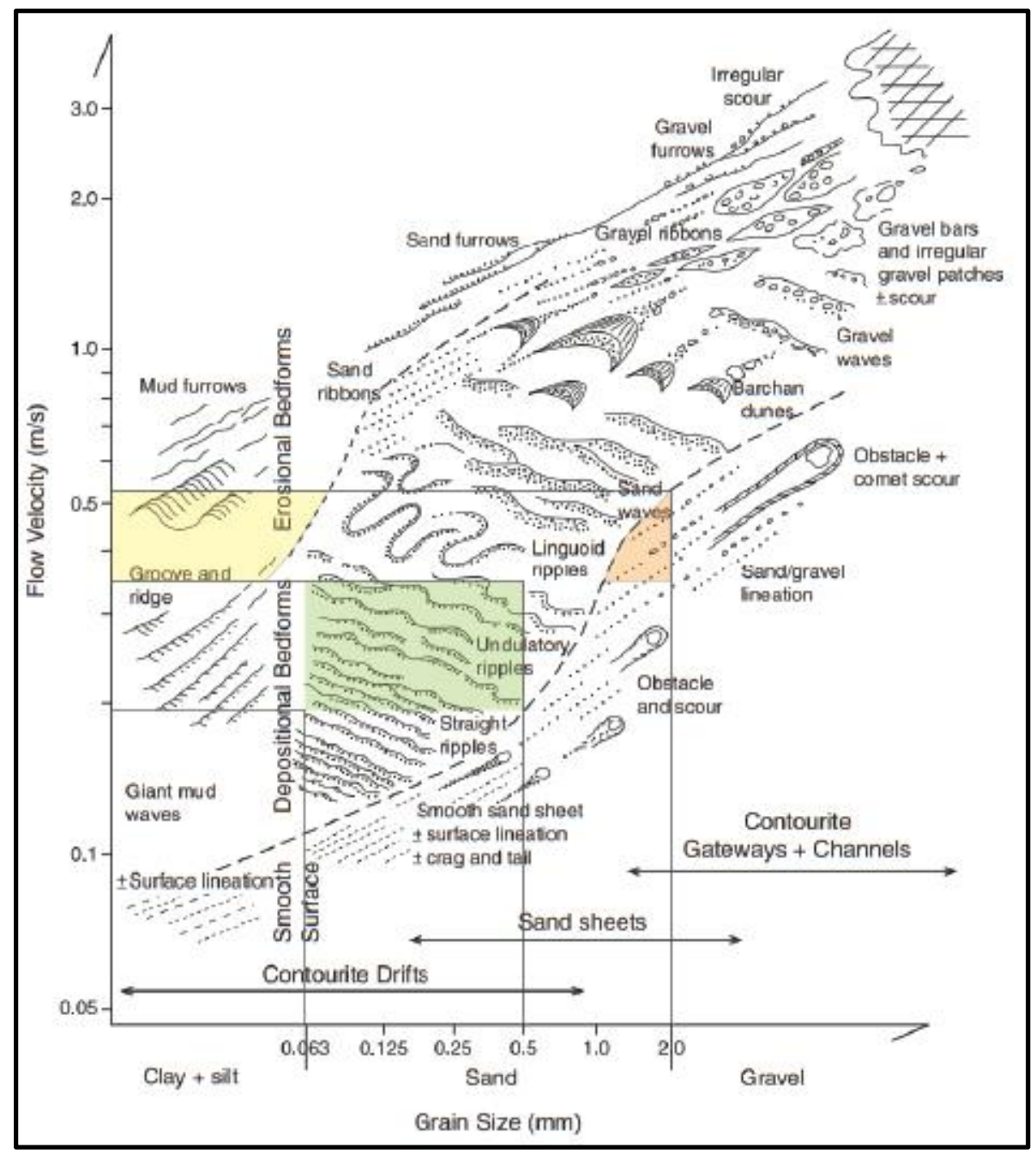

Figure 27: Bedform-velocity diagram modified from Stow et al. (2009). The green field associates undulatory ripples in fine-medium sand, like those observed in the ripple facies, to current velocities of $\sim 0.2-0.35 \mathrm{~m} . \mathrm{s}^{-1}$. The orange field associates flat beds in medium-coarse sand, like the sea floor in the dropstones facies, to current velocities of $\sim 0.2-0.5 \mathrm{~m}^{-1} \mathrm{~s}^{-1}$. At the upper range of these flow speeds, fine sand is being eroded and removed (yellow field).

Bedforms and sea floor textures can develop in minutes and persist until they are overwritten by a higher energy event or buried by subsequent rainout sedimentation. The precise timing of the formation of ripples at KIS-GZ is unclear. However, because the $0.5-2 \mathrm{~cm}$ amplitude ripples are evident on the sea floor and superimposed on mounds, less than $2 \mathrm{~cm}$ of sediment must have accumulated following their formation. The sedimentation rate provided in Chapter 4 therefore constrains the timing of ripple formation to the last decade, probably within the last several years. The strengthened currents required to generate the ripples may be associated with the emerging phenomenon of "sub-ice shelf tsunamis", which are periods of strengthened currents that appear to propagate beneath the ice shelf from the open ocean and may be 
associated with seismic or iceberg calving events (Stevens, pers. comm., 2021). The timing of these events is random, though measurements from a central-RIS oceanographic mooring record several events/year (Stevens, pers. comm., 2021). Spatial variability in current strength is likely driven by interactions between the geometry of the ocean cavity and several different oceanographic processes. The KIS grounding zone is influenced by tidal currents, general circulation currents, and probably the aforementioned "sub-ice shelf tsunamis" (Stevens, pers. comm., 2021). Additionally, the overlying ice shelf is populated with basal crevasses (Lawrence, pers. comm., 2020). I speculate that the interplay between the heterogeneity of the ice shelf geometry and complex ocean currents likely modulates current strength, resulting in the spatially variable sea floor texture and bedforms.

The scale, shape, and textural characteristics of the rare decimetre-scale bedforms observed near the borehole and in the dropstone facies and transition zone appear to have a different genesis to current-generated bedforms. While they are orientated transverse to the flow of the modern tidal regime, the steep profile of the bedforms relative to their wavelength is incompatible with formation by currents (Table 2 of Boggs, 2014). Additionally, dm-scale bedforms require current velocities in excess of 50 $\mathrm{cm} . \mathrm{s}^{-1}$ to form (Stow et al., 2009), which is also inconsistent with the presence of $\leq 50 \%$ silt and clay measured in bedforms present at the borehole (Grain size analysis, Chapter 3). With a current genesis excluded, the most likely formation mechanism for the $\mathrm{dm}$-scale bedforms is some as-yet-undefined interaction between ice, water, and the sea floor. I note that the geometry and amplitude of the $\mathrm{dm}$-scale bedforms are approximately equivalent to scalloping textures observed on the ice shelf base in the study area (Figure 28), which develop where turbulent flows at a water-ice interface modify ice geometry (Bushuk et al., 2019). I speculate that the bedforms formed very close to the grounding line when the ocean cavity was decimetres-metres in height, where the influence of any water expelled from the base of the ice stream on the sea floor sediment would have been amplified. The orientation of the bedforms, approximately parallel to the paleo-flow direction of KIS, is consistent with outflowing water excavating the sea floor. Further analysis of the distribution, orientation, geometry and internal composition of $\mathrm{dm}$-scale bedforms in grounding zones is required. 


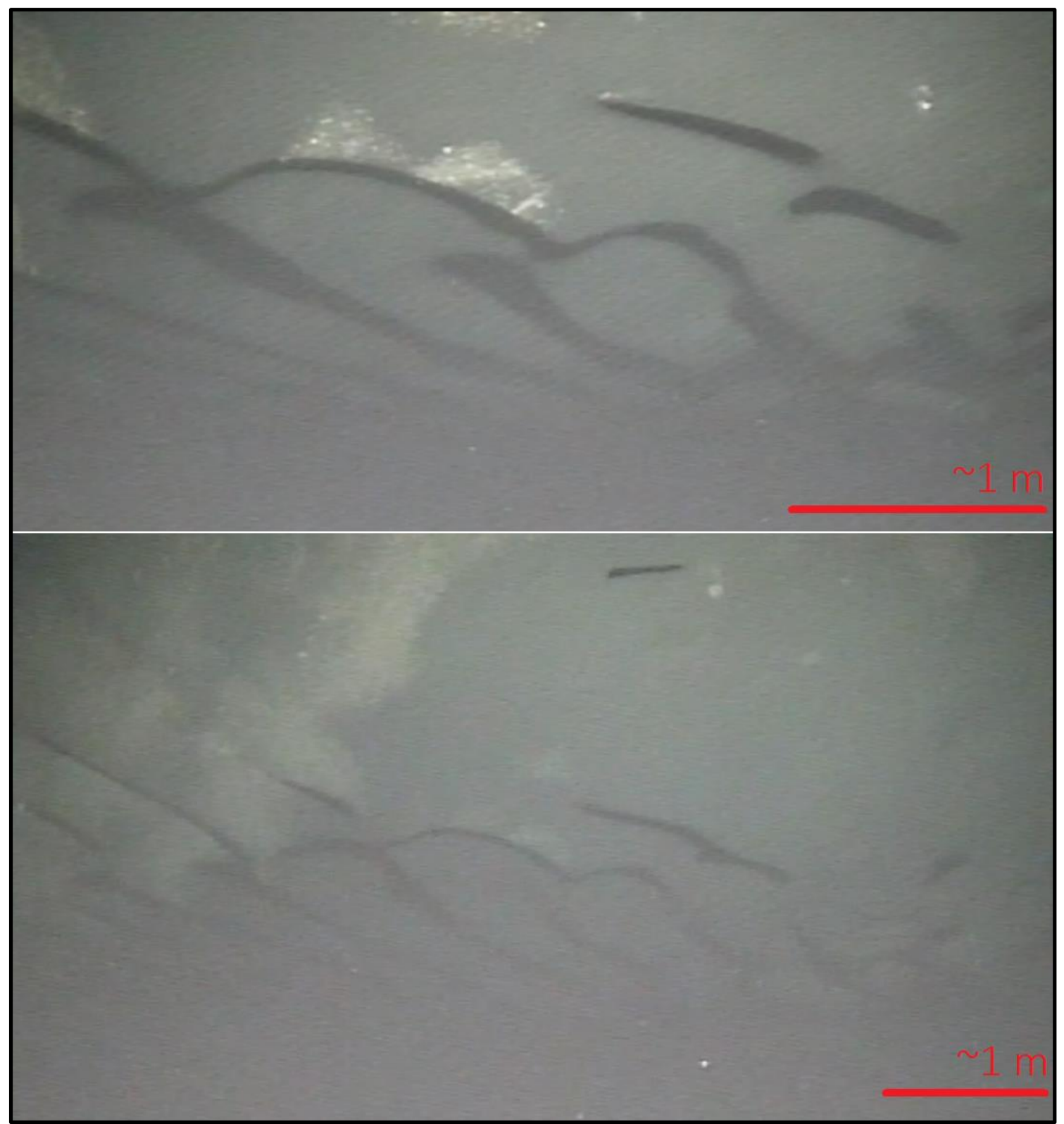

Figure 28: Scalloping on the ice shelf base is approximately consistent with the geometry of the rare decimetre-scale bedforms observed in the dropstone facies. Scale is visually estimated. Lastly, the origin and significance of the grey streaks noted in section 2.3.1 remains unclear.

\subsubsection{Methodological improvements}

This analysis shows that an SfM approach yields useable data for understanding sub-ice shelf sedimentary processes while highlighting the limitations of how this dataset was collected. The following steps are recommended if a dedicated survey mapping the seabed for SfM analysis is to be conducted: 
- Flight paths should be designed to maximise spatial coverage whilst examining key areas in enough detail to extract high-quality quantitative data (e.g. Figure 29). Single-pass video, as used in this analysis, is acceptable for identifying locations of interest, but multi-pass, grid-style surveys over important areas would significantly reduce vertical uncertainties.

- All areas should be surveyed at a constant speed and altitude above the sea floor to ensure that comparisons between imagery take place under consistent conditions

- Camera and lighting settings should be optimised pre-dive to reduce shadowing; bright, strobe-style illumination with a shutter camera capturing still images may be a more effective solution than shooting video footage with a constantly illuminated light source (Lawrence, pers. comm., 2021)

- If assessing the textural characteristics of the sea floor in a sub-ice shelf environment, any efforts to quantify the sediment properties of the overlying ice (or sediment from other sources) via physical sampling or imaging would be enormously helpful

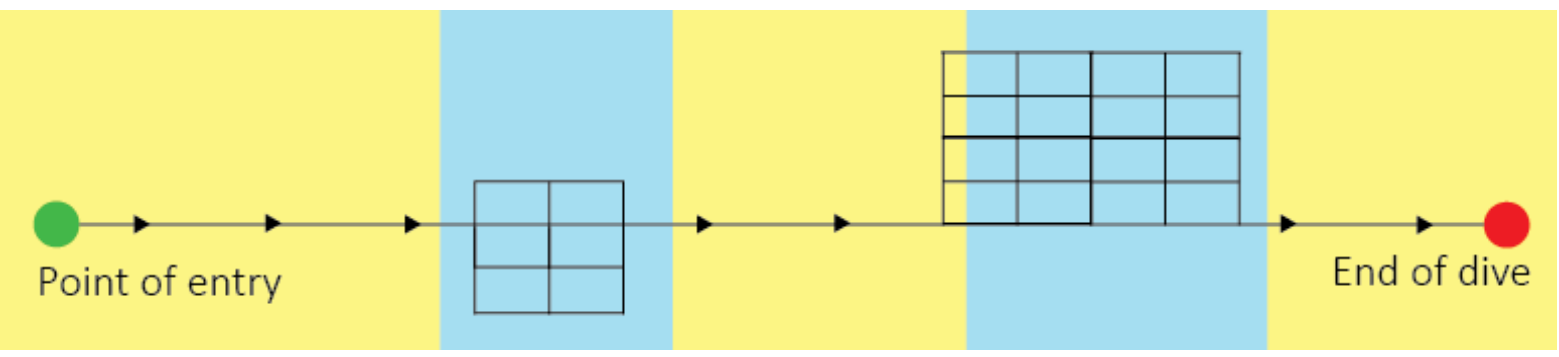

Figure 29: A theoretical dive path designed to maximise coverage and SfM usability. Single-pass surveys over low-interest areas (yellow), multi-pass grids over areas of high interest (blue). The entire dive should be completed at a uniform speed and altitude above the sea floor.

\subsection{Conclusion}

1. Two end-member sediment facies are observed with a transition between them. Their genesis is attributed to reworking of rainout sediment by variable ocean currents, which generated ripples in places and winnowed the bed in others.

2. Observed tidal currents align with ripple orientations but are too slow to generate ripples or erode the bed. The ripples are therefore relict, and almost certainly formed sometime within the last several years. 
3. Areas devoid of ripples but with a coarser texture and common dropstones are attributed to transitory currents winnowing fine sediment from the sea floor.

4. The dm scale bedforms have not previously been observed. However, their geometry precludes an ocean current origin. They most likely relate to more complex ice/ocean/sediment interactions. 


\section{Sediment Core}

\subsection{Introduction}

In the 40 years since the first sediment core was recovered from beneath the Ross Ice Shelf (RIS), the sea floor beneath RIS has been sampled in only six locations (Figure 30). This Chapter outlines the collection and analysis of the upper $49 \mathrm{~cm}$ of a short $(0.6 \mathrm{~m})$ gravity core recovered from the sea floor at the KIS-GZ hot water drill site (Lat. -82.7841, Long. -155.2626) in late 2019. This KIS-GZ borehole lies $3.3 \mathrm{~km}$ seaward of the grounding line of the Kamb Ice Stream, which has been stagnant for the past 160 years (Retzlaff \& Bentley, 1993). The resulting stratigraphy, facies, chronology, petrology and geochemical analyses are considered here in the context of sedimentary facies models and more broadly in terms of the dynamics of the Kamb Ice Stream. A synthesis of these data and those from Chapter 2 is provided in the final Chapter (4).

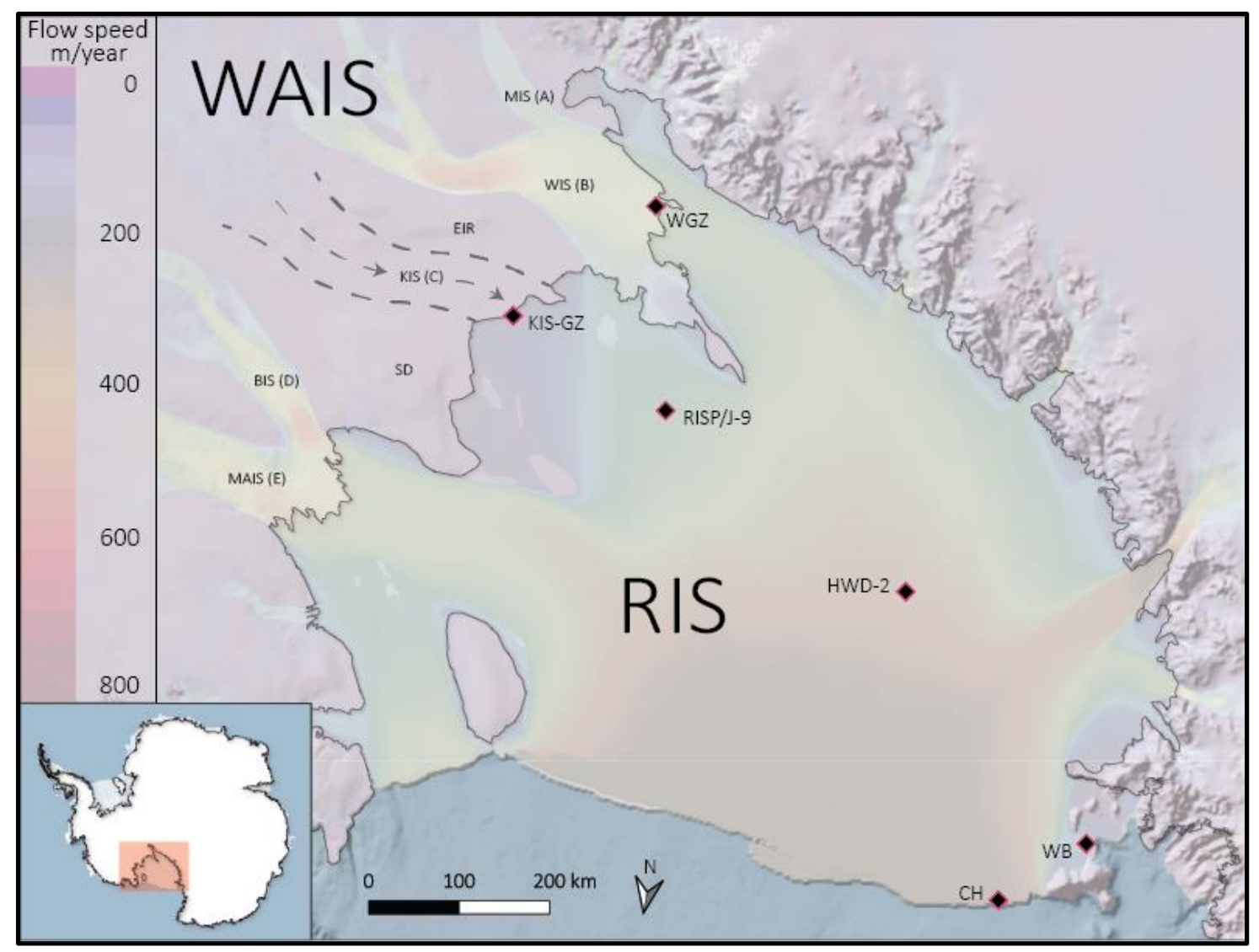

Figure 30: The seafloor beneath the Ross Ice Shelf (RIS) has only been sampled in six places; Whillans Grounding Zone (WGZ); Kamb Grounding Zone (KIS-GZ, this study); Ross Ice Shelf Project J-9 (RISP/J-9); Hot Water Drill Site-2 (HWD-2); Windless Bight (WB); Coulman High (CH). The Eastern portion of RIS is fed by ice streams that flow from the West Antarctic Ice Sheet (WAIS) across the Siple Coast. The Kamb Ice Stream (KIS) itself is stagnant and has been for the past 160 years for reasons not well understood. MIS = Mercer Ice Stream, WIS = Whillans Ice Stream, BIS = Bindschadler Ice Stream, MAIS = MacAyeal Ice Stream, EIR = Engelhardt ice 
Ridge, $S D=$ Siple Dome. Bracketed letters refer to the old ice stream identification scheme. The colour scale on this map highlights different ice flow velocities.

Data in this chapter provided by other workers are as follows:

\begin{tabular}{|c|c|}
\hline Topic & Worker \\
\hline Biosiliceous microfossils & David Harwood \\
\hline Oceanography & (University of Nebraska-Lincoln) \\
\hline Ramped pyrolysis radiocarbon & $\begin{array}{c}\text { Craig Stevens, Natalie Robinson } \\
\text { (National Institute of Water and }\end{array}$ \\
\hline Petrography & Atmospheric Research) \\
& Cathy Ginnane, Jocelyn Turnbull \\
& (GNS Science, Rafter \\
& Radiocarbon laboratory) \\
\hline Geochemical provenance indicators & Adam Martin \\
& (GNS Science, Dunedin) \\
\hline
\end{tabular}

However, in each case, the interpretation is that of the author.

\subsection{Methodology}

Methods are described in the order that they were carried out.

\subsubsection{Core recovery}

The sea floor was accessed via a $350 \mathrm{~mm}$ diameter hole melted through the $587 \mathrm{~m}$-thick Ross Ice Shelf at -155.2627 (longitude), -82.7841 (latitude). Four coring instruments were used with mixed success; two gravity corers, a hammer corer and a vibracorer (Table 3). A gravity corer designed and constructed by the Alfred Wegner Institute (AWI) fitted with a $52 \mathrm{~mm}$ (internal) polycarbonate core tube and catcher was used to recover the KIS-GZ core examined in this thesis. The core tube and catcher were rinsed in $3 \%$ $\mathrm{H}_{2} \mathrm{O}_{2}, 18 \mathrm{M} \Omega$ water and ethanol prior to deployment.

Table 3: Seven coring attempts using four instruments resulted in the recovery of 5 sediment cores; this thesis focuses on KIS-1 191216 GC2 (referred to in this thesis as KIS-GZ). W-GC= 
Sediment Core

Waikato gravity corer, V-GC= Victoria University of Wellington/AWI gravity corer, JLU-VC= Jilin University vibra-corer. Inset picture shows the Victoria University of Wellington/AWI gravity corer fitted with U-PVC core barrel and stainless-steel core catcher, pictured following KIS-1 191216 GC1 core recovery. Note plastic cover fitted to the weight-bearing section of corer to avoid the metal weights freezing to the sides of the borehole.

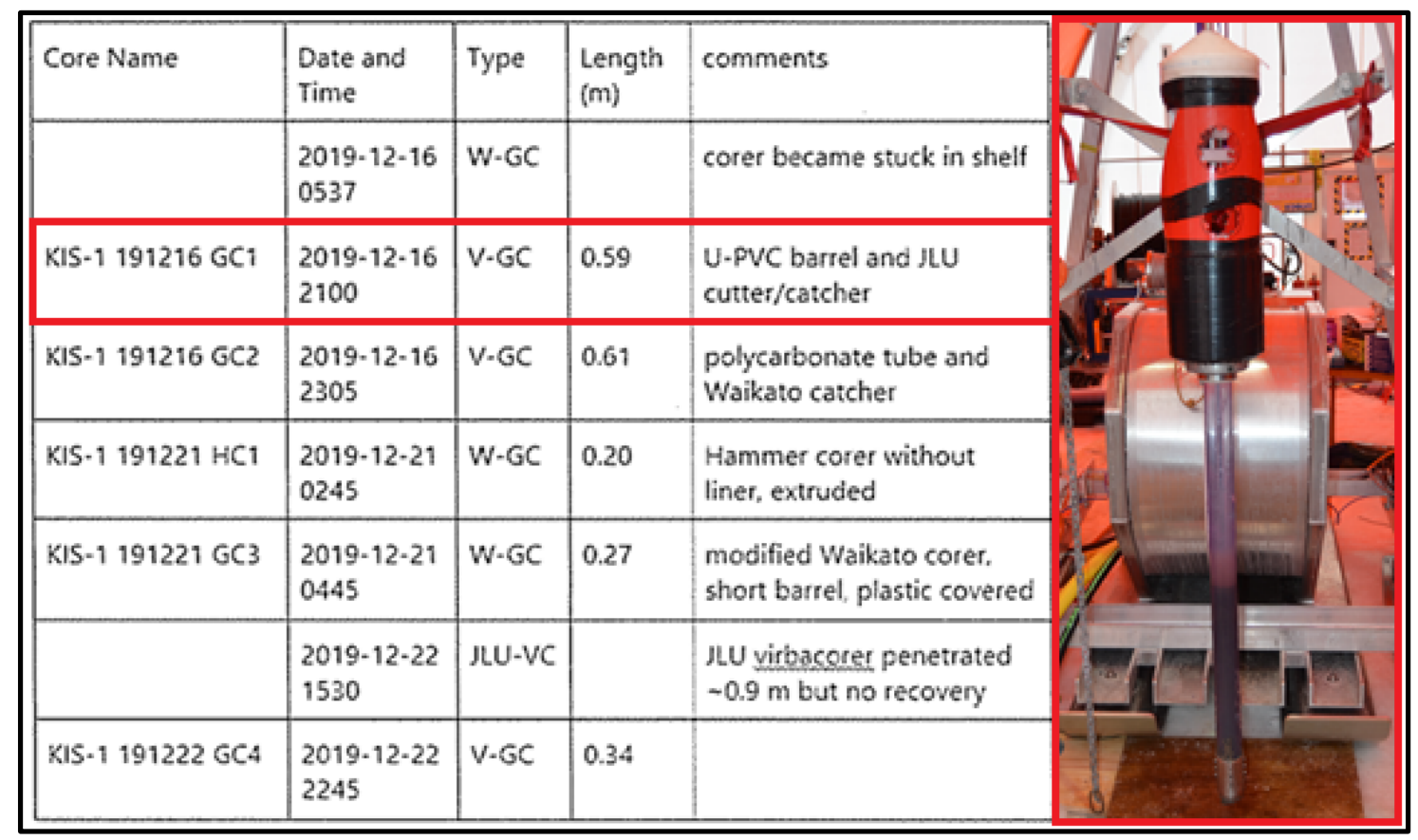

The AWI corer was lowered to $\sim 20 \mathrm{~m}$ above the sea floor and the winch disengaged, allowing the corer to 'freespool' to the sea floor and embed itself. Upon retrieval, KISGZ was cut above the core catcher before capping and sealing, which reduced the accessible length of the core from $61 \mathrm{~cm}$ to $49 \mathrm{~cm}$. The core tube was detached from the instrument, headwater drained, and the upper tube packed with porous foam, cut to size, and sealed. The core was stored horizontally in an insulated box maintained at a constant temperature above freezing. Following transfer to New Zealand, the core was refrigerated at $4^{\circ} \mathrm{C}$.

\subsubsection{Computed tomography (CT) scanning and analysis}

\section{Scanning and viewing}

The core was subject to computed tomography (CT) scanning approximately five months after collection using a GE Medical Systems Brightspeed CT scanner at Pacific Radiology Ltd., Lower Hutt. The scanner was run in helical mode and yielded 1079 axial slices spaced $0.625 \mathrm{~mm}$ apart and a voxel size of $0.2734 \times 0.2734 \times 0.625 \mathrm{~mm}^{3}$. Output files were provided in DICOM raster image format, where greyscale values represent Hounsfield units (HU). Viewing and analysis of the DICOM files were carried out in the ImageJ FIJI software package (https://imagej.net/software/fiji/downloads). The HU density units of 
the CT scans were converted to $\mathrm{g} / \mathrm{cm}^{3}$ using the empirical relationship of Reilly et al. (2017; provided below). Though Reilly et al. (2017)'s samples comprise clay-rich, laminated sediments rather than diamicton like the KIS-GZ core, agreement between computed and expected density values in the KIS sediment encouraged the use of this relationship.

$$
\mathrm{HU} \times 0.0008+1=\mathrm{g} / \mathrm{cm}^{3}
$$

\section{Clast concentration}

A machine-learning plugin for FIJI called 'Trainable Weka Segmentation' (TWS) was used to determine the proportion of clasts to matrix in the core sediment. A representative core scan containing a variety of clast densities was selected to train the classifier. 'Clasts' were defined as discrete objects greater than $2 \mathrm{~mm}^{2}$ in area with a density greater than $2.2 \mathrm{~g} / \mathrm{cm}^{3}$. Clasts were further classified into $2.2-2.5 \mathrm{~g} / \mathrm{cm}^{3}, 2.5-3 \mathrm{~g} / \mathrm{cm}^{3}$, and $3.0 \mathrm{~g} / \mathrm{cm}^{3}$ bins. Examples of each sediment density were visually identified and manually highlighted, and then classified into one of the six constituent groups (e.g. > $3.0 \mathrm{~g} / \mathrm{cm}^{3}, 2.5-3 \mathrm{~g} / \mathrm{cm}^{3}, 2.2-2.5 \mathrm{~g} / \mathrm{cm}^{3},<2.2 \mathrm{~g} / \mathrm{cm}^{3}$ ('matrix'), 'CT apparatus', 'background') (Figure 31).

The machine-learning software was iteratively trained and retrained, with 'problem areas' (where the software failed to identify the sediment correctly) manually reclassified until the software accurately approximated the location of the different density sediments. The TWS software was used to generate maps of the coverage of each density class, and then a threshold was applied to transform the segmented images into binary format. The coverage of each class was then extracted and measured. Summary statistics were then calculated for clast coverage downcore and within intervals of similar clast abundances.

Analyses were carried out on 2D CT slices at depth midpoints corresponding to each $1400 \mu \mathrm{m}$ grain size analysis. Clast proportions showed good agreement with visual estimates of clast coverage from unadulterated CT scans. Analysis of clast shape, fabric, and orientation was considered, but the unavailability of required software put these analyses beyond the scope of this thesis. 


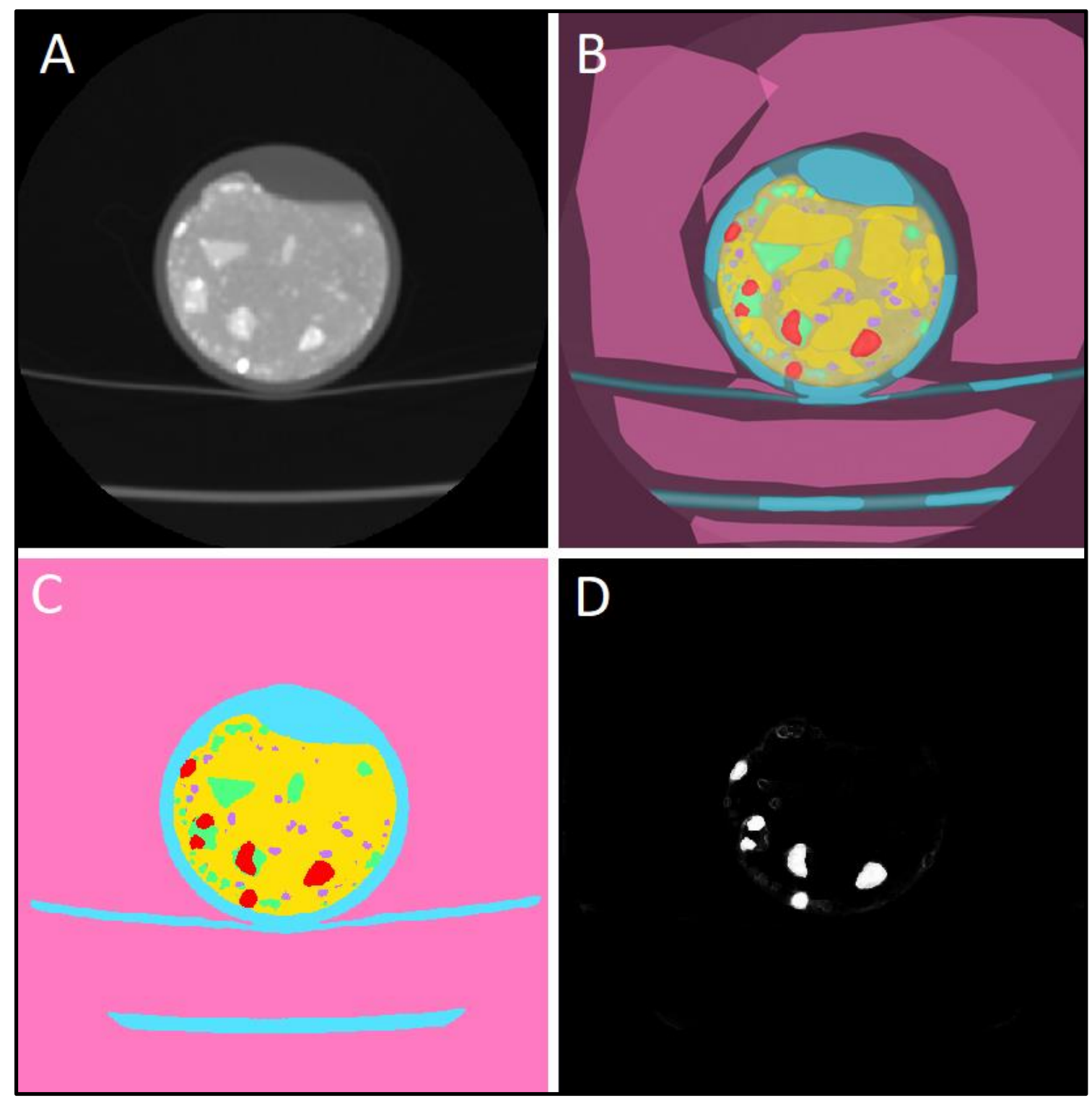

Figure 31: Trainable Weka Segmentation workflow for determining clast concentration from CT scans. A) Raw CT scan with a range of sediment; B) Manually highlighted 'training' areas of different sediment; $C$ ) The result of automated sediment classification by TWS using the training areas from $B$; D) Areas with a density $>3.3 \mathrm{~g} \mathrm{~cm}^{3}$

\subsubsection{Measurement of Geothermal Properties}

The geothermal properties of the core were measured for Sarah Neuhaus (University of California Santa Cruz) before the core was split. The core was removed from the refrigerator and left at room temperature (approx. $16^{\circ} \mathrm{C}$ ) overnight to reach thermal equilibrium. A series of pairs of $1.5 \mathrm{~mm}$-diameter holes were drilled through the core tube at $40 \mathrm{~mm}$ spacing along the length of the core to provide access for the probe. Holes were drilled just through the core tube, penetrating the sediment as little as possible. The drill bit was cleaned ultrasonically and sterilised with ethanol between drilling each hole. An additional hole was drilled to drain a small amount of excess water 
from the core tube. Following the procedure outlined in the KD2 Pro Manual, a KD2 Pro Thermal Properties Analyser fitted with an SH-1 sensor was inserted through the holes and used to measure the thermal conductivity, diffusivity, resistivity, and specific heat capacity of the sediment. All measurements were made at room temperature using room temperature equipment for a duration of five minutes. Geothermal measurements were bracketed by measurements against both the KD2 and gelatine standards. The interpretation of these measurements is beyond the scope of this thesis. Results are attached in Appendix B.

\subsubsection{Core Splitting}

Cores were split using a Geotek core splitter at GNS Science Ltd., Gracefield, approximately seven months after they were recovered. All instruments and surfaces were sanitised with ethanol. The core splitter was used to cut through the plastic core tube before nylon fishing line was drawn through the cut slits on either side of the core tubing to separate the core halves. The core was photographed, then cling-wrapped for storage. In the $\sim 15$ minutes the core was exposed to air, the colour of parts of the exposed surface changed from grey to brown.

\subsubsection{Ramped Pyrolysis radiocarbon dating}

*Ramped pyrolysis measurement was carried out by Drs. Catherine Ginnane and Jocelyn Turnbull of GNS Science. This subsection reports their results.*

Traditional radiocarbon dating methods often cannot derive dates that accurately constrain the time of deposition for sub-ice shelf sediment. A fundamental cause is the presence of radiocarbon from multiple sources in single sediment horizons, much of which may pre-date the time of that sediment's deposition and thus skew radiocarbon dates to older values (Andrews et al., 1999; Domack et al., 1999). To accurately date the deposition of sediment in environments where other geochronological controls (i.e. foraminiferal biostratigraphy) are absent, radiocarbon deposited contemporaneously with its host sediment must be isolated and dated. Rosenheim et al. (2008)'s 'ramped pyrolysis' (RPO) method attempts to isolate syn-depositional carbon by progressively heating sediment samples and splitting them based on the combustion temperature of sub-fractions of the sample, which occurs as a result of differences in the 
Sediment Core

thermochemical stability of aged and 'fresh' radiocarbon. Each 'stage' of radiocarbon is then dated, providing each sediment sample with a set of radiocarbon ages representing different organic carbon fractions within the sample. Ramped pyrolysis radiocarbon analysis was employed on this core as an alternative to conventional bulk radiocarbon dating in an attempt to mitigate the well-established difficulties associated with radiocarbon dating in sub-ice shelf environments. All radiocarbon analysis was carried out at the Rafter Radiocarbon Laboratory in GNS Science's National Isotope Centre at Gracefield, Wellington, New Zealand. Samples were taken at four depth intervals to capture differing sedimentary characteristics downcore: $0.5-2.5 \mathrm{~cm}, 5-7.5 \mathrm{~cm}, 20-22.5$ $\mathrm{cm}$, and $42-44.5 \mathrm{~cm}$. The mean wet weight of the samples was $8.8 \mathrm{~g}(1 \mathrm{~d}$.p.). The core was scraped, and samples collected using sterilised stainless-steel instruments and transferred to glass beakers. Samples were freeze dried and sorted to remove mineral grains and lithic fragments before being homogenised by mortar and pestle. Ginnane and Turnbull, Rafter Radiocarbon Lab. (pers. comm.) note "Samples were acidified, rinsed to neutral $\mathrm{pH}$, dried, and homogenised prior to ramped pyrolysis analysis. The samples were pyrolyzed under He flow from room temperature to $900^{\circ} \mathrm{C}$ at a rate of $5^{\circ} \mathrm{C} /$ minute and then combusted under $\mathrm{He}$ and $\mathrm{O}_{2}$ at $800^{\circ} \mathrm{C}$. The temperatures at which $\mathrm{CO}_{2}$ fractions were split were determined by transition points in the thermograph of evolved $\mathrm{CO}_{2}$. Splits were cryogenically sealed on a vacuum line into pyrex tubes with $\mathrm{CuO}$ and $\mathrm{Ag}$ wire for re-combustion at $500^{\circ} \mathrm{C}$ for 4 hours to eliminate any sulfur byproducts which may have been produced. Splits were then graphitised and measured for radiocarbon."

\subsubsection{Paleomagnetic Sampling and Analysis}

A series of $8 \mathrm{~cm}^{3}$ samples were collected along the long axis of the core for paleomagnetic analysis. $2 \times 2 \times 2 \mathrm{~cm}$ plastic cubes were pushed into the working half of the core and extracted using Teflon instruments to avoid demagnetising the sediment. The sampling regime was interrupted by a large clast at $9 \mathrm{~cm}$ depth. The thickness of the sampling cubes and the presence of small clasts resulted in some sampling midpoints being separated by $2.5 \mathrm{~cm}$. Twenty-one samples in total were taken down the $49 \mathrm{~cm}$ core. Sampling cubes were transferred to a magnet-shielded container and transported to the University of Otago for paleomagnetic analysis. Analysis revealed that the samples had been demagnetised at an indeterminate time, possibly when the 
geothermal probe was inserted into the core. The samples were returned to Victoria University of Wellington, and no further paleomagnetic analyses were carried out.

\subsubsection{X-ray Fluorescence (XRF)}

XRF analysis was carried out to determine the source of lithogenic sediment and the relative proportions of biogenic to lithogenic sediment in the core. Freeze-dried sediment from the paleomagnetic cubes was wet-sieved using deionised water at 2000 $\mu \mathrm{m}$ and then $64 \mu \mathrm{m}$ into beakers, covered with breathable material, and left to evaporate at $50^{\circ} \mathrm{C}$ for approximately 72 hours. The dried $<64 \mu \mathrm{m}$ sediment was homogenised using a mortar and pestle and 2-3 g subsamples taken, providing an integrated sample of the $2 \mathrm{~cm}$ around the paleomagnetic cube midpoint. Measurements were made using an Olympus Vanta M-series XRF scanner mounted within an antiradioactive workstation. Each sample was subjected to measurement using both the XRF's built-in '3-beam geochemistry' and '3-beam soils' modes to ensure that abundances of both light (e.g. Si, Ca) and heavy (e.g. Ba, Sr) elements were accurately and precisely measured. '3-beam geochemistry' mode employed three beams at 10, 40 and $50 \mathrm{kv}$, while '3-beam soils' mode used three beams at 15, 40 and $50 \mathrm{kv}$. A suite of nine internationally recognised standards were measured at the beginning and end of the measurement run to provide a baseline to calibrate the instrument to ppm so the results could be compared with the published literature. Raw data were calibrated by deriving the linear relationship between the measured and known concentrations of elements in the standards and applying the slope coefficient to measured elemental abundances of the KIS samples. Three samples of KIS sediment were remeasured to prove the reproducibility of the method.

\subsubsection{Covered Smear Slides}

Smear slides were made at $10 \mathrm{~cm}$ intervals down the core to rapidly assess the composition of the fine fraction of the sediment. Two drops of deionised water were placed on a glass microscope slide and used to disaggregate a toothpick-tip's worth of sediment. The wetted slide was heated at $65^{\circ} \mathrm{C}$ on a hotplate until standing water evaporated. A glass coverslip was applied to ensure that all grains sat in the same optical plane and attached to the slide using Norland Optical (UV curing) Adhesive \#61. 
Sediment Core

\subsubsection{Grain Size Preparation and Analysis}

Samples between 0.16-0.29 $\mathrm{g}$ in weight were taken at 2-2.5 cm intervals. Each sample was disaggregated and wet-sieved at $1400 \mu \mathrm{m}$ to remove coarse sediment, which the Beckman Coulter LS 13320 Laser Particle Size Analyser (LPSA) used for this analysis cannot analyse. Wet-sieving was carried out using deionised water from a pressure spray bottle along with occasional mechanical agitation; the cohesive nature of the diamicton required around $50 \mathrm{ml}$ of water to disaggregate each sample. The sieved samples were decanted into centrifuge tubes, and the headwater centrifuged off. Hydrogen peroxide $\left(27 \% \mathrm{H}_{2} \mathrm{O}_{2}\right)$ was added to the tubes, and the sediment agitated to dissolve organic sediment in the samples. Additional $\mathrm{H}_{2} \mathrm{O}_{2}$ was incrementally added and the samples re-agitated over the following six hours, after which samples were left to digest. After approximately 48 hours, $\mathrm{pH}$ tests indicated that digestion of the organic component of the samples was complete. Samples were heated to $70^{\circ} \mathrm{C}$ and agitated to catalyse any further reactions, but little activity was observed. Samples were then flushed with deionised $\mathrm{H}_{2} \mathrm{O}$ until they returned a neutral $\mathrm{pH}$ before all liquid was centrifuged from the sample. Samples were not processed for biogenic carbonate or silica removal. The lithological characteristics of the core and smear slide observations indicate that any carbonate or biogenic silica present is most likely reworked, thus part of the first order sedimentary regime at the coring site.

Grain size distributions were measured using the Beckman Coulter LS 13320 Laser Particle Size Analyser (LPSA) with the aqueous liquid module. Processed samples were dispersed into a $1 \mathrm{~g} / \mathrm{l}$ Calgon solution $\left(\mathrm{Na}_{6} \mathrm{P}_{6} \mathrm{O}_{18}\right)$ and mechanically agitated in an ultrasonic bath for at least 30 minutes to reduce cohesion between fine particles and induce suspension of the sediment. Samples were added to the LPSA instrument in sequential depth order, with the measurements bracketed by glass bead standards at the beginning, middle, and end of the measurement session. Analysis for each sample totalled 60 seconds. Between each measurement, the unit was rinsed for one minute to minimise contamination, the instrument's background readings and offsets were measured, and the laser was realigned. The QuartzNatural.rf780d optical model, which assumes all particles have the refractive index of quartz, was used to process the raw data into grain size distributions. Sediment size classifications followed Gallagher et al. (2017; Table 4), except for the clay/silt boundary, which was moved to $8 \mu \mathrm{m}$ to correct 
for the analytical bias of the LPSA, which tends to underestimate the proportion of clay relative to more traditional settling methods (Konert \& Vandenberghe, 1997).

Table 4: Grain size class boundaries used here, modified from Gallagher et al. (2017); clay/silt boundary modified to account for LPSA bias.

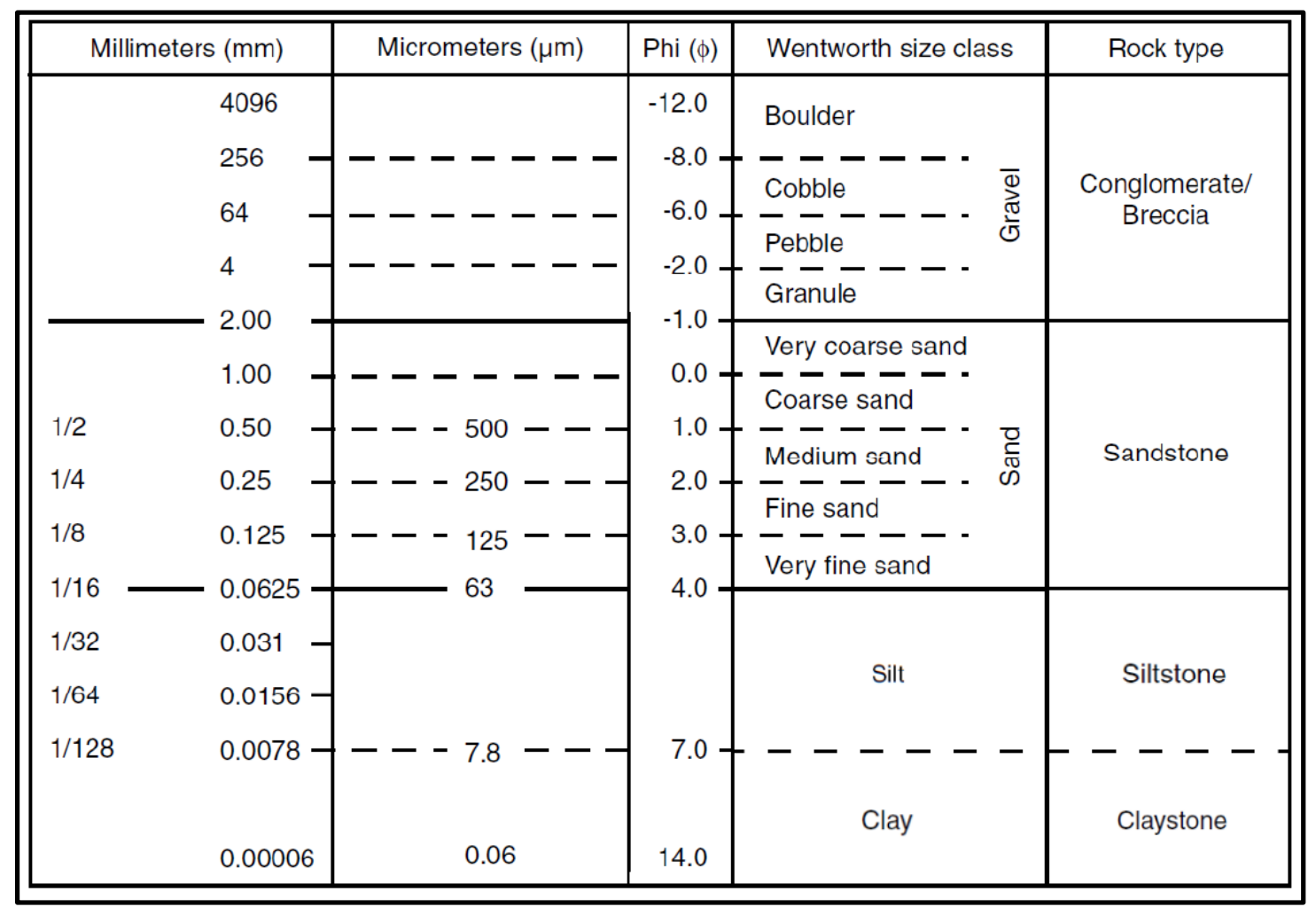

\subsubsection{Isolating Till Pellets}

During core splitting, a mottled band of sediment between 17 and $20 \mathrm{~cm}$ depth was noted. The interval had a superficial resemblance to a unique 'till pellet' facies identified in some Ross Sea cores, which has been interpreted as a grounding-line proximal deposit (Domack et al., 1999; Smith et al., 2019). A $~ 50$ g sample of the mottled sediment was extracted and gently pressure-sprayer through a $2000 \mu \mathrm{m}$ sieve in an attempt to isolate any granules/pellets causing the mottling, but no cohesive sediment was recovered. To confirm the applicability of the method, the same approach was applied to sediment cored at site HWD-2 (Lat. -80.65767, Long. 174.46263) in the central Ross Ice Shelf where till pellets are prominent. The method was able to recover cohesive granule-sized pellets (Figure 32), suggesting that till pellets either are not present in the KIS-GZ sediment or are less cohesive than those recovered at HWD-2. 


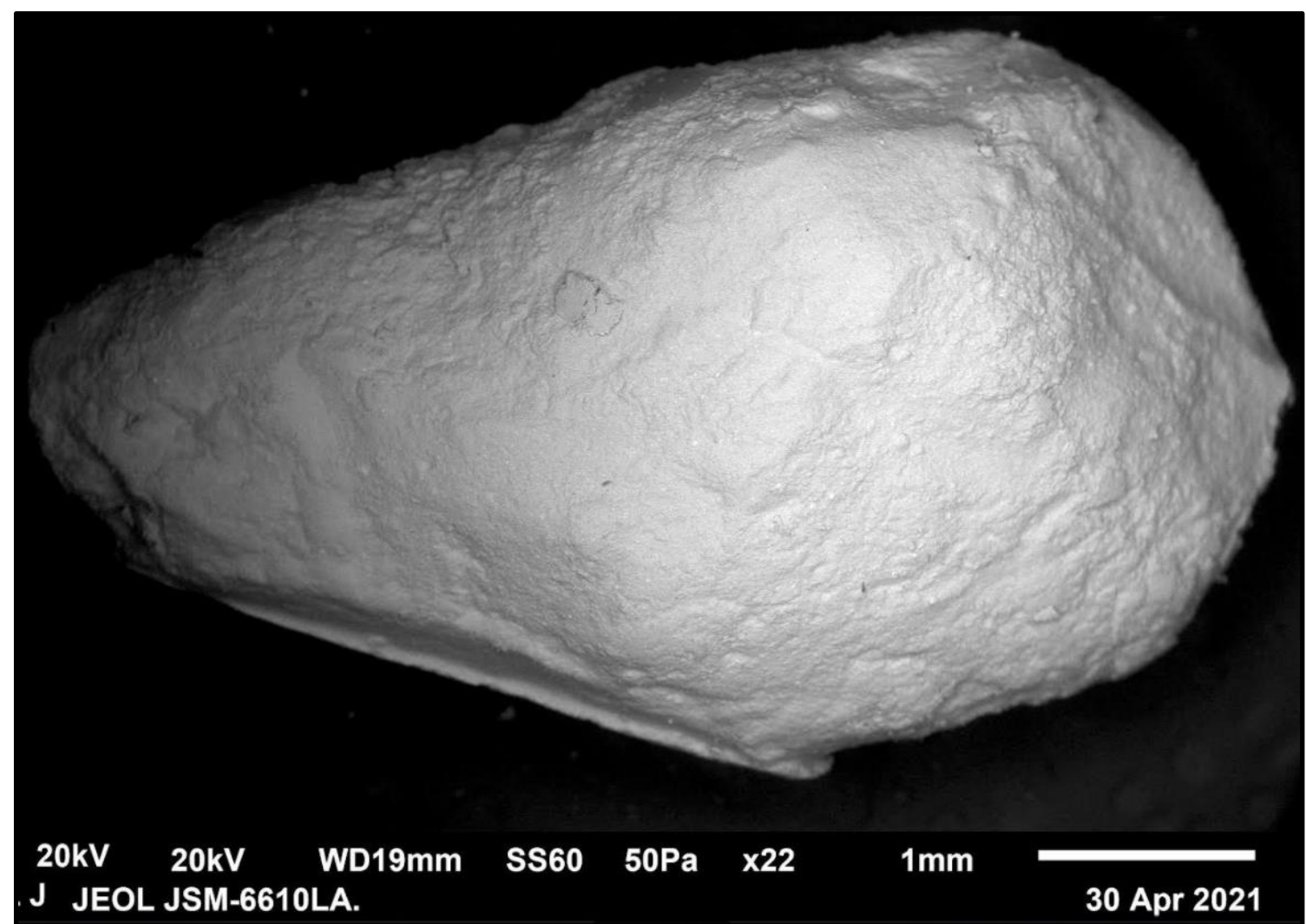

Figure 32: SEM image of till pellet recovered from HWD-2 core.

\subsubsection{Lithofacies Classification}

Lithofacies were classified based on the proportion of biogenic to lithogenic sediment, and within the lithogenic fraction of the relative proportions of clasts, silt, and mud. Sediment comprised of terrigenous sediment was classified by just its terrigenous classification, with an "x-bearing" prefix added if biogenic content fell between 10 and $25 \%$ of the total sediment. Terrigenous naming conventions followed Moncrieff (1989)'s classification scheme for poorly sorted sediment due to the presence of clasts throughout the core. Primary classification was based on gravel abundance (Table 5), with sand/mud ratios providing modifying names (Table 6). 
Table 5: First order classification scheme based on the relative proportion of terrigenous to biogenic sediment.

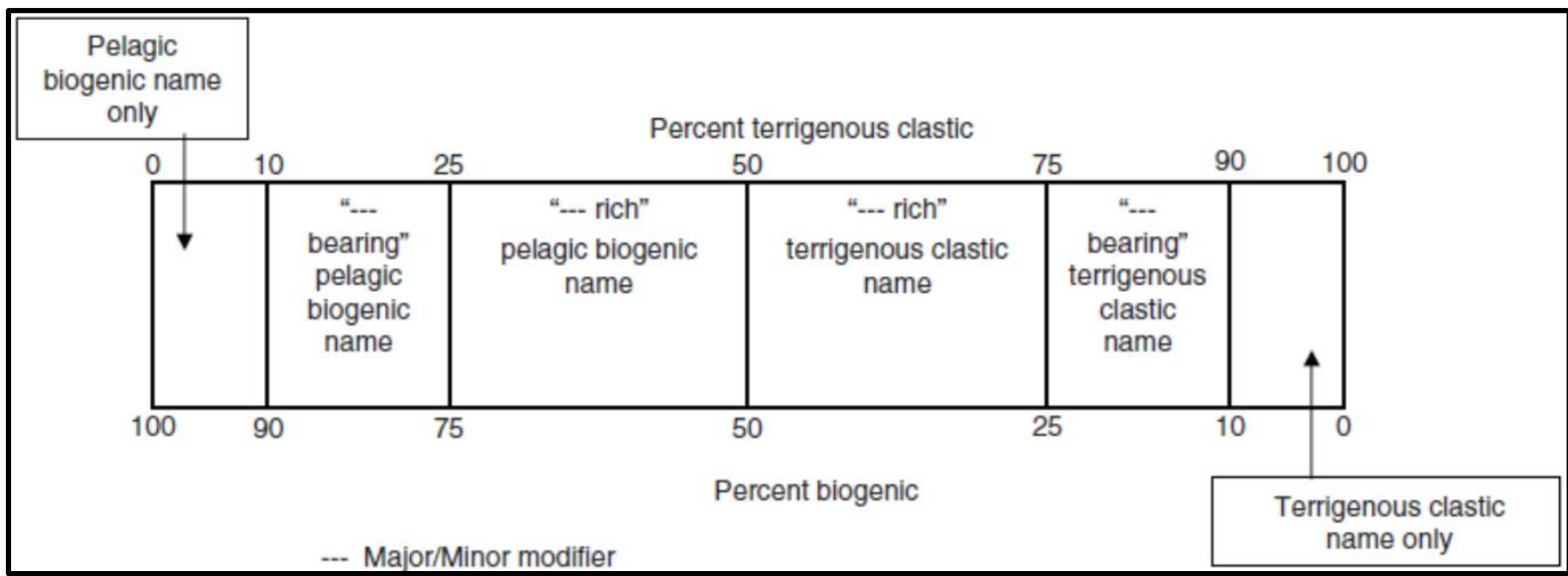

Table 6: Classification scheme for terrigenous sediment containing clasts, after Moncrieff (1989).

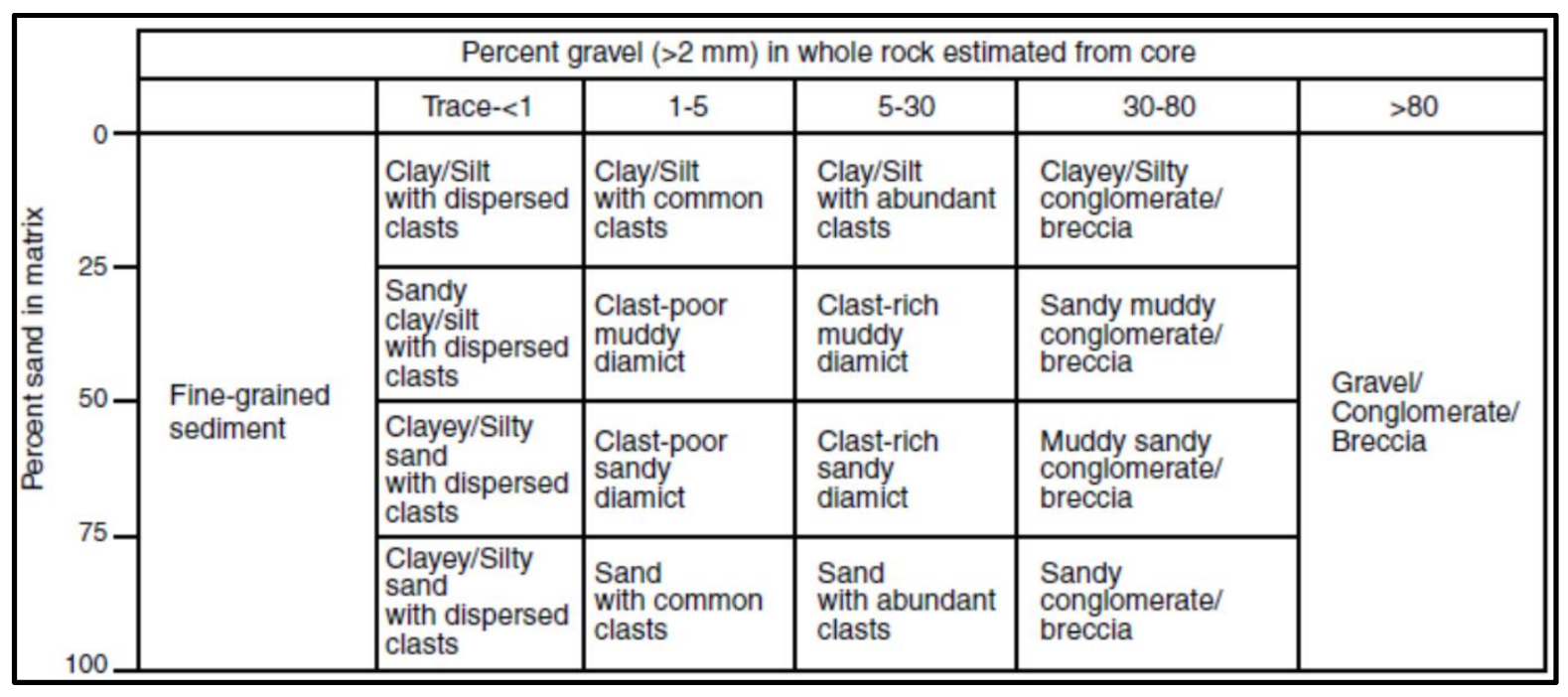

\subsubsection{Siliceous Microfossil Analysis}

*Assessment of biogenic sediment was carried out by Professor David Harwood of the University of Nebraska. This subsection reports his work.* 
Sediment Core

Bulk sediment samples taken from scrapings of a geothermal probe at KIS were processed to isolate biogenic sediment for identification and analysis (Figure 33: Geothermal probe with sediment to a depth of $1.7 \mathrm{~m}$.). Samples of 5-10 g of unsorted sediment were saturated with water, with 1-2 drops of that dispersed on a glass microscope slide to provide an unadulterated reference sample. The remaining saturated sediment was shaken to induce suspension before the suspended fraction was sieved at $20 \mu \mathrm{m}$ and repeated until a sufficient quantity of $>20 \mu \mathrm{m}$ sediment was extracted from the bulk sample. This process was repeated with different settling times to separate grains of differing sizes and hydrodynamic settling regimes. Following Harwood (1986), the 'Bubble Method' was then applied to hydrodynamically separate the biogenic and lithic components of the $<20 \mu \mathrm{m}$ sediment, before microscope slides of all size fractions were assembled. The remaining $<20 \mu \mathrm{m}$ sediment was agitated to induce suspension, left to settle, and then turbid water pipetted off to separate the relatively quickly-settling biogenic sediment (previously

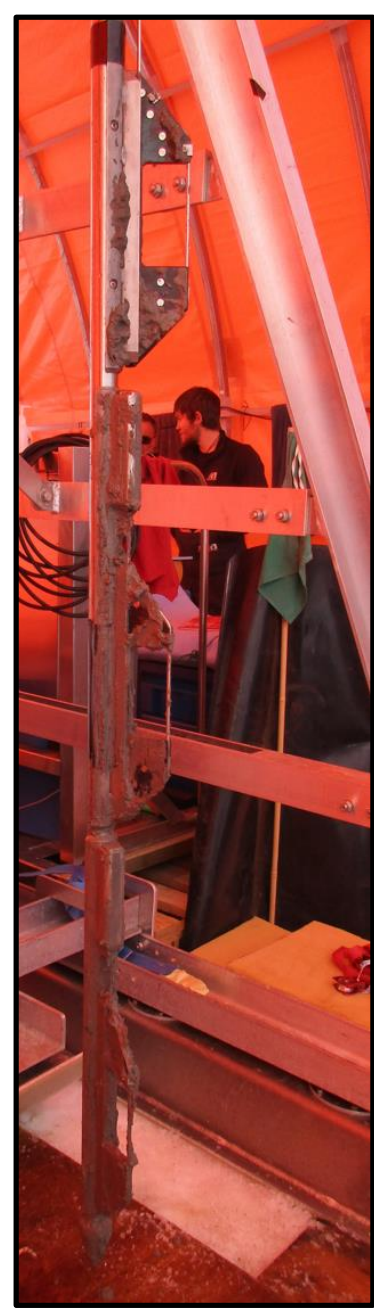

Figure 33: Geothermal probe with sediment to a depth of $1.7 \mathrm{~m}$. separated from most lithic sediment) from the slow-settling clay.

This process was repeated until biogenic sediment were sufficiently isolated, and then microscope slides of the concentrated biogenic sediment were assembled and inspected. The $>20 \mu \mathrm{m}$ sediment fraction was inspected for diatom bearing clasts, but none were identified.

\subsubsection{Petrographic Analysis}

*Petrographic assessment of the 64-2000 $\mu \mathrm{m}$ fraction of the KIS sediment was carried out by Dr. Adam Martin of GNS Science. This subsection reports his work.*

Petrographic descriptions of both sand and pebble-sized fractions of a bulk sample of KIS sediment were made. Thin sections of both size fractions were prepared by Rob Spiers of the University of Canterbury and used for Gazzi-Dickinson point counting (311 grains). Staining for potassium and alkali feldspars and scanning electron micro-scope elemental map montages were used to ensure accurate grain identification. 


\subsection{Results}

Results of CT, laboratory, and visual analysis of the $49 \mathrm{~cm}$ of accessible core above the KIS-GZ core catcher cut are outlined below.

\subsubsection{Lithological characteristics}

The key lithological features of the KIS-GZ core are summarised in Figure 34. Following the classification scheme outlined in Table 5 Table 6, as a package, the core can be described as a sandy diamicton with weak stratification defined by $\mathrm{dm}$-scale changes in clast abundance. In detail, three intervals differentiated by the abundance of clasts and biogenic silica can be identified. To a depth of $18 \mathrm{~cm}$, the core is a clast-rich sandy diamicton. Between 18 and $29.5 \mathrm{~cm}$, the sediment comprises clast-poor sandy diamicton. The lower $19.5 \mathrm{~cm}$ of the core, between 32 and $49 \mathrm{~cm}$, is a diatom-bearing clast-poor sandy diamicton. The bottom contact of the diamicton was not observed. Penetration of the geothermal probe to $172 \mathrm{~cm}$, and recovery of a sandy diamicton from the bottom of the probe, indicates that the diamicton likely continues to at least $172 \mathrm{~cm}$ depth. 


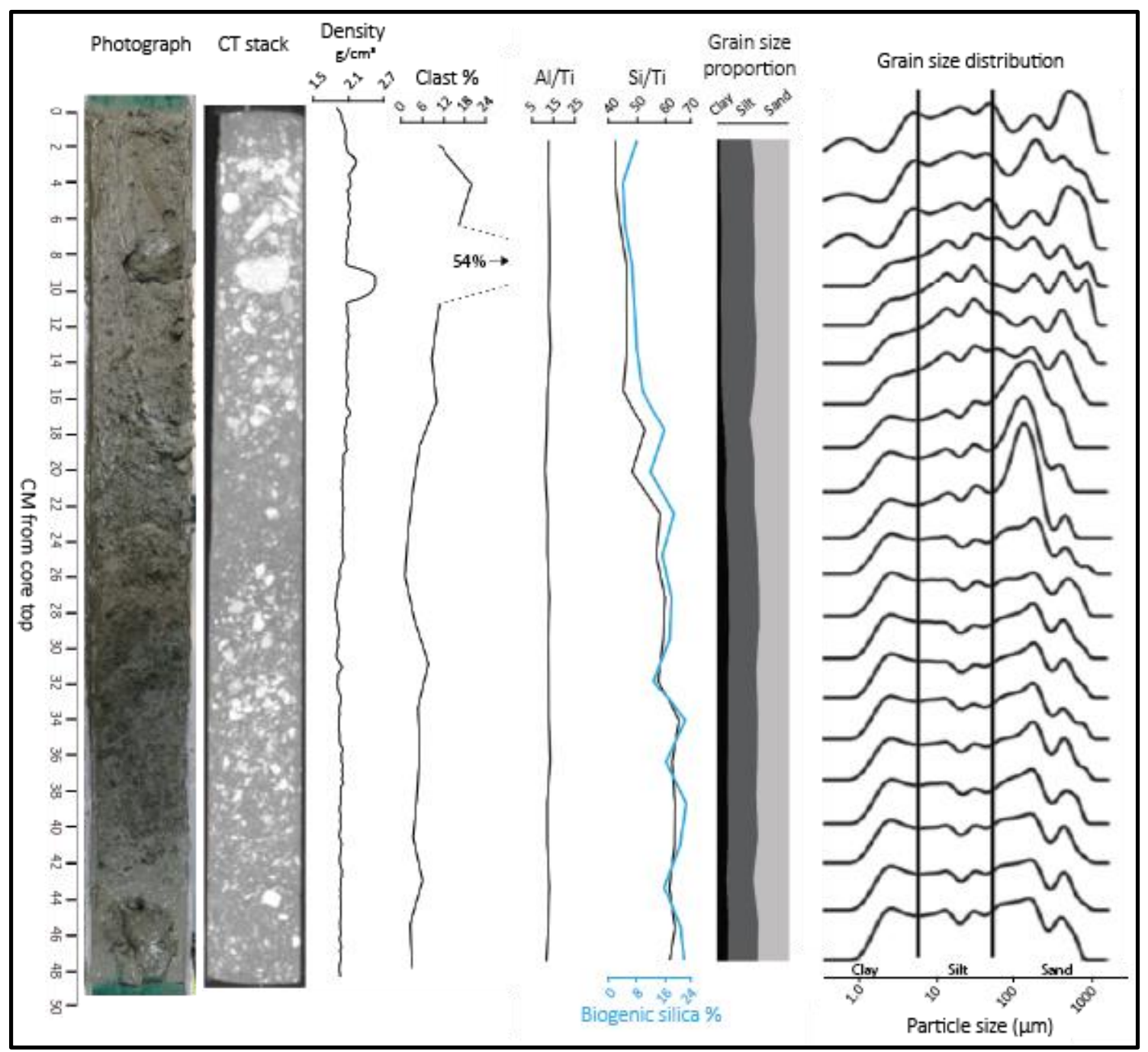

Figure 34: Compiled analyses of the KIS-GZ GC-2 sediment core. Different length curves are the result of different sampling depths. The apparent change in colour in the photograph $(26-36 \mathrm{~cm})$ is an unfortunate shadow.

Particles $<1400 \mu \mathrm{m}$ (the maximum size analysed by the laser sizer) exhibit a polymodal grain size distribution, with approximately $1: 1$ sand vs combined silt and clay over the length of the core (Appendix C). An interval of moderately-well sorted sand is present between 18 and $22.5 \mathrm{~cm}$. The sediment is normally compacted, with a mean matrix bulk density of $\sim 1.9 \mathrm{~g} / \mathrm{cm}^{3}$ that rises slightly toward the top of the core. The measured bulk density corresponds to a porosity of $46 \%$ assuming a uniform mineral density of 2.65 $\mathrm{g} / \mathrm{cm}^{3}$ and pore fluid density of $1.027 \mathrm{~g} / \mathrm{cm}^{3}$. The sediment is dark grey to dark browngrey, with minor light-grey mottling between 17 and $20 \mathrm{~cm}$ depth. There is no bedding, macrofossils, or sedimentary structures visible. Visual inspection indicates that clast roundness ranges from sub-angular to sub-rounded with no clear preferred clast shape or evidence of striations. 
The core comprises 77 to $97 \%$ terrigenous sediment with biogenic silica, predominantly diatoms (diatom detail in section 3.3.3 Biostratigraphy), making up the remainder. Biogenic silica is significantly more abundant below $18 \mathrm{~cm}$ core depth.

Adam Martin of GNS determined the petrography of the sediment from a bulk sample of scrapings from the geothermal probe. Pebble and sand-sized lithic fragments in the core are dominated by plutonic and sedimentary lithologies, including dioritoids, granitoids, and immature sandstones and conglomerates. The sand-sized fraction has an arkose composition (McBride, 1963) equivalent to a whole-rock composition of quartz-rich granitoid (Martin, pers. comm., 2020). While quartz and plagioclase are abundant, potassium feldspar and mafic minerals are also present (Martin, pers. comm., 2021).

\subsubsection{Geochemistry}

Elemental abundances determined by XRF are presented in Appendix D. A Pearson's correlation matrix was used to identify significant relationships between the abundance of key indicator elements (Table 7). Selected data were used to investigate sediment composition and provenance. Trends in the elemental ratios of $\mathrm{Al} / \mathrm{Ti}, \mathrm{Si} / \mathrm{Al}$, and $\mathrm{Ca} / \mathrm{Al}$ are outlined below.

Table 7: Pearson's cross-correlation matrix showing the relationship between elemental abundances determined by XRF. Strong (0.8-1) correlations coded blue; moderate (0.5-0.8) correlations coded yellow.

\begin{tabular}{|c|c|c|c|c|c|c|c|c|c|}
\hline & $\mathbf{M g}$ & $\mathbf{A l}$ & $\mathbf{S i}$ & $\mathbf{K}$ & $\mathbf{C a}$ & $\mathbf{T i}$ & $\mathbf{F e}$ & $\mathbf{S r}$ & $\mathbf{B a}$ \\
\hline $\mathbf{M g}$ & 1 & & & & & & & & \\
\hline $\mathbf{A l}$ & 0.400 & 1 & & & & & & & \\
\hline $\mathbf{S i}$ & -0.364 & -0.907 & 1 & & & & & & \\
\hline $\mathbf{K}$ & 0.187 & 0.681 & -0.548 & 1 & & & & & \\
\hline $\mathbf{C a}$ & 0.114 & 0.474 & -0.331 & -0.042 & 1 & & & & \\
\hline $\mathbf{T i}$ & 0.242 & 0.898 & -0.828 & 0.817 & 0.346 & 1 & & & \\
\hline $\mathbf{F e}$ & 0.427 & 0.894 & -0.898 & 0.656 & 0.240 & 0.806 & 1 & & \\
\hline $\mathbf{S r}$ & 0.174 & 0.536 & -0.371 & 0.530 & 0.422 & 0.720 & 0.326 & 1 & \\
\hline $\mathbf{B a}$ & -0.147 & -0.523 & 0.575 & -0.255 & -0.108 & -0.468 & -0.624 & -0.089 & 1 \\
\hline
\end{tabular}

$\mathrm{Al} / \mathrm{Ti}$ ratios in this core show little variability (Figure 34). Typical $\mathrm{Al} / \mathrm{Ti}$ ratios for rocks found in the western Ross embayment range between approximately 3 and 21 (Roser \& 
Sediment Core

Pyne, 1989). The Al/Ti ratios of 12.7-15.2 found in this system sit between the relatively evolved trachybasalts and trachytes of the McMurdo Volcanic Group, and the Ferrar Dolerite (Roser \& Pyne, 1989). Silicon is present throughout the core, with minimum concentrations of around 2.9 relative to aluminium, indicating that it does have a constant lithogenic source (Figure 34). However, the sharp increase in silicon abundance at around $18 \mathrm{~cm}$ depth indicates the presence of a secondary source; qualitative estimates of diatom abundance from smear slide microscopy are consistent with a biogenic source for this silicon. Ca/Al ratios fluctuate between 0.054 and 0.085 downcore, following the trend of silicon abundance, but calcium in the core is comparatively scarce. If all is assumed to be hosted in $\mathrm{CaCO}_{3}$ (unlikely based on smear slide observations), $\mathrm{CaCO}_{3}$ would account for $<2 \%$ of the total sample mass.

\subsubsection{Biostratigraphy}

*Assessment of biogenic sediment was carried out by Professor David Harwood of the University of Nebraska. This subsection reports his results.*

Recognisable biogenic material in the KIS core is dominated by biosiliceous microfossils. Marine diatoms (both benthic and neritic) are the most common form. This work focuses on the occurrence and condition of the marine diatoms in the context of providing chronological constraints for and assessing the transport history of sediment recovered from KIS-GZ. Biosiliceous silicoflagellates, ebridians, chryosphycean cysts, endoskeletal dinoflagellates, radiolarians, and sponge spicules are also present, along with pollen, spores, and foraminifera, which are present in trace amounts but are not considered further here.

Marine diatoms are distributed throughout the core but are more abundant below 18 $\mathrm{cm}$ (Figure 35). Most of the biosiliceous material in the core is highly fragmented, though intact diatom specimens are present below the $18 \mathrm{~cm}$ boundary. Identified marine diatoms comprise three main chronologic cohorts (groups of taxa correlated by mutually overlapping age ranges), encompassing the late Oligocene-early Miocene, early Miocene, and late Miocene, respectively (Figure 36; Harwood, pers. comm., 2021). Taxa of each cohort are present throughout the core and appear thoroughly mixed. While the age ranges of some identified taxa do extend into the early Pleistocene, the assemblages they occur with indicate that none are unequivocally younger than the late Miocene (Harwood, pers. comm., 2021). 


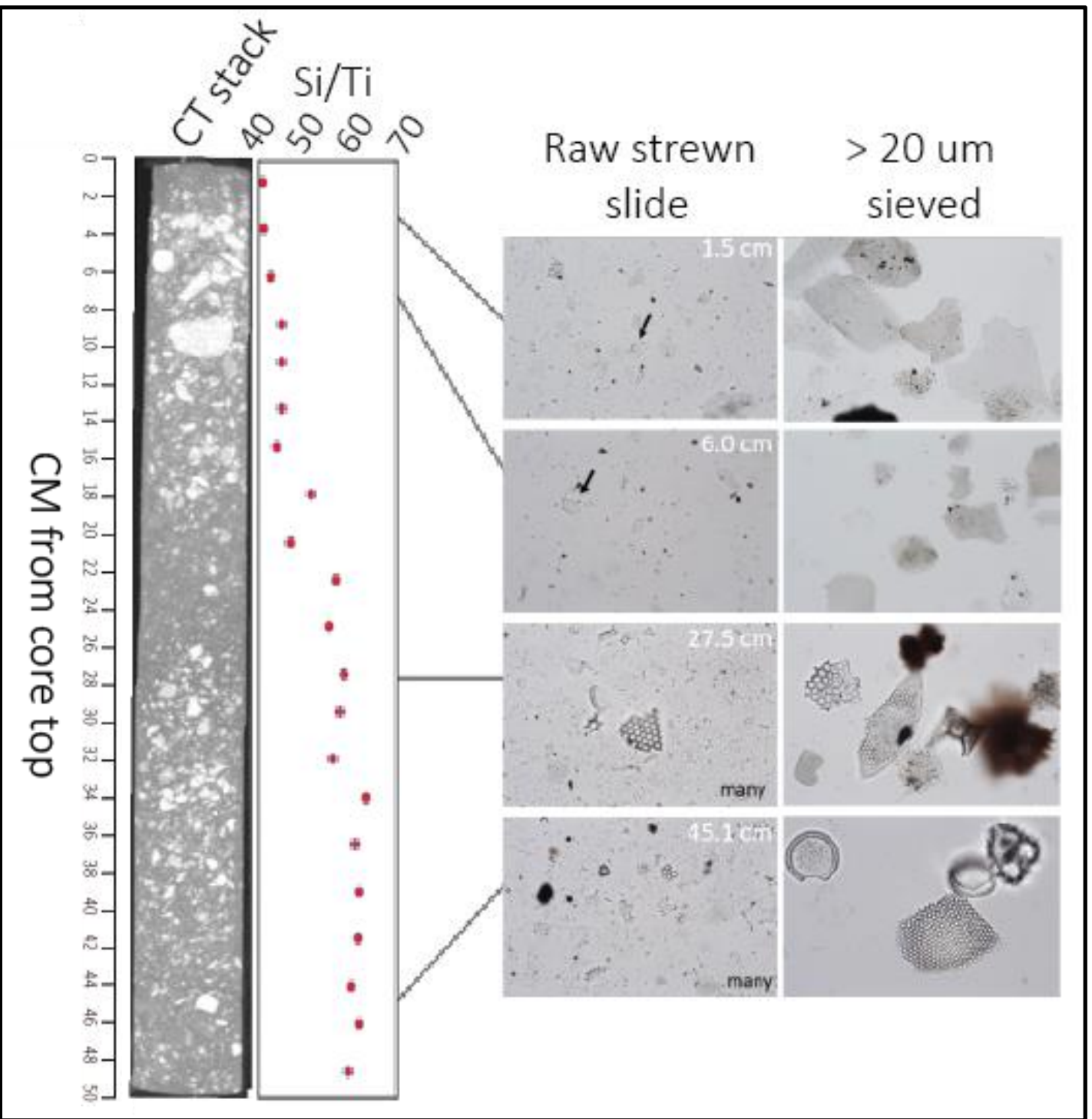

Figure 35: Diatoms are found throughout the core but are significantly more abundant below 18 $\mathrm{cm}$. Most diatoms are highly fragmented. Diatom images courtesy of Prof. David Harwood (UNL). 


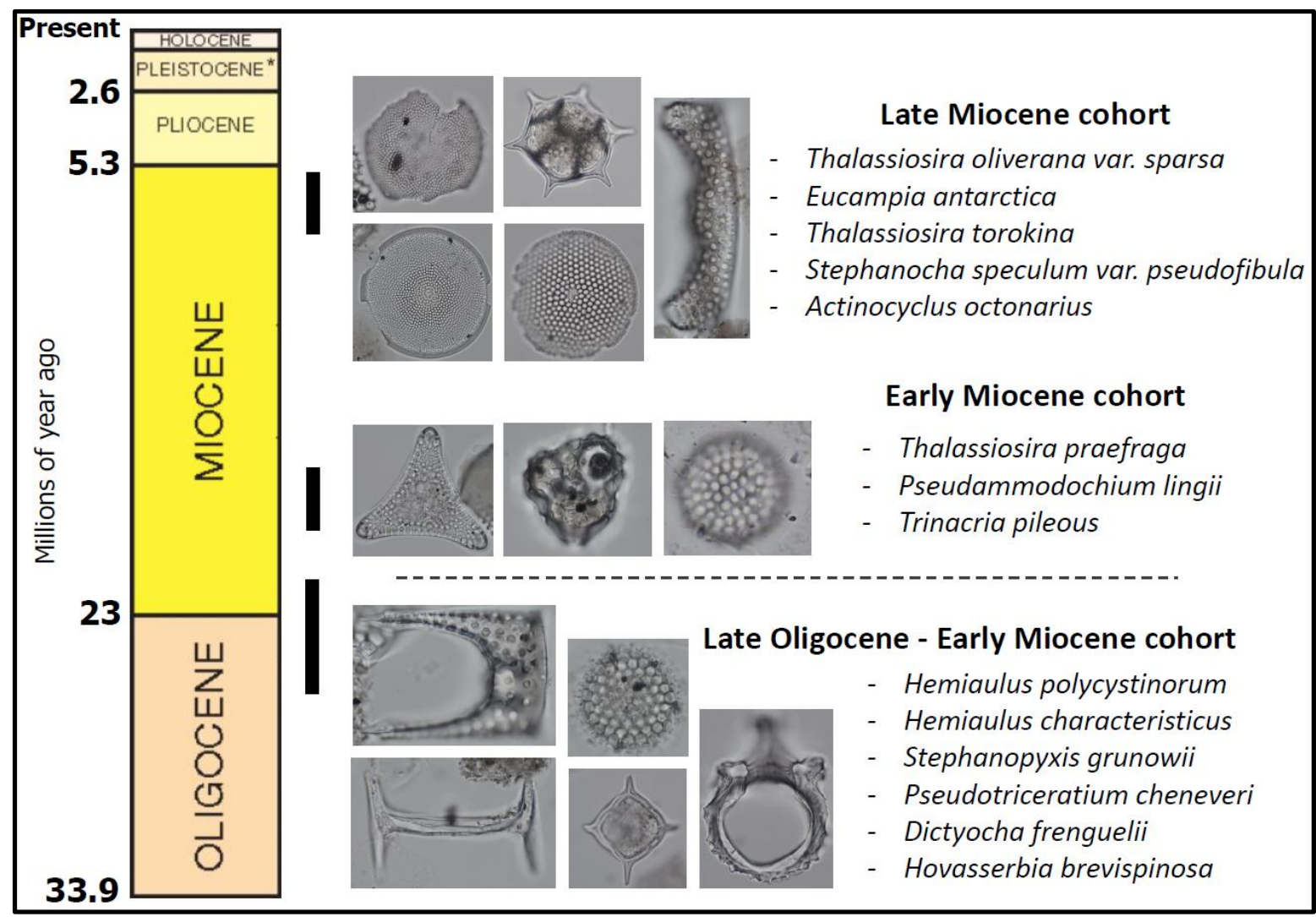

Figure 36: Three diatoms cohorts are present and encompass the late Oligocene-early Miocene, early Miocene, and late Miocene. The cohorts are not stratigraphically separated in the core. Diatom images courtesy of Prof. David Harwood (UNL).

\subsubsection{Radiocarbon geochronology}

*All ramped pyrolysis analysis was carried out by Drs. Catherine Ginnane and Jocelyn Turnbull of GNS Science. This subsection reports their results.*

Results of the ramped pyrolysis radiocarbon analysis are presented in Table 8. 
Table 8: Results of ramped pyrolysis radiocarbon measurements on KIS-GZ sediment. CRA= conventional radiocarbon age, TOC = total organic carbon, $F=$ fraction modern.

\begin{tabular}{|c|c|c|c|c|c|c|c|c|c|}
\hline Sample depth & Split fraction & Temp. of split & CRA & CRA error & $\Delta^{14} C$ & $\Delta^{14} C$ error & TOC & $\mathrm{F}$ & Ferror \\
\hline$[\mathrm{cm}]$ & & {$\left[{ }^{\circ} \mathrm{C}\right]$} & [yBP] & & {$[\%]$} & & {$[\%]$} & [] & \\
\hline $0.5-2.5$ & bulk & 900 & B & & -992.2 & 3.5 & 0.42 & 0.0079 & 0.0035 \\
\hline $5-7.5$ & bulk & 900 & B & & -994.2 & 3.5 & 0.38 & 0.0059 & 0.0035 \\
\hline $20-22.5$ & bulk & 900 & 33216 & 1753 & -984.1 & 3.5 & 0.15 & 0.0160 & 0.0035 \\
\hline $42-44.5$ & bulk & 900 & B & & -994.8 & 3.5 & 0.31 & 0.0052 & 0.0035 \\
\hline $0.5-2.5$ & 3 & 390 & 31511 & 2076 & -980.4 & 5.1 & & 0.0198 & 0.0051 \\
\hline $0.5-2.5$ & 4 & 430 & B & & -993.1 & 5.7 & & 0.0069 & 0.0058 \\
\hline $0.5-2.5$ & 5 & 530 & B & & -990.7 & 4.3 & & 0.0093 & 0.0043 \\
\hline $0.5-2.5$ & 6 & 900 & B & & -992.2 & 16.8 & & 0.0079 & 0.0169 \\
\hline $5-7.5$ & 2 & 385 & B & & -986.8 & 5.7 & & 0.0133 & 0.0057 \\
\hline $5-7.5$ & 3 & 430 & B & & -994.2 & 5.3 & & 0.0059 & 0.0053 \\
\hline $5-7.5$ & 4 & 495 & B & & -992.7 & 6.6 & & 0.0074 & 0.0067 \\
\hline $20-22.5$ & 2 & 380 & B & & -972.7 & 12.3 & & 0.0276 & 0.0124 \\
\hline $20-22.5$ & 3 & 430 & B & & -988.8 & 14.0 & & 0.0113 & 0.0141 \\
\hline $20-22.5$ & 4 & 525 & B & & -982.3 & 10.9 & & 0.0179 & 0.0110 \\
\hline $20-22.5$ & 5 & 900 & B & & -988.3 & 12.7 & & 0.0118 & 0.0128 \\
\hline $42-44.5$ & 2 & 395 & B & & -993.4 & 6.1 & & 0.0067 & 0.0062 \\
\hline $42-44.5$ & 3 & 440 & B & & -999.4 & 7.6 & & 0.0006 & 0.0076 \\
\hline $42-44.5$ & 4 & 540 & B & & -997.4 & 6.0 & & 0.0026 & 0.0060 \\
\hline $42-44.5$ & 5 & 900 & B & & -999.8 & 9.9 & & 0.0002 & 0.0100 \\
\hline $\begin{array}{l}\text { Background res } \\
\text { reported fractio } \\
\text { Conventional R } \\
\text { Fraction moder }\end{array}$ & $\begin{array}{l}\text { ults }(B) \text { are indis } \\
n \text { modern is a lir } \\
\text { diocarbon Age } \\
(F) \text { is the blank }\end{array}$ & $\begin{array}{l}\text { inguishable fron } \\
\text { niting age, not a } \\
\text { CRA) and } \Delta^{14} C \\
\text { corrected fracti }\end{array}$ & $\begin{array}{l}\text { C-free ba } \\
\text { ute. } \\
\text { reported } \\
\text { modern } n\end{array}$ & $\begin{array}{l}\text { ound materia } \\
\text { fined by Stuix } \\
\text { lized to } \delta^{13} \mathrm{C}\end{array}$ & $\begin{array}{l}\text { epared an } \\
\text { d Polach } \\
5 \% \text {, defin }\end{array}$ & $\begin{array}{l}\text { asured concu } \\
\text { iocarbon } 19 \\
\text { y Donahue et }\end{array}$ & \multicolumn{2}{|c|}{$\begin{array}{l}\left.\text { Conventional Radiocarbon Age (CRA) and } \Delta^{14} \mathrm{C} \text { are reported as defined by Stuiver and Polach (Radiocarbon } 19: 355-363,1977\right) \text {. } \\
\text { Fraction modern (F) is the blank corrected fraction modern normalized to } \delta^{13} \mathrm{C} \text { of }-25 \% \text {, defined by Donahue et al. (Radiocarbon, 32 (2):135-142, 1990). }\end{array}$} & \\
\hline
\end{tabular}

Concentrations of total organic carbon in each KIS-GZ sample varied between 0.15 and $0.42 \%$. The blank corrected fraction of modern carbon ranged between 0.0002 and $0.0276 \%$, with a mean value of $0.0097 \%$. Radiocarbon dates were taken for the four bulk samples, in addition to the four RPO splits for each sample. The sample between 5-7.5 cm was only subject to three RPO splits. Of the 19 ages, 17 were indistinguishable from the background age produced by the materials involved in the measurement process. The age of the bulk radiocarbon in the $20-22.5 \mathrm{~cm}$ sample, combusted at $900^{\circ} \mathrm{C}$, was found to be 33,216 yr B.P., and the third split of the $0.5-2.5 \mathrm{~cm}$ sample, combusted at $390^{\circ} \mathrm{C}$, was found to be $31,511 \mathrm{yr}$ B.P. An interpretation of these ages is provided in the discussion below.

\subsection{Discussion}

\subsubsection{Source of sediment}

Five lines of evidence provide information about the source of sediment at KIS-GZ.

$\mathrm{Al} / \mathrm{Ti}$ ratios and $\mathrm{Nd} / \mathrm{Sr}$ isotopes indicate that all lithogenic sediment in the core is derived from similar source rocks. Zircon ages and petrographic similarities to upstream samples tie the core to the Kamb catchment, while the sediment maturity 
Sediment Core

suggests that the source is within several tens of kilometres. A shift in the abundance of diatoms downcore suggests that upstream changes in erosion/transport translate to $\mathrm{cm}-\mathrm{dm}$ scale variations in the composition of the core but do not affect overall texture. Overall, the impression is of a localised sediment source with some variation in composition based on differential ice erosion and transport pathways (e.g. Scherer et al., 1998).

Plutonic lithologies form much of the basement of West Antarctica (Jordan et al., 2020). Aluminium and titanium are key indicator elements for rock composition in environments where plutonic rocks are abundant (Young \& Nesbitt, 1998). The compositional similarity of the sand-sized fraction to a quartz-rich granitoid source and the abundance of quartz- and plagioclase-rich plutonic sediment, including granitoid and dioritoid clasts (Martin, pers. comm, 2020), indicate that a significant component of the KIS-GZ sediment is derived from plutonic lithologies. The close association of aluminium and titanium $(r 2=0.898)$ over the length of the KIS-GZ core shows that there was no major change in the composition of the lithogenic source rocks (e.g. Young \& Nesbitt, 1998). This interpretation is supported by strong-moderate positive relationships between aluminium/titanium and other key lithogenic elements, including iron and potassium (Table 7). Additionally, neodymium isotopes from the upper $2 \mathrm{~cm}$ and the $26.5-28.5 \mathrm{~cm}$ intervals of the core are analytically indistinguishable, reinforcing the idea that the source of lithogenic sediment does not change to at least that depth (Marschalek, pers. comm., 2021).

The sole outcrop in the Kamb catchment, the Whitmore Mountains, is comprised of Jurassic granites (Craddock et al., 2017) and calcareous Cambrian sedimentary rocks (Cox \& Lyttle, 2019)(Figure 37). The only sediment samples recovered from beneath KIS, at $\mathrm{UpC}$, show similar $\mathrm{Nd} / \mathrm{Sr}$ isotope ratios and comparable concentrations of quartz/feldspar grains and lithic fragments to sand from KIS-GZ (Marschalek, pers. comm., 2021; Vogel, 2004; Martin, pers. comm., 2020). UpC and KIS-GZ are further related by the fragmentation, mixing, and taxanomic composition of their diatom assemblages, though the late Miocene assemblage at KIS-GZ is absent at UpC, and the trace concentrations (2-3\%) of Pliocene-Pleistocene diatoms identified at UpC are absent at KIS-GZ (KIS-GZ: Harwood, pers. comm., 2021; UpC: Coenen, 2016). The composition of lithogenic sediment from both sites is comparable with the plutonic 
lithologies exposed at the Whitmore Mountains (Martin, pers. comm., 2020). The close relationship between the known lithologies in the KIS catchment and the KIS-GZ core indicate that the sediment is sourced from within the catchment, which is supported by zircon provenance work completed by James Marschalek (pers. comm., 2021; discussed in Timing of deposition section below). Martin (pers. comm., 2021) suggested that the presence of mafic grains, which are typically quick to break down under most weathering conditions (Goldich, 1938), along with pebbles and fragments of immature sedimentary rocks, indicate that the sand-pebble sized fraction of KIS-GZ sediment was sourced within several kilometres to tens of kilometres of the core site. However, reduced crushing, abrasion, and comminution of particles in sub-ice stream settings (Tulaczyk et al., 1998) due to high pore water pressures (Engelhardt \& Kamb, 1997) insulating grains against interparticle stress may increase the possible transport range before particle breakdown.

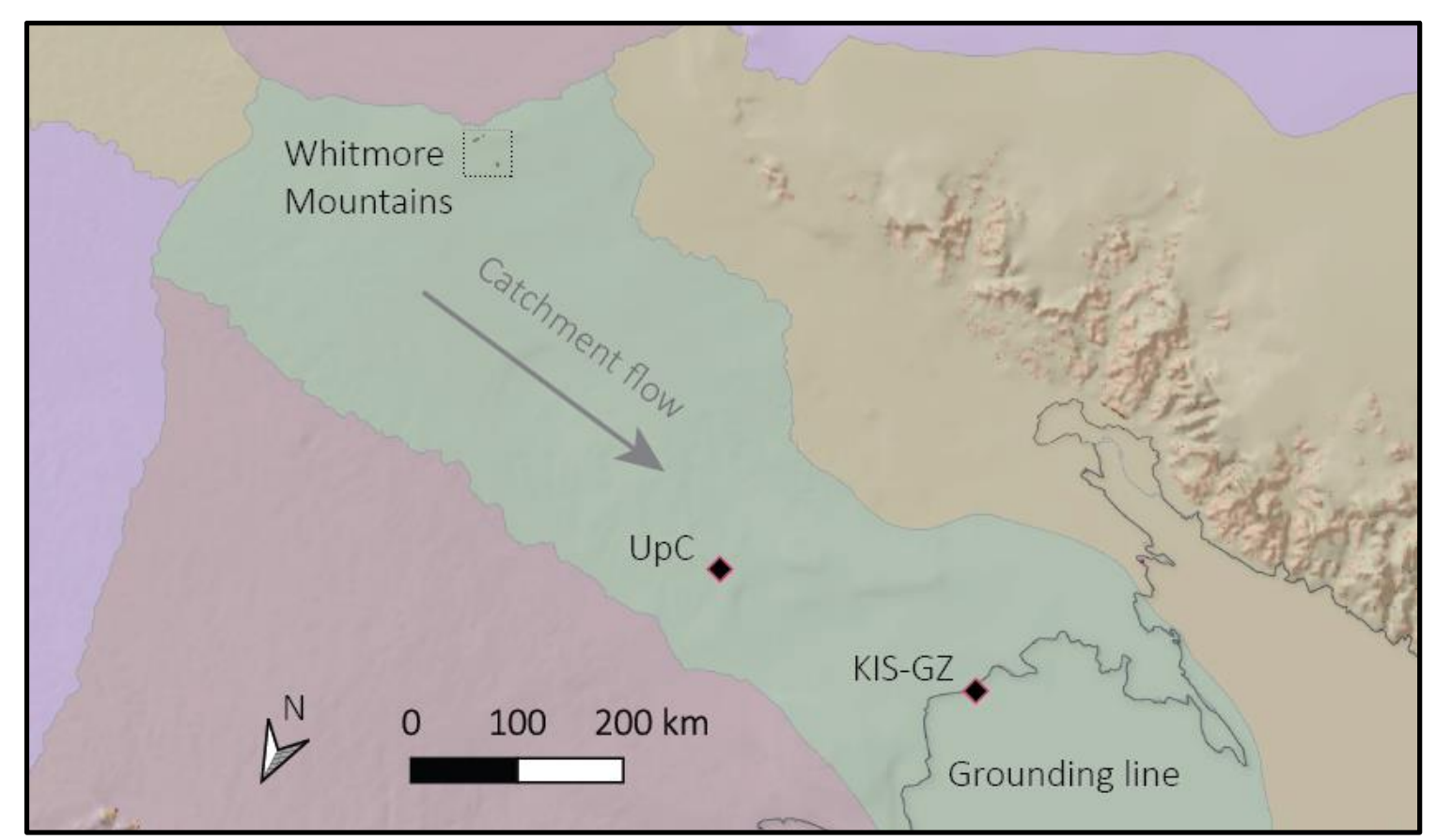

Figure 37: Jurassic granite outcrops at the Whitmore Mountains, $700 \mathrm{~km}$ up-catchment of KISGZ; similar lithologies are present at KIS-GZ and at UpC, $270 \mathrm{~km}$ up-catchment from the grounding line. $\mathrm{Nd} / \mathrm{Sr}$ isotopes and mineral abundances from KIS-GZ and UpC are also comparable.

The distinguishing compositional feature is the down core jump in diatom content at $18 \mathrm{~cm}$ depth from $\sim 5 \%$ to $\sim 18 \%$ of the total sediment volume. The cause of this difference is uncertain. Diatoms are by far the most common biogenic component of 
Sediment Core

the sediment (detail in Results and Glaciological significance of diatoms sections, this Chapter). While the diatoms may have been reworked numerous times in the past (e.g. Kellogg et al., 1979; Scherer et al., 1998), stratigraphic mixing of diatoms of different ages and comparable fragmentation of diatoms indicate that all diatoms in the core likely have a shared history for the most recent episode of erosion and deposition. There is no evidence to suggest that the change in the composition of the core reflects a change in the depositional setting of the sediment (detail in Depositional mechanism and setting section). I suggest that the compositional change at $18 \mathrm{~cm}$ is caused by rainout sedimentation preserving the variable sediment composition of layers of sediment entrained in the base of the ice stream (e.g. Engelhardt \& Kamb, 2013).

\subsubsection{Timing of deposition}

Extracting reliable chronological information from Ross Embayment sediment is notoriously difficult (Subt et al., 2017). A regional paucity of calcareous microfossils typically precludes foraminiferal radiocarbon dating (Licht et al., 1998), and radiocarbon that is present often returns dates much older than depositional timings inferred from other characteristics of the sediment (Andrews et al., 1999). Alternatively, acid-insoluble organic sediment (AIOM) provides a target for radiocarbon dating. Dateable AIOM is primarily derived from contemporary phytoplankton (principally diatoms) (Rosenheim et al., 2008), although it may also be generated by bacterial oxidation (Horrigan, 1981; Priscu et al., 1990). However, the bulk of AIOM throughout the Ross Sea was glacially eroded from the bedrock that underlies the Antarctic Ice Sheet (Sackett et al., 1974; Cristina Subt et al., 2016), and due to its advanced age is 'radiocarbon dead'. The ramped pyrolysis (RPO) methodology was employed here to attempt to isolate carbon deposited 'in situ' from carbon reworked from sediment underlying the modern ice sheets.

The ages of the radiocarbon within the KIS-GZ sediment determined by RPO dating are not consistent with lithological evidence that constrains the timing of deposition (refer to Depositional mechanism and setting section, this Chapter). Instead, the ages likely represent a midpoint between the age of the young and old carbon, which can skew the radiocarbon dates to older values (Rosenheim et al., 2008). Samples which contain extremely low concentrations of young radiocarbon are therefore more susceptible to producing older ages or ages indistinguishable from background laboratory materials, regardless of the age of the youngest radiocarbon in the sample and the timing of 
deposition (Subt et al., 2017). Young radiocarbon at KIS-GZ is extremely scarce (Table 8). In contrast, sediment from the Whillans grounding zone tested by Venturelli et al. (2020) contains more than $10 x$ the concentration of modern radiocarbon. The paucity of radiocarbon at KIS likely negatively impacted the utility of the results for dating (Ginnane and Turnbull, pers. comm., 2020). Increasing the resolution of the low-temperature RPO volatilisation (i.e. making more splits at low temperatures where the young radiocarbon is concentrated) may yield radiocarbon ages that more accurately reflect deposition timing (Subt et al., 2017). While the extracted ages do not necessarily reflect the timing of sediment deposition, the fact that two of the RPO intervals were distinguishable from background readings does indicate that there is some source of young radiocarbon between $0.5-2.5$ and $20-22.5 \mathrm{~cm}$ in the core. Accordingly, I interpret the KIS ages of 31.5 and $33.2 \mathrm{kyr}$ as maximum ages skewed to significantly older-than-depositional values by the presence of reworked radiocarbon-dead carbon in all the RPO intervals.

There are few alternative dating methods applicable to post-glacial sub-ice shelf sediment. Analysis of samples for Pb-210 and Cs-137 to constrain deposition rates should deposition be in the last century is being carried out, but final results were not available at the time of submission of this thesis. Indirect evidence constraining the timing of deposition is inferred from glacial flow lines and the provenance of sediment found in the KIS-GZ core.

Ice stream transport pathways across the Ross Sea region evolved significantly following the Last Glacial Maximum (LGM; Figure 38). Distinguishing sediment provenance during glacial/interglacial periods may prove important for developing a chronology for the planned deep drill core at KIS-GZ. Before 5 kyr, ice that flowed over the KIS-GZ core site originated in outlet glaciers along the southern Transantarctic Mountains (TAM). During this period, the sediment deposited at KIS-GZ likely reflected the composition of sediment which originated in the TAM. TAM sediment is compositionally distinct from sediment derived beneath the WAIS (Licht et al., 2005). Notably, the presence of abundant diatoms and relative dearth of mafic minerals at KIS-GZ indicates a WAIS provenance and therefore constrains the timing of core deposition to within the last $5 \mathrm{kyr}$. 


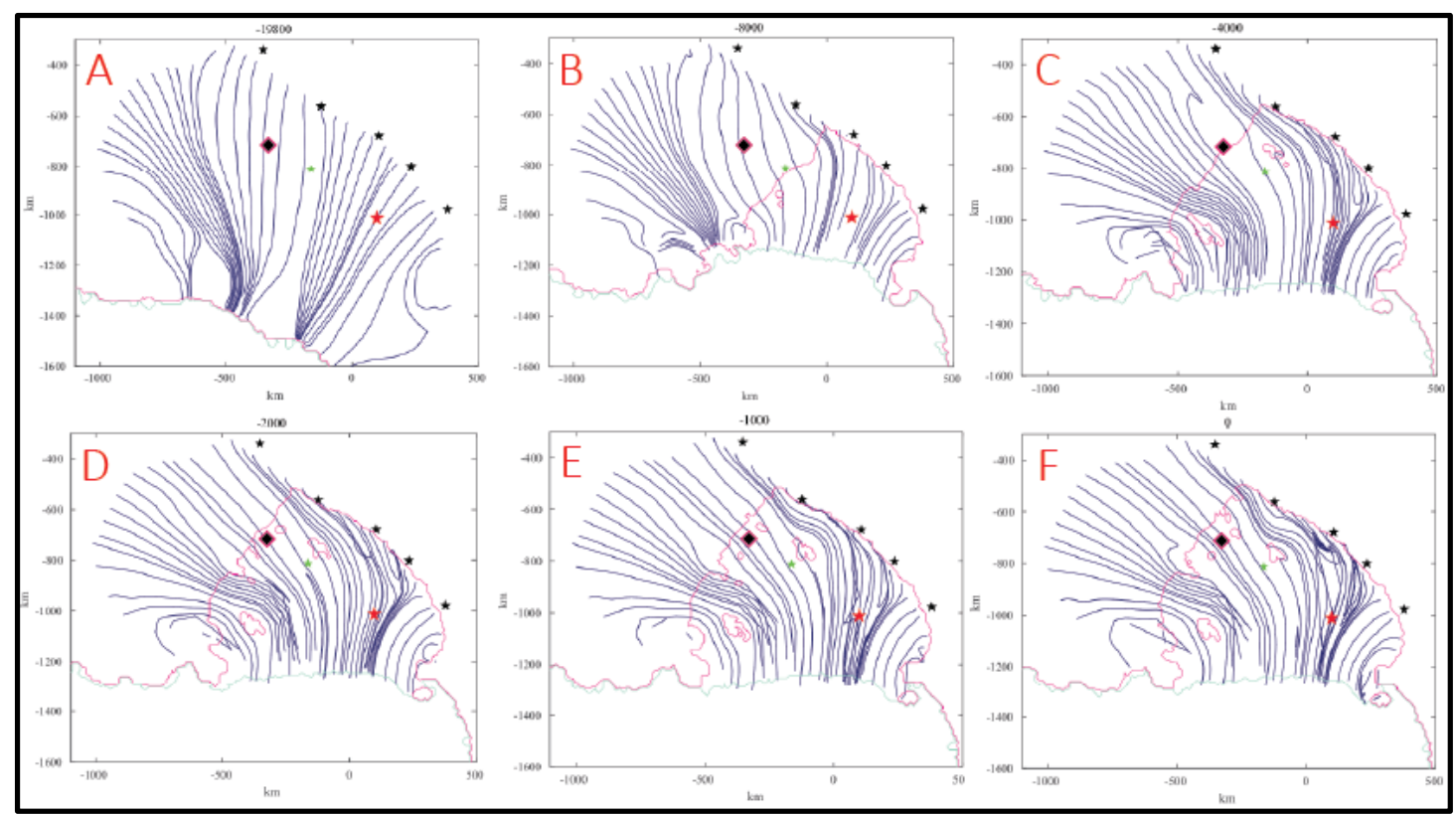

Figure 38: Ice transport pathways through the Ross embayment from A (19.8 ka), B (8 ka), C (4 $\mathrm{ka}), D(2 \mathrm{ka}), E(1 \mathrm{ka})$ years ago to present (F). The black cube with pink background shows the location of KIS-GZ. Note shift in source of ice flowing past the site between 8 and $4 \mathrm{ka}$; the shift from EAIS to WAIS source occurs $5 \mathrm{ka}$. Ice passing over KIS-GZ has only been sourced from the KIS catchment for < $2 \mathrm{ka}$. Maps courtesy of Christina Hulbe (University of Otago, 2021).

Along the Siple Coast, the presence of distinctive populations of Cretaceous and Ordovician zircons in the WIS, KIS, and BIS catchments allow otherwise compositionally similar sediment to be distinguished (Figure 39; Marschalek, pers. comm., 2021). The distribution of zircon ages in KIS-GZ sediment is consistent with a provenance in the KIS catchment and is similar to the zircon age distribution from sediment recovered at UpC (Marschalek, pers. comm., 2021). The present configuration of the Siple Coast ice streams, where the KIS flow pathway extended through the modern KIS catchment, was only achieved $\sim 2$ kyr. Deposition of the KIS-GZ sediment therefore likely occurred within the last $2 \mathrm{kyr}$. 


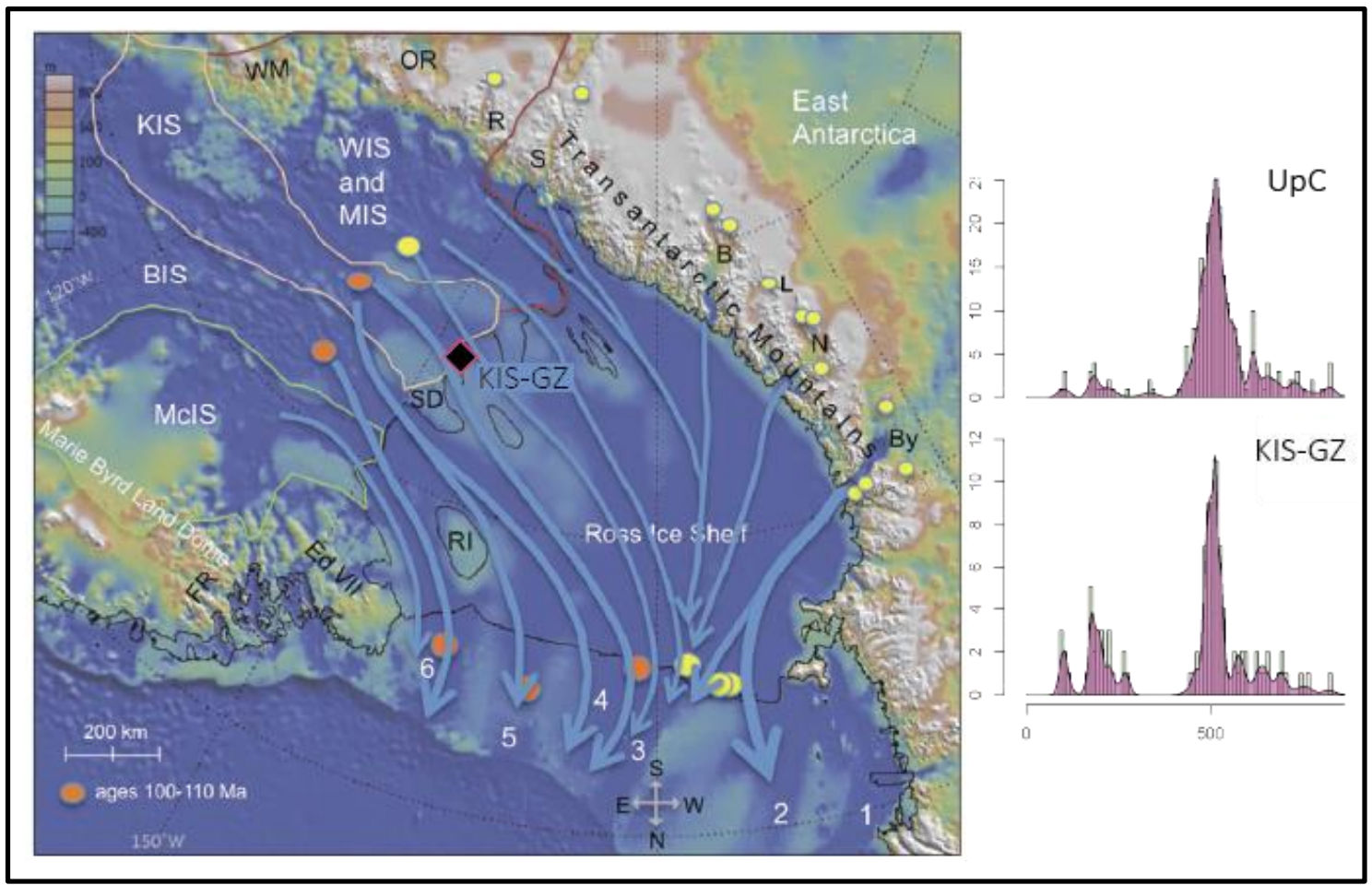

Figure 39: An analysis of the distribution of zircon ages was provided by James Marschalek (pers. comm., 2021) and is presented here for comparison with the map and previously published analysis of zircon ages in UpC sediment from Licht et al. (2014). The age distributions are indicative of a KIS-based source for the KIS-GZ sediment (Marschalek, pers. comm., 2021).

At a smaller temporal and spatial scale, Horgan et al. (2017) present a compelling argument that the Siple Coast grounding line retreated across the KIS-GZ site between 35 and 160 years before present. If this shift in environmental conditions is recognisable in the core, the depositional timing of the sediment can be even more narrowly constrained.

\subsubsection{Relationship between KIS-GZ core and sedimentary facies models}

Geological studies around Antarctica show consistent relationships between sedimentary facies and the environment of deposition, including an indication of the proximity of glaciologically important grounding and calving lines (Figure 40; Domack \& Harris, 1998; Smith et al., 2019). 


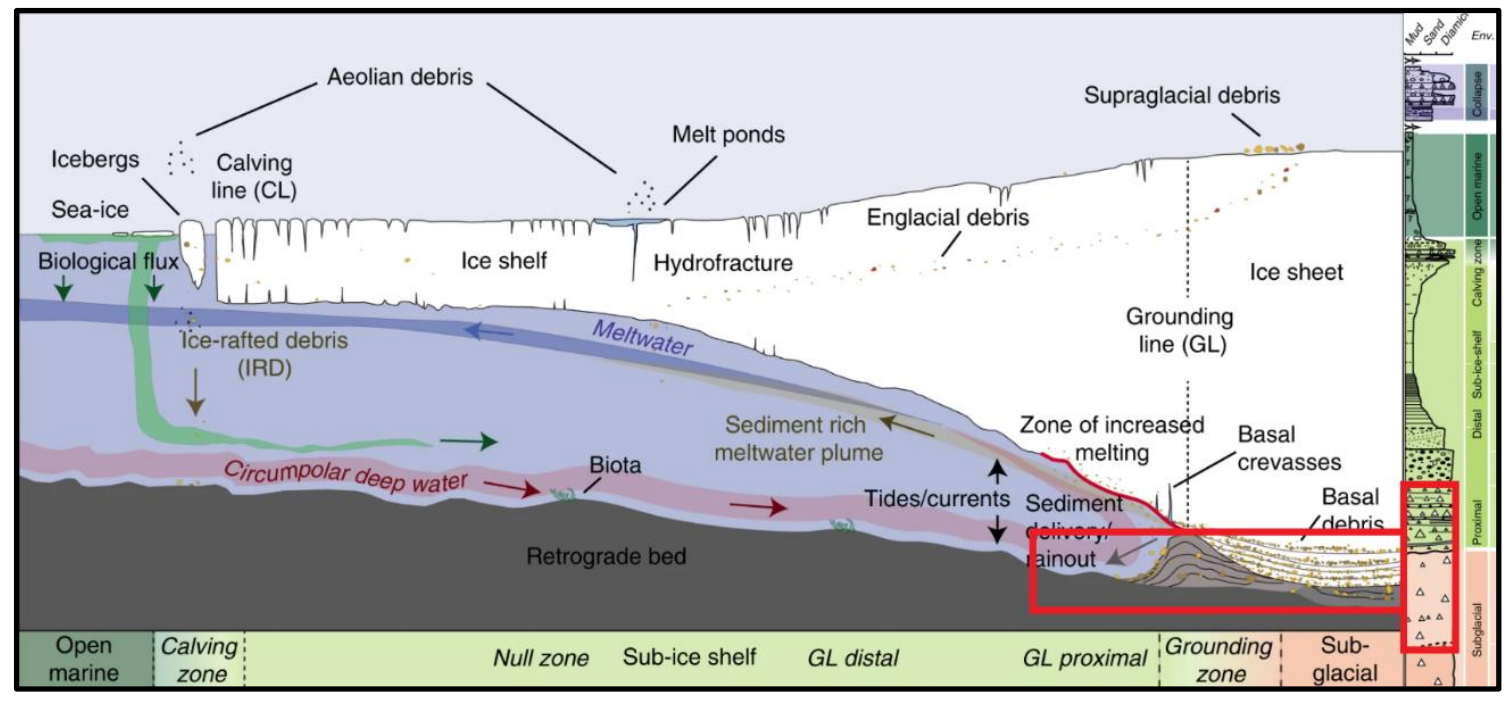

Figure 40: The spatial (left) and temporal (right, glacial retreat sequence shown) relationship between glacio-marine setting and sediment facies (modified from Smith et al. (2019); further detail and numbers provided in the article). The lithological characteristics of the KIS-GZ core constrain its depositional setting to the red rectangles. Evidence for and against deposition under grounded ice is covered in section 3.4.4.

The sedimentary characteristics of the KIS-GZ core are inconsistent with deposition in open ocean, calving-line proximal and grounding-line distal sub-ice shelf settings, or beneath grounded ice that is not subject to streaming flow. An open ocean or calvingline proximal setting is ruled out due to the absence of a significant modern diatom cohort and the very low abundance of organic carbon (Table 8). Sub-ice shelf deposits distal from the influence of both grounding and calving line processes are typically dominated by mud, which is often stratified by the processes associated with suspended mud particles settling. Stratified sands and muds and till pellets (the granulated facies) are absent from the KIS-GZ record. The core also does not exhibit the diagnostic characteristics of the overconsolidated 'stiff diamicton' lithology formed beneath grounded, non-flowing ice where the load of the overlying ice exceeds that supported by buoyancy; planar structures are absent, and the bulk density (and implied shear strength) of the sediment is too low.

The KIS-GZ core exhibits characteristics of both the 'soft diamicton' and 'stratified diamicton' facies (corresponding to deposition beneath grounded ice subject to streaming flow and in the ocean cavity immediately proximal to the grounding line, respectively; Smith et al., 2019). Identifying which process deposited the KIS-GZ core is important if the sedimentological characteristics of the core are to play a role in constraining depositional timing and has important implications in the context of the drill programme planned at KIS. If the sediment was deposited beneath grounded ice, 
the relatively low compaction and shear strength of the sediment indicates that the effective pressure exerted on the ice stream bed is low, and therefore that flow of the ice stream is facilitated by highly pressurised basal water rather than deformation of the basal sediment. This scenario would suggest that subglacial erosion at KIS is low even during periods of streaming flow, with implications for the preservation potential of a record recovered by deep drilling. If the sediment was deposited following the retreat of the grounding line within the last 160 years, a longer sediment record may encounter thick packages of sediment associated with very short depositional timeframes, limiting the temporal extent of the record.

\subsubsection{Assessment of the evidence for and against sub-glacial deposition}

Sub-glacial soft diamictons are ubiquitous beneath modern Siple Coast ice streams (Bell et al., 1998; Dowdeswell et al., 2004; Studinger et al., 2001). These 5-10 m thick layers of homogenised structureless till (glacially deposited diamicton) appear to form beneath grounded, flowing ice via the erosion, mixing, and subglacial deformation of weak sediment which underlie the till itself (Tulaczyk et al., 1998). Though these diamictons lie beneath thick ice streams, the presence of relatively abundant subglacial water, which is confined both by overlying ice and the properties of the basal till, appears to hydrostatically bear much of the weight of the overlying ice, simultaneously preventing compaction and providing a 'low friction' surface for ice stream flow (Tulaczyk et al., 1998). The resulting deposits are characterised by high water content, low shear strength, and the absence of planar or shear structures (Smith et al., 2019; Tulaczyk et al., 1998). Reworked diatom sediment is often abundant, but modern forms are absent due to a lack of exposure to the ocean, and carbon concentrations are low (Smith et al., 2019). The absence of grounded ice at the core site now does not preclude the KIS-GZ core from having been deposited beneath grounded ice; if sedimentation rates in the sub-ice cavity are low $(\sim \mathrm{cm} / \mathrm{kyr})$, then sediment deposited beneath grounded ice could be preserved at or near the sea floor/ocean interface (e.g. Licht et al., 1999).

Stratified diamictons form in the ocean cavities adjacent to ice stream grounding lines and are shaped by interactions between sediment and water. Sediment is typically transported to the ocean cavity by the movement of the ice stream, which deforms the till layer which underlies the ice (Alley et al., 1989) and carries a load of englacial 
Sediment Core

sediment (Alley et al., 1997). High melt rates near the grounding line cause englacial sediment to be rained out and mix with soft subglacial till deposited the grounding line. The sediment is re-sorted by jets or plumes of pressurised water expelled from subglacial channels (Powell, 1990) to form stratified deposits. However, the stratification which is typically present in grounding-line proximal deposits cannot be assumed to be present at KIS, because the reduction in subglacial water flow (Anandakrishnan \& Alley, 1997; absence of subglacial channels, Horgan et al., 2017) following stagnation of the ice stream would have diminished the fluid sorting mechanisms which usually generate the stratified deposits.

Most attributes of the KIS-GZ sediment are consistent with both the soft (subglacial) and stratified (grounding-line proximal) diamicton facies of Smith et al. (2019). The bulk of the sediment in both scenarios is derived from the sub-ice stream basal till, meaning that the composition, provenance, and textural characteristics (e.g. particle size range, sorting, clast shape) of the core cannot be used to distinguish the depositional setting of the sediment (e.g. Licht et al., 1998). Assuming high pore water pressure when KIS was grounded over the core site, the density of the sediment also cannot differentiate the depositional setting (values comparable to WIS till assuming a mean grain density of $2.65 \mathrm{~g} / \mathrm{cm}^{3}$; Tulaczyk et al., 2001). High total organic carbon (TOC) concentrations over the length of the KIS core suggest that the sediment may have been exposed to some external source of carbon during deposition, possibly via advection, though there is no evidence of modern diatoms having been advected to KIS-GZ at any point in the core.

The lack of diagnostic characteristics in the sediment mean that there is no single line of lithological evidence which definitively constrains the depositional setting of the KIS-GZ core. Importantly, there is no evidence (i.e. shearing, mixing, unique sorting characteristics) to suggest that the core captures the transition from deposition beneath grounded ice to deposition in sub-ice shelf conditions. It is therefore likely that the entire core was deposited in one setting.

Based on my judgement of the most likely depositional scenario, the following Chapter (4) presents a simple sedimentary model for the KIS grounding zone. The model assumes deposition occurred wholly via rainout of sediment within the last 160 years following the stagnation of the ice stream and retreat of the grounding line. Basal ice upstream of KIS-GZ exhibits a $15.5 \mathrm{~m}$ thick accretionary basal ice layer containing up to $2.1 \mathrm{~m}$ vertical 
equivalent of sediment (Christoffersen et al., 2010). Assuming an even distribution of sediment over the length of KIS, formation of the $30 \mathrm{~m}$ thick ocean cavity at modern KISGZ by melt of the base of the ice stream would have deposited the sediment via rainout. The presence of a $\sim 2 \mathrm{~m}$ thick rainout deposit is consistent with the lithological characteristics of the $60 \mathrm{~cm}$ core and with the geothermal probe penetrating $\sim 1.7 \mathrm{~m}$ into a diamicton deposit. The model outlined in Chapter 4 is also consistent with observations of the texture and morphology of the sea floor around the borehole (Chapter 2).

\subsubsection{Glaciological significance of diatoms}

Diatoms are by far the most commonly preserved microfossil in Antarctic sediments. Their biostratigraphic significance has proven controversial since the recovery of the first sediment core beneath the Ross Ice Shelf in 1979 (e.g. Harwood et al., 1989; Kellogg et al., 1979; Webb et al., 1979). Because the presence of in situ diatoms implies sufficient light for photosynthesis, their presence is taken as evidence for open water conditions at the time of their deposition (e.g. Scherer et al., 1998). The presence of 'Quaternary' diatoms in sediment from the upper WIS (UpB; Figure 41), in particular, Thalassosira Antarctica with a first appearance datum (FAD) of 0.57-0.64 ma (Cody et al., 2008) has been forwarded as evidence for the complete collapse of the Ross Ice Shelf in the Quaternary - most likely in either or both of the warmest interglacial periods at $125 \mathrm{ka}$ (Marine Isotope Stage 5e (MIS5e)) and 400 ka (MIS11) respectively (Kingslake et al., 2018; Scherer et al., 1998; Venturelli et al., 2020). The implication is that all of the area now covered by the Ross Ice Shelf was open sea, conducive to the production of phytoplankton and deposition of their skeletal remains on the sea floor. 


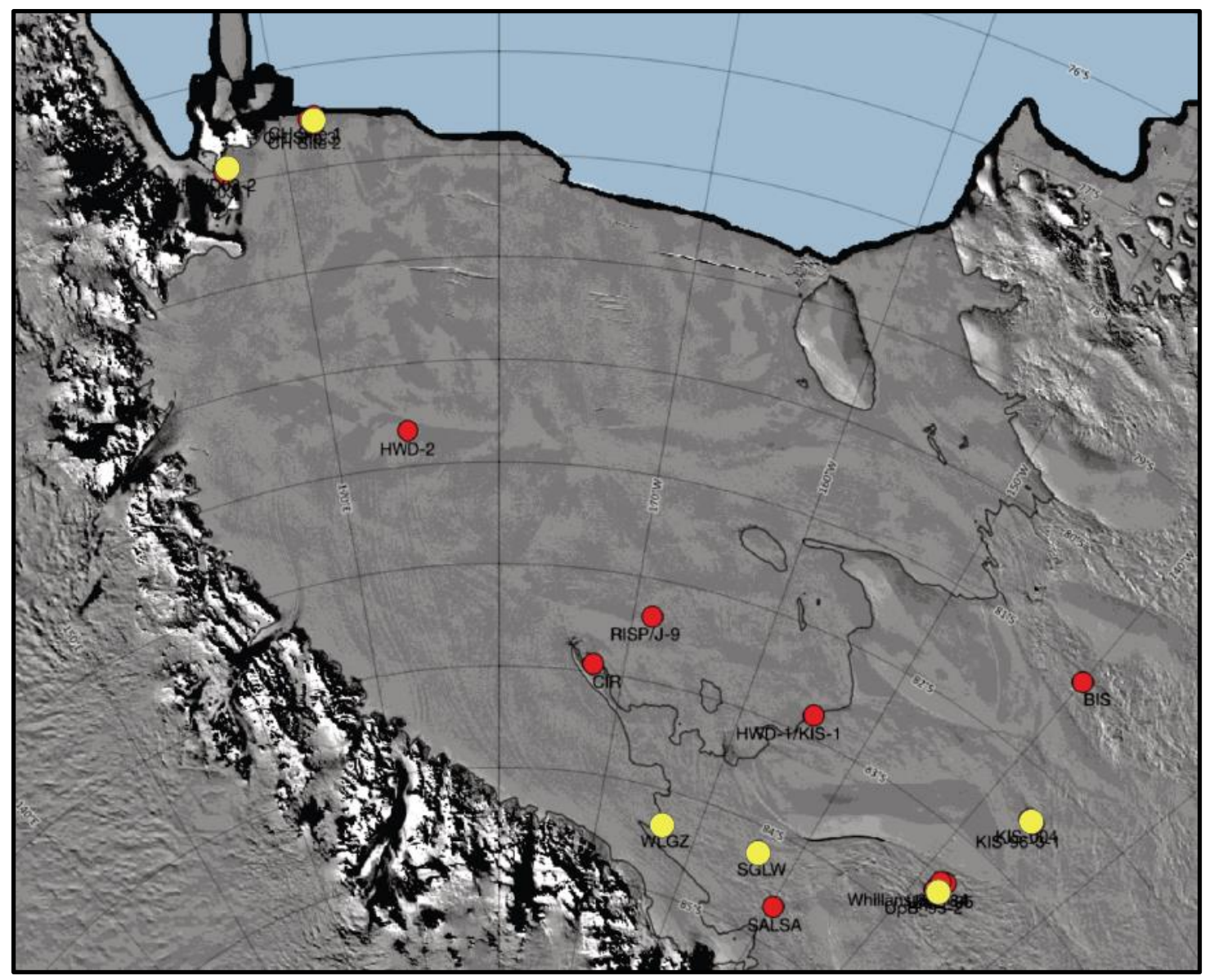

Figure 41: Distribution of Quaternary diatoms in sediment from the Ross embayment. Sediment where Quaternary diatoms have been identified are shown in yellow; sediment where Quaternary diatoms are absent are shown in red. Figure courtesy of Gavin Dunbar (VUW, 2021). On this map KIS-GZ is identified by its operational name of HWD-1/KIS-1.

Quaternary diatoms have been identified in subglacial sediment at four locations along the Siple Coast, but in other locations are absent. At KIS-GZ, three diatom cohorts span the late Oligocene-early Miocene, early Miocene, and late Miocene (Harwood, pers. comm., 2021). To date, no diatoms which are unequivocally younger than the late Miocene have been identified in the KIS-GZ core (Harwood, pers. comm., 2021). Assuming complete collapse of the Ross Ice Shelf (RIS) and partial collapse of the West Antarctic Ice Sheet (WAIS) (e.g. Scherer et al., 1998), the absence of Quaternary diatoms at KIS-GZ and other subglacial sediment from the Siple Coast is difficult to reconcile, particularly in light of Quaternary diatoms having been identified upstream in the KIS catchment at UpC (Coenen, 2016). One possibility is that ice shelf collapse during either or both of MIS5e and MIS11 may have been short-lived and the resulting accumulation of diatoms may be very thin, and thus discontinuous in their distribution across the paleo-sea floor. Alternatively, modelling by Clark et al. (2020; Figure 42) and Golledge et 
al. (2021) presents the possibility of collapse of ice within the Thwaites sector in MIS5e, whist preserving the Ross (and Ronne/Filchner) ice shelves, bringing open water conditions (and diatoms) close enough to the Siple Coast to be subsequently reworked into the upper ice stream catchments. Slight variations in transport pathways and flow conditions may have resulted in variable deposition of the reworked diatoms within ice stream catchments.

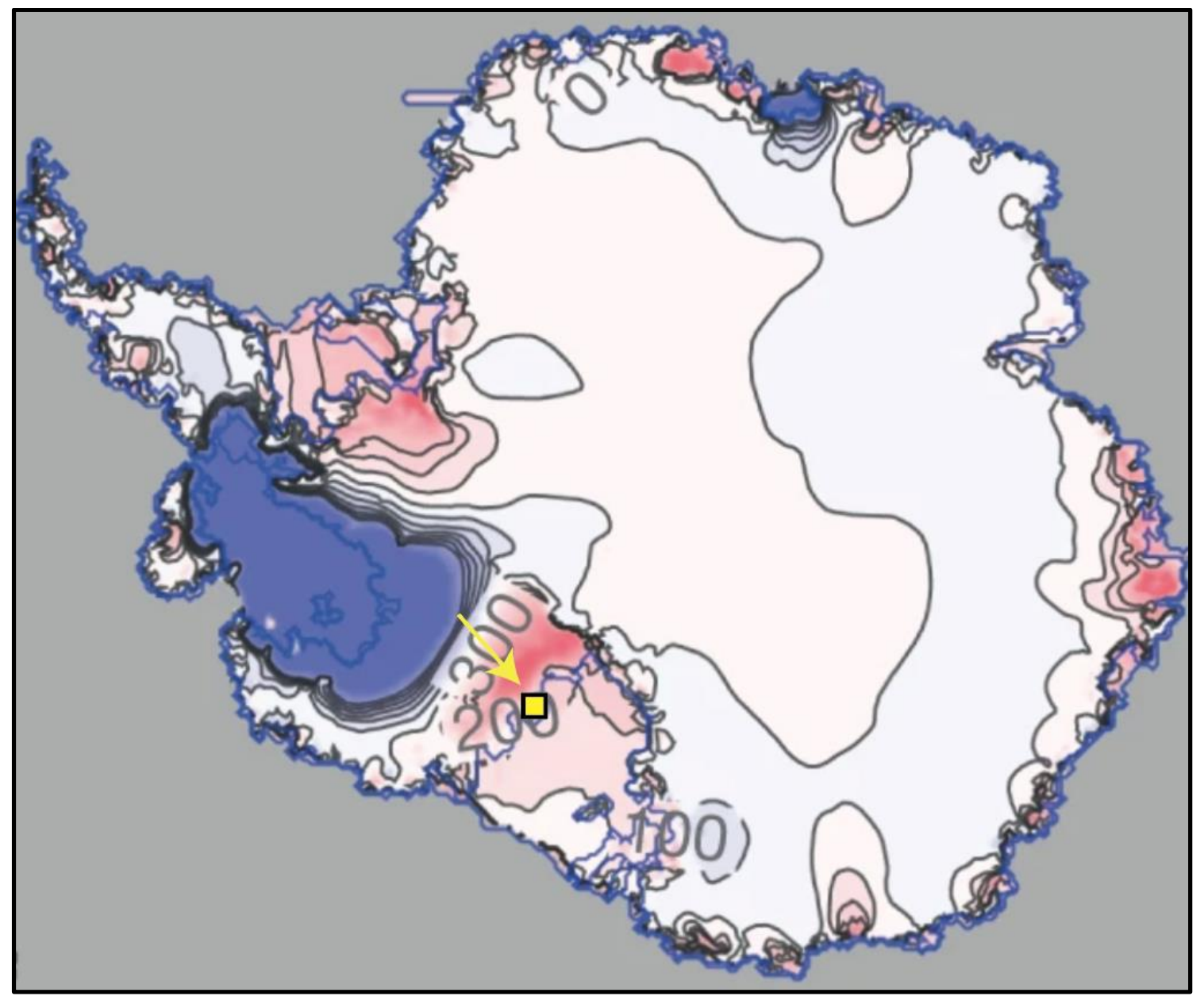

Figure 42: New modelling indicates that major ice loss through the Thwaites sector during MIS5e may have opened the upper KIS catchment to open marine conditions, allowing diatom deposits to accumulate and be reworked downstream following re-glaciation. Here the yellow square represents the approximate location of KIS-GZ, while the yellow arrow approximates the paleoflow direction of KIS (figure modified from Clark et al., 2020).

\subsection{Conclusions}

1. Sediment in the core is derived from the KIS catchment, probably within several tens of kilometres of the core site. 
Sediment Core

2. Compositional differences in the core are likely the product of erosion from different parts of the Kamb catchment (and different again from those contributing sediment to the base of the Kamb Ice Stream at UpC), resulting in compositionally (but likely not texturally) differentiated layers of sediment within the overall basal sediment load of the Kamb Ice Stream.

3. Abundant reworked Tertiary diatoms and radiocarbon-dead organic matter resulted in the timing of deposition being unable to be dated using either biostratigraphy or radiocarbon dating.

4. On balance, the core was most likely deposited by rain-out sedimentation following retreat of the grounding line. A sedimentation model of this scenario is examined in detail in Chapter 4. 


\section{Sedimentary model and conclusions}

This Chapter synthesises the findings of Chapters 2 and 3 and presents a model for sedimentation at the grounding zone of the Kamb Ice Stream. The model (provided schematically in Figure 44) represents my judgement of the most likely scenario under which the textural, morphological, and sedimentary features observed at KIS-GZ formed, and outlines the temporal evolution at the core site from before KIS stagnated to the present.

\subsection{Environmental constraints}

The absence of subglacial drainage channels or a grounding zone wedge deposit between the modern KIS grounding line and the inferred paleo-grounding line, $25 \mathrm{~km}$ seaward of the modern grounding line (GL) position, indicates that GL retreat occurred following the stagnation of KIS 160 years ago (Horgan et al., 2017). The chronology of my sedimentation model is constrained by Horgan et al. (2017)'s GL retreat model and associated linear retreat rate of $200 \mathrm{~m} /$ year, which is based on a modern grounding line occupation period of 35 years (Horgan \& Anandakrishnan, 2006).

Stagnation of the ice stream caused the transport of basal sediment along the lower part of the Kamb Ice Stream (including the section grounded beyond the KIS-GZ site) to cease. The sediment entrained in overlying ice at any point along the ice stream therefore represented the total volume of sediment available to be deposited. Based on the petrographic, mineralogical, and isotopic similarities noted between UpC and KIS-GZ sediment in Chapter 3, sediment appears to be sourced along the KIS transport pathway and not from outside the Kamb catchment. In one borehole higher in the KIS catchment, entrained sediment was observed to be distributed between an $8.2 \mathrm{~m}$ thick basal and 7.3 m-thick overlying ice layer, containing $20 \%$ and $5 \%$ sediment by volume, respectively (Christoffersen et al., 2010). Sediment is concentrated in the lowest few metres of ice near the ice-sediment interface, with particles from claycobble size present (Engelhardt \& Kamb, 2013). I assume that, prior to stagnation, the basal ice at KIS-GZ contained a similar concentration and vertical distribution of poorly sorted sediment. 
Sedimentary model and conclusions

Basal melt rates of the Ross Ice Shelf in the vicinity of the KIS-GZ site were measured during the 2019-2020 field season. Basal ice at the modern grounding line melts at a rate of $\sim 0.9-1.2 \mathrm{~m} /$ year (Horgan, pers. comm., 2021). Basal melt rates when the grounding line was actively retreating were likely much higher. Modern basal melt at the KIS-GZ borehole is $\sim 0.35 \mathrm{~m} /$ year (Horgan, pers. comm., 2021).

\subsection{Streaming flow conditions $\left(T_{1} ;>160\right.$ years ago; Figure 44)}

Prior to KIS stagnating, the core site was covered by grounded ice. The ice probably flowed over a basal till at rates of several hundred $\mathrm{m} /$ year, transporting significant volumes of englacial and subglacial sediment to the grounding line, $25 \mathrm{~km}$ seaward of its present position. The character of the till was likely similar to the till recovered from beneath KIS at UpC (Vogel, 2004). High pore water pressure (e.g. Engelhardt \& Kamb, 1997) would have lubricated the bed and hydrostatically supported much of the load of the ice stream, resulting in low compaction of the sediment and low erosion rates (an important consideration for temporal continuity in the context of deeper drilling at this site). Regelation and basal freeze-on likely generated a 10-15 m thick layer of sediment-laden basal ice (Christoffersen et al., 2010; Engelhardt \& Kamb, 2013), with sediment concentrations decreasing with height above the till-ice interface.

\subsection{Stagnation and retreat $\left(T_{2} ;\right.$ 160-35 years ago; Figure 44$)$}

Stagnation of KIS approximately 160 years ago appears to have initiated a period of grounding line retreat (Horgan et al., 2017). Using Horgan et al. (2017)'s linear retreat rate of $200 \mathrm{~m} /$ year, the grounding line would have retreated past the core site 55 years ago. With fresh sediment no longer being supplied by the ice stream, sedimentation along the retreat pathway would have been generated entirely by the release of englacial sediment as the stagnant ice melted, which would have been deposited atop the subglacial till exposed by retreat of the grounding line. The total volume of sediment available to accumulate was controlled by the abundance of sediment in the overlying ice. With sediment concentrated in the lower several metres of basal ice and high basal melt associated with the retreat, based on the mass flux calculation for this period below sedimentation would have been rapid.

$$
\mathrm{T}_{\mathrm{sed}}=\mathrm{C}_{\mathrm{sed}} * \mathrm{Lt} * \mathrm{Mr} *\left(1 /\left(1-\mathrm{P}_{\mathrm{gzw}}\right)\right)
$$


Where $T_{\text {sed }}$ is the total accumulated sediment in metres, $C_{\text {sed }}$ is the concentration of sediment in the ice shelf, Lt is the thickness of the sediment-bearing ice layer in metres, $\mathrm{Mr}$ is the rate of basal melt of the ice shelf in metres, and $\mathrm{Pgzw}_{\mathrm{g}}$ is the porosity of the deposit.

$$
\begin{aligned}
& C_{\text {sedA }}=0.20 \\
& \mathrm{Lt}_{\mathrm{A}}=8.2 \\
& \mathrm{Mr}=1 \mathrm{~m} / \mathrm{yr} \\
& P_{\text {gzw }}=0.25 \\
& \mathrm{~T}_{\text {sedA }}=2.19 \mathrm{~m} \\
& C_{\text {sedB }}=0.05 \\
& \mathrm{Lt}_{\mathrm{B}}=7.3 \\
& \mathrm{Mr}=1 \mathrm{~m} / \mathrm{yr} \\
& P_{g z w}=0.25 \\
& \mathrm{~T}_{\text {sedB }}=0.49 \mathrm{~m} \\
& \mathrm{~T}_{\text {sedA }}+\mathrm{T}_{\text {sedB }}=2.67 \mathrm{~m}
\end{aligned}
$$

Sedimentation rate $=17.2 \mathrm{~cm} /$ year 
Sedimentary model and conclusions

The above equations indicate that up to $2.67 \mathrm{~m}$ of sediment may have been deposited at the core site over 15.5 years, assuming a basal melt rate of $1 \mathrm{~m} /$ year (present KIS GL melt rate; Horgan, pers. comm., 2021), comparable sediment distribution to UpC (e.g. Figure 43; Christoffersen et al., 2010), and similar sediment porosity to deposits at the Whillans grounding zone (Alley et al., 1987). Approximately half of the sediment would have been deposited within five years.

The sedimentation rate at the core site is a function of the basal melt rate, but, critically, the total volume of sediment accumulated cannot exceed the volume of sediment contained in the ice overlying the core site, because without a flowing ice stream there is no source of new sediment. That is, once the ice shelf stagnated, the only sediment available to be deposited is that which is above the seabed at the time of stagnation. Since almost all sediment in ice streams is observed to be concentrated in the lower few metres via regelation and freeze-on of basal till, the composition of the rained-out

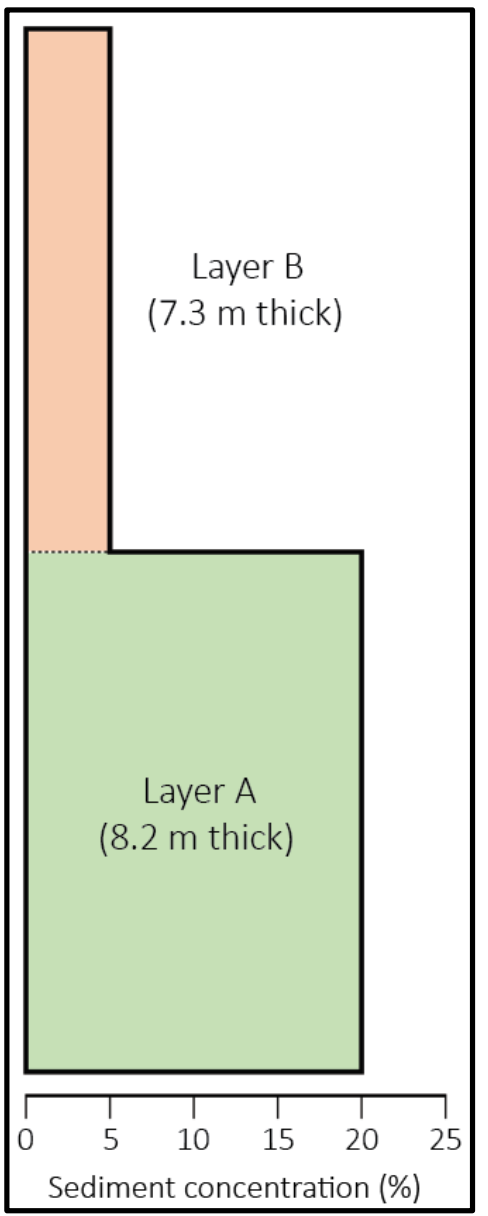

Figure 43: Schematic of the concentration of sediment in basal ice observed at UpC. The bottom $8.2 \mathrm{~m}$ of ice contain $\sim 82 \%$ of the total sediment volume. sediment would be comparable to the basal tills recovered higher in the KIS catchment. Texturally, expected deposits would be extremely poorly sorted, uncompacted, and lack the stratification typical of grounding-line proximal deposits, given the diminished fluid sorting processes associated with the reduced subglacial drainage following ice stream stagnation. The thin water column would also have limited hydrodynamic grading of the particles as they settled. This grounding line configuration is likely associated with the generation of a series of decimetre-scale bedforms, which must have developed after the bulk of the basal sediment had been deposited otherwise they would be buried (discussed in Chapter 2).

\subsection{Static grounding line $\left(T_{3},<35\right.$ years ago; Figure 44$)$}

Assuming a melt rate of $1 \mathrm{~m} /$ year, the $15.5 \mathrm{~m}$-thick layer of sediment-laden basal ice at the core site would have been completely melted by approximately 40 years ago. With 
the ice stream remaining stagnant, the sediment supply mechanism outlined in $T_{2}$ would continue to operate. However, the basal melt rate would be lower, owing to increased distance from the grounding line; measurements over the 2019-2020 season recorded a melt rate of $0.35 \mathrm{~m} /$ year at the borehole. Additionally, with the bulk of accreted basal ice melted, the sediment concentration would be much lower. The sediment concentration in the base of the modern ice shelf was not measured, but imagery indicates that sediment abundance is very low and, in some places, is absent. Here I adopt a representative uniform sediment concentration of $0.5 \%$.

This equation uses the same parameters as the equations above but substitutes years (Ye) for the thickness of the sediment-bearing ice layer since time becomes the factor limiting total sediment accumulation. Here I use 40 years, based on the calculated timing of linear retreat over the core site minus the $\sim 15$ years required to melt the sedimentladen basal $15 \mathrm{~m}$ of ice.

$$
\begin{aligned}
& \mathrm{T}_{\mathrm{sed}}=\mathrm{C}_{\mathrm{sed}} * \mathrm{Ye}^{*} \mathrm{Mr} *\left(1 /\left(1-\mathrm{P}_{\mathrm{gzw}}\right)\right) \\
& \mathrm{Mr}=0.35 \mathrm{~m} / \mathrm{yr} \quad \mathrm{C}_{\text {sed }}=0.005 \quad \mathrm{Ye}=40 \quad \mathrm{P}_{\mathrm{gzw}}=0.25 \\
& \mathrm{~T}_{\text {sed }}=0.093 \mathrm{~m}
\end{aligned}
$$

\section{Sedimentation rate $=0.23 \mathrm{~cm} /$ year}

While calculated sedimentation rates over the past several decades are low, the presence of widespread dropstones and dropstone craters across the studied sea floor confirms that rainout sedimentation is ongoing. The change in sedimentation rate is unlikely to be distinguishable from the lithological characteristics of deposits because the depositional process is the same for both $T_{2}$ and $T_{3}$. Ripples and winnowed sands throughout the study area indicate that the modern sea floor is influenced by a spatially and temporally variable current regime based on the sedimentological evidence discussed in Chapter 2. 


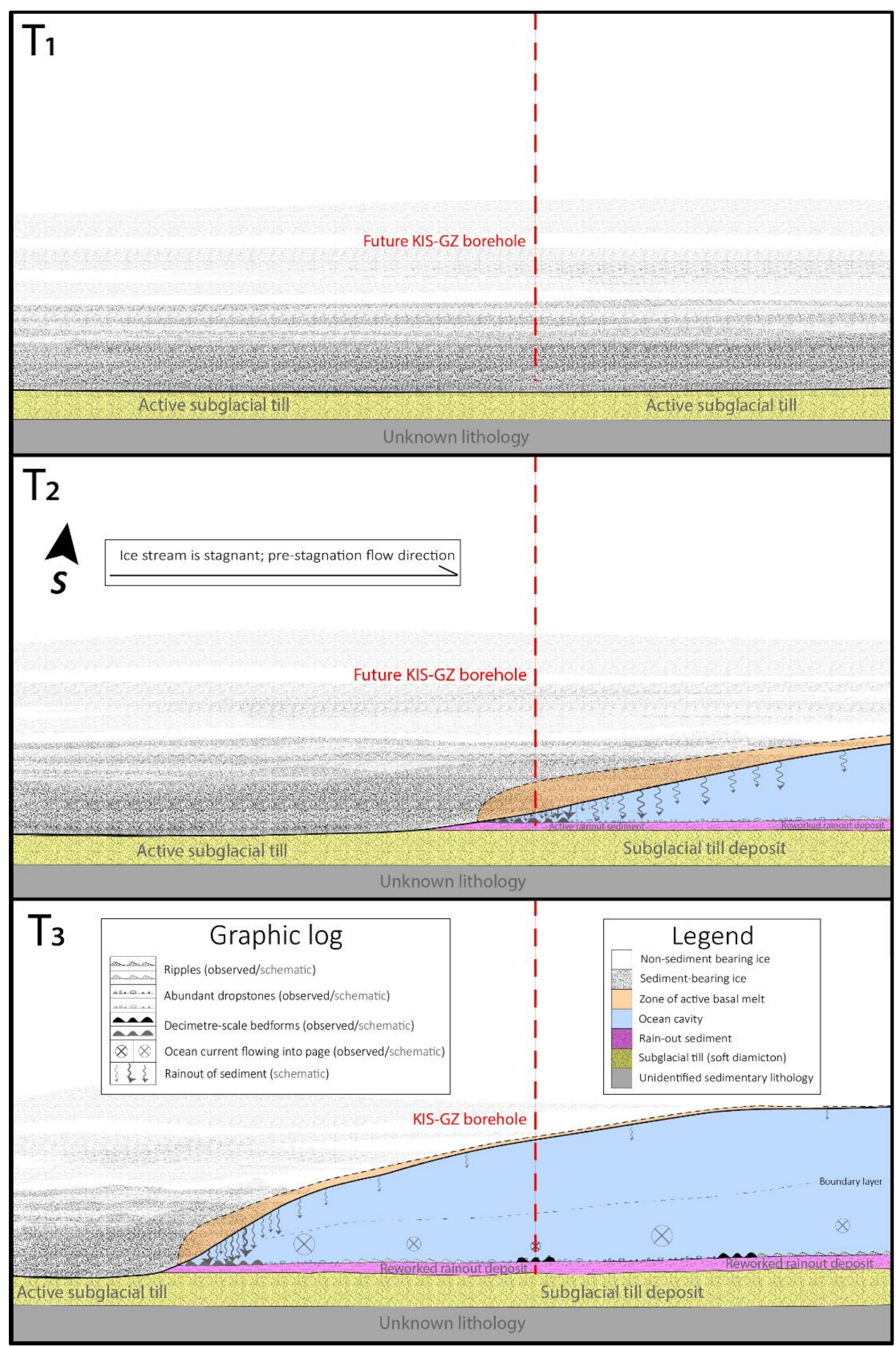

Figure 44: Schematic sedimentary model for time evolution of KIS-GZ depositional environment. T1, prior to KIS stagnation, features grounded ice flowing over a deformable subglacial till. Englacial sediment is concentrated in a 10-15 m thick layer of basal ice, with only trace amounts of sediment above this. During $T 2$, the retreat of the GL following stagnation exposes the KIS-GZ core site to the ocean, resulting in rapid basal melt of the ice shelf and release of the 
englacial material, which is rained-out on the sea floor. Decimetre scale bedforms are generated on the sea floor in the thin ocean cavity by ice-water-sediment interactions. T3, equivalent to today, features an expanded ocean cavity and spatially and temporally variable currents, which rework the rain-out sediment to form a patchwork sea floor texture at $\mathrm{km}$ scale. Sedimentation rates are low.

\subsection{Summary and conclusions}

1. The sediment deposited at the KIS-GZ core site is derived from higher in the Kamb catchment and was transported to the grounding zone by the Kamb Ice Stream before it stagnated. Differential upstream erosion is the cause of sediment compositional variability at the grounding zone, but lack of sorting within the ice stream means the textural characteristics of the sediment deposited on the seafloor are reasonably constant.

2. Following stagnation of the ice stream $\sim 160$ years ago, the KIS grounding line retreated $\sim 25 \mathrm{~km}$ before stabilising at its current position. Rapid melt of the ice shelf base as the grounding line retreated released large volumes of sediment entrained in basal ice layers, which was deposited via rain-out. The texture and composition of the rain-out sediment reflected that of the sediment previously entrained in the base of the flowing ice stream. The bulk of the entrained sediment was likely deposited well within a decade of exposure to the ocean cavity. After the sediment-laden basal ice layers were melted and melt rates had slowed following further grounding line retreat, the sedimentation rate decreased dramatically.

3. Within the last several years, a spatially and temporally variable current regime has interacted with the rained-out sediment on the sea floor, in places generating ripples and in others winnowing fine-grained sediment to leave lag deposits of coarse sand and dropstones. This is likely an ongoing process.

Overall, the depositional facies and sedimentary processes observed at KIS-GZ are consistent with generic glaciomarine facies models (e.g. Smith et al. (2019)) where grounding zone sedimentation is dominated by the deposition of diamicton melted from overlying ice. Observation of the seafloor in the study area has highlighted the local factors that have determined the processes by which such deposition - and subsequent modification - take place. The implications for a deep drill core at 
Sedimentary model and conclusions

(nearly) the same location are that the generic glaciomarine facies model is (unsurprisingly) a sound basis for interpreting ice shelf dynamics. Importantly, details of ice shelf dynamics under glacial (i.e. not open water) conditions may be determined from changing source sediment provenance, which modelling suggests changes markedly as the Antarctic Ice Sheets expand and contract. Lastly, determining the age of deposition will be an ongoing challenge. 


\section{References}

Alley, R B, Blankenship, D. D., Bentley, C. R., \& Rooney, S. T. (1987). Till beneath ice stream B: 3. Till deformation: evidence and implications. Journal of Geophysical Research: Solid Earth, 92(B9), 8921-8929.

Alley, Richard B., Blankenship, D. D., Rooney, S. T., \& Bentley, C. R. (1989).

Sedimentation beneath ice shelves - the view from ice stream B. Marine Geology, 85(2-4), 101-120.

Alley, Richard B, Cuffey, K. M., Evenson, E. B., Strasser, J. C., Lawson, D. E., \& Larson, G. J. (1997). How glaciers entrain and transport basal sediment: physical constraints. Quaternary Science Reviews, 16(9), 1017-1038.

Anandakrishnan, S., \& Alley, R. B. (1997). Stagnation of ice stream C, West Antarctica by water piracy. Geophysical Research Letters, 24(3), 265-268.

Anandakrishnan, S., Alley, R. B., Jacobel, R. W., \& Conway, H. (2001). The Flow Regime of Ice Stream C and Hypotheses Concerning Its Recent Stagnation. In Richard B. Alley \& R. A. Bindschadler (Eds.), The West Antarctic Ice Sheet: Behavior and Environment (Vol. 77, pp. 283-296). American Geophysical Union. https://doi.org/10.1029/ar077p0283

Anandakrishnan, S., Catania, G. A., Alley, R. B., \& Horgan, H. J. (2007). Discovery of till deposition at the grounding line of Whillans Ice Stream. Science, 315(5820), 1835-1838.

Andrews, J. T., Domack, E. W., Cunningham, W. L., Leventer, A., Licht, K. J., Jull, A. J. T. T., DeMaster, D. J., \& Jennings, A. E. (1999). Problems and possible solutions concerning radiocarbon dating of surface marine sediments, Ross Sea, Antarctica. Quaternary Research, 52(2), 206-216. https://doi.org/10.1006/qres.1999.2047

Atre, S. R., \& Bentley, C. R. (1993). Laterally varying basal conditions beneath Ice Streams B and C, West Antarctica. Journal of Glaciology, 39(133), 507-514.

Baas, J. H. (1994). An empirical model for the development and equilibrium morphology of current ripples in fine sand. Sedimentology, 41, 185-209. https://doi.org/10.1046/j.1365-3091.1999.00206.x 
References

Begeman, C. B., Tulaczyk, S. M., Marsh, O. J., Mikucki, J. A., Stanton, T. P., Hodson, T. O., Siegfried, M. R., Powell, R. D., Christianson, K., \& King, M. A. (2018). Ocean Stratification and Low Melt Rates at the Ross Ice Shelf Grounding Zone. Journal of Geophysical Research: Oceans, 123(10), 7438-7452. https://doi.org/10.1029/2018JC013987

Bell, R. E., Blankenship, D. D., Finn, C. A., Morse, D. L., Scambos, T. A., Brozena, J. M., \& Hodge, S. M. (1998). Influence of subglacial geology on the onset of a West Antarctic ice stream from aerogeophysical observations. Nature, 394(6688), 5862.

Bennett, M. R., Doyle, P., \& Mather, A. E. (1996). Dropstones: their origin and significance. Palaeogeography, Palaeoclimatology, Palaeoecology, 121(3-4), 331339.

Blankenship, D. D., Bell, R. E., Hodge, S. M., Brozena, J. M., Behrendt, J. C., \& Finn, C. A. (1993). Active volcanism beneath the West Antarctic ice sheet and implications for ice-sheet stability. Nature, 361(6412), 526-529.

Blankenship, D. D., Bentley, C. R., Rooney, S. T., \& Alley, R. B. (1987). Till beneath Ice Stream B: 1. Properties derived from seismic travel times. Journal of Geophysical Research: Solid Earth, 92(B9), 8903-8911.

Blatt, H., Middleton, G. V, \& Murray, R. C. (1972). Origin of sedimentary rocks.

Boggs Jr, S. (2014). Principles of sedimentology and stratigraphy (4th ed.). Pearson Education.

Bosello, F., Nicholls, R. J., Richards, J., Roson, R., \& Tol, R. S. J. (2012). Economic impacts of climate change in Europe: sea-level rise. Climatic Change, 112(1), 6381. https://doi.org/10.1007/s10584-011-0340-1

Brink, J., Jarrard, R. D., Krissek, L. A., \& Wilson, T. (1998). Lonestone abundance and size variations in CRP-1 drillhole, Victoria Land Basin, Antarctica. Terra Antartica, 5(3), 367-374.

Bronikowska, M., Pisarska-Jamroży, M., \& van Loon, A. J. (2021). Dropstone deposition: Results of numerical process modeling of deformation structures, and implications for the reconstruction of the water depth in shallow lacustrine and marine successions. Journal of Sedimentary Research, 91(5), 507-519. 
Bushuk, M., Bushuk, M., Holland, D. M., Stanton, T. P., Stern, A., \& Gray, C. (2019). Ice scallops: a laboratory investigation of the ice-water interface. Journal of Fluid Mechanics, 873, 942-976. https://doi.org/10.1017/jfm.2019.398

Catania, G., Hulbe, C., Conway, H., Scambos, T. A., \& Raymond, C. F. (2012). Variability in the mass flux of the Ross ice streams, West Antarctica, over the last millennium. Journal of Glaciology, 58(210), 741-752. https://doi.org/10.3189/2012JoG11J219

Christianson, K., Jacobel, R. W., Horgan, H. J., Alley, R. B., Anandakrishnan, S., Holland, D. M., \& DallaSanta, K. J. (2016). Basal conditions at the grounding zone of Whillans Ice Stream, West Antarctica, from ice-penetrating radar. Journal of Geophysical Research: Earth Surface, 121(11), 1954-1983.

Christoffersen, P., Tulaczyk, S., \& Behar, A. (2010). Basal ice sequences in Antarctic ice stream: Exposure of past hydrologic conditions and a principal mode of sediment transfer. Journal of Geophysical Research: Earth Surface, 115(3), 1-12. https://doi.org/10.1029/2009JF001430

Clark, P. U., He, F., Golledge, N. R., Mitrovica, J. X., Dutton, A., Hoffman, J. S., \& Dendy, S. (2020). Oceanic forcing of penultimate deglacial and last interglacial sea-level rise. Nature, 577(7792), 660-664. https://doi.org/10.1038/s41586-020-1931-7

Cody, R. D., Levy, R. H., Harwood, D. M., \& Sadler, P. M. (2008). Thinking outside the zone: High-resolution quantitative diatom biochronology for the Antarctic Neogene. Palaeogeography, Palaeoclimatology, Palaeoecology, 260(1-2), 92121. https://doi.org/10.1016/j.palaeo.2007.08.020

Coenen, J. J. (2016). Inferring West Antarctic Subglacial Basin History and Ice Stream Processes Using Siliceous Microfossils. Northern Illinois University.

Conway, H., Catania, G., Raymond, C. F., Gades, A. M., Scambos, T. A., \& Engelhardt, H. (2002). Switch of flow direction in an antarctic ice stream. Nature, 419(6906), 465-467. https://doi.org/10.1038/nature01081

Costello, W. R., \& Southard, J. B. (1981). Flume experiments on lower flow regime bed forms in coarse sand. Journal of Sedimentary Petrology, 51(3), 849-864. 
References

Craddock, J. P., Schmitz, M. D., Crowley, J. L., Larocque, J., Pankhurst, R. J., Juda, N., Konstantinou, A., \& Storey, B. (2017). Precise U-Pb zircon ages and geochemistry of Jurassic granites, Ellsworth-Whitmore terrane, central Antarctica. GSA Bulletin, 129(1-2), 118-136.

Deconto, R. M., \& Pollard, D. (2016). Contribution of Antarctica to past and future sealevel rise. Nature, 531(7596), 591-597. https://doi.org/10.1038/nature17145

Domack, E. W., \& Harris, P. T. (1998). A new depositional model for ice shelves, based upon sediment cores from the Ross Sea and the Mac. Robertson shelf, Antarctica. Annals of Glaciology, 27, 281-284.

Domack, E. W., Jacobson, E. A., Shipp, S., \& Anderson, J. B. (1999). Late Pleistocene-Holocene retreat of the West Antarctic Ice-Sheet system in the Ross Sea: Part 2sedimentologic and stratigraphic signature. Geological Society of America Bulletin, 111(10), 1517-1536.

Douglas L. Inman. (1949). Sorting of Sediments in the Light of Fluid Mechanics. SEPM Journal of Sedimentary Research, Vol. 19(427). https://doi.org/10.1306/d426934b-2b26-11d7-8648000102c1865d

Dowdeswell, J. A., Cofaigh, C. Ó., Pudsey, C. J., Ó Cofaigh, C., \& Pudsey, C. J. (2004). Thickness and extent of the subglacial till layer beneath an Antarctic paleo-ice stream. Geology, 32(1), 13-16. https://doi.org/10.1130/G19864.1

Dutton, A., Carlson, A. E., Long, Aj., Milne, G. A., Clark, P. U., DeConto, R., Horton, B. P., Rahmstorf, S., \& Raymo, M. E. (2015). Sea-level rise due to polar ice-sheet mass loss during past warm periods. Science, 349(6244).

Engelhardt, H., \& Kamb, B. (1997). Basal hydraulic system of a West Antarctic ice stream: constraints from borehole observations. Journal of Glaciology, 43(144), 207-230.

Engelhardt, H., \& Kamb, B. (2013). Kamb Ice Stream flow history and surge potential. Annals of Glaciology, 54(63), 287-298. https://doi.org/10.3189/2013AoG63A535

Fretwell, P., Pritchard, H. D., Vaughan, D. G., Bamber, J. L., Barrand, N. E., Bell, R., Bianchi, C., Bingham, R. G., Blankenship, D. D., Casassa, G., Catania, G., Callens, D., Conway, H., Cook, A. J., Corr, H. F. J., Damaske, D., Damm, V., Ferraccioli, F., Forsberg, R., ... Zirizzotti, A. (2013). Bedmap2: Improved ice bed, surface and 
thickness datasets for Antarctica. Cryosphere, 7(1), 375-393.

https://doi.org/10.5194/tc-7-375-2013

Gallagher, S. J., Fulthorpe, C. S., Bogus, K., Auer, G., Baranwal, S., Castañeda, I. S., Christensen, B. A., De Vleeschouwer, D., Franco, D. R., Groeneveld, J., Gurnis, M., Haller, C., He, Y., Henderiks, J., Himmler, T., Ishiwa, T., Iwatani, H., Jatiningrum, R. S., Kominz, M. A., ... Zhang, W. (2017). Expedition 356 methods (Vol. 356, Issue February). International Ocean Discovery Program. https://doi.org/10.14379/iodp.proc.356.102.2017

Goldich, S. S. (1938). A study in rock-weathering. The Journal of Geology, 46(1), 17-58. Golledge, N. R., Clark, P. U., He, F., Dutton, A., Turney, C. S. M., Fogwill, C. J., Naish, T. R., Levy, R. H., Mckay, R. M., Lowry, D. P., Bertler, N. A. N., Dunbar, G. B., \& Carlson, A. E. (2021). Retreat of the Antarctic Ice Sheet During the Last Interglaciation and Implications for Future Change. Geophysical Research Letters, 48(17), 1-11. https://doi.org/10.1029/2021gl094513

Harwood, D M. (1986). Diatoms. Antarctic Cenozoic history from the MSSTS-1 drillhole, McMurdo Sound. DSIR Bulletin, 237, 69-107.

Harwood, David M, Scherer, R. P., \& Webb, P.-N. N. (1989). Multiple Miocene Marine Productivity Events in West Antarctica as Recorded in Upper Miocene Sediments Beneath the Ross Ice Shelf (Site J-9). Marine Micropaleontology, 91(115), 91-115. Holland, P. R. (2008). A model of tidally dominated ocean processes near ice shelf grounding lines. Journal of Geophysical Research: Oceans, 113(C11), 1-15. https://doi.org/10.1029/2007JC004576

Horgan, H. J., \& Anandakrishnan, S. (2006). Static grounding lines and dynamic ice streams: Evidence from the Siple Coast, West Antarctica. Geophysical Research Letters, 33(18), 1-6. https://doi.org/10.1029/2006GL027091

Horgan, H. J., Hulbe, C., Alley, R. B., Anandakrishnan, S., Goodsell, B., Taylor-Offord, S., \& Vaughan, M. J. (2017). Poststagnation Retreat of Kamb Ice Stream's Grounding Zone. Geophysical Research Letters, 44(19), 9815-9822. https://doi.org/10.1002/2017GL074986 
References

Horgan, Huw J, Christianson, K., Jacobel, R. W., Anandakrishnan, S., \& Alley, R. B. (2013). Sediment deposition at the modern grounding zone of Whillans Ice Stream, West Antarctica. Geophysical Research Letters, 40(15), 3934-3939. https://doi.org/10.1002/grl.50712

Horrigan, S. G. (1981). Primary production under the Ross Ice Shelf, Antarctica 1. Limnology and Oceanography, 26(2), 378-382.

Jordan, T. A., Riley, T. R., \& Siddoway, C. S. (2020). The geological history and evolution of West Antarctica. Nature Reviews Earth \& Environment, 1(2), 117-133.

Joughin, I., \& Alley, R. B. (2011). Stability of the West Antarctic ice sheet in a warming world. Nature Geoscience, 4(8), 506-513. https://doi.org/10.1038/ngeo1194 Joughin, I., \& Tulaczyk, S. (2002). Positive mass balance of the Ross Ice Streams, West Antarctica. Science, 295(5554), 476-480. https://doi.org/10.1126/science.1066875

Joughin, I., Tulaczyk, S., Bindschadler, R., \& Price, S. F. (2002). Changes in West Antarctic ice stream velocities: observation and analysis. Journal of Geophysical Research: Solid Earth, 107(B11), EPM--3. https://doi.org/10.1029/2001jb001029

Kamb, B. (2001). Basal zone of the West Antarctic ice streams and its role in lubrication of their rapid motion. The West Antarctic Ice Sheet: Behavior and Environment, 77, 157-199.

Kellogg, T. B., Truesdale, R. S., \& Osterman, L. E. (1979). Late Quaternary extent of the West Antarctic ice sheet: new evidence from Ross Sea cores. Geology, 7(5), 249253.

Kingslake, J., Scherer, R. P., Albrecht, T., Coenen, J., Powell, R. D., Reese, R., Stansell, N. D., Tulaczyk, S., Wearing, M. G., \& Whitehouse, P. L. (2018). Extensive retreat and re-advance of the West Antarctic Ice Sheet during the Holocene. Nature, 558(7710), 430-434. https://doi.org/10.1038/s41586-018-0208-x

Konert, M., \& Vandenberghe, J. E. F. (1997). Comparison of laser grain size analysis with pipette and sieve analysis: a solution for the underestimation of the clay fraction. Sedimentology, 44(3), 523-535.

Kyle, P. R., Jezek, P. A., Mosley-Thompson, E., \& Thompson, L. G. (1981). Tephra layers 
in the Byrd Station ice core and the Dome C ice core, Antarctica and their climatic importance. Journal of Volcanology and Geothermal Research, 11(1), 29-39. https://doi.org/10.1016/0377-0273(81)90073-1

Kyle, P. R., Peter, A. J. E. Z. E. K., \& Jezek, P. A. (1978). Compositions of three tephra layers from the Byrd Station ice core, Antarctica. Journal of Volcanology and Geothermal Research, 4(3-4), 225-232.

Licht, K J, Dunbar, N. W., Andrews, J. T., \& Jennings, A. E. (1999). Distinguishing subglacial till and glacial marine diamictons in the western Ross Sea, Antarctica: Implications for a last glacial maximum grounding line. Geological Society of America Bulletin, 111(1), 91-103.

Licht, Kathy J, Cunningham, W. L., Andrews, J. T., Domack, E. W., \& Jennings, A. E. (1998). Establishing chronologies from acid-insoluble organic 14C dates on Antarctic (Ross Sea) and Arctic (North Atlantic) marine sediments. Polar Research, $17(2), 203-216$.

Licht, Kathy J, Hennessy, A. J., \& Welke, B. M. (2014). The U-Pb detrital zircon signature of West Antarctic ice stream tills in the Ross embayment, with implications for Last Glacial Maximum ice flow reconstructions. Antarctic Science, 26(6), 687-697.

Licht, Kathy J, Lederer, J. R., \& Swope, R. J. (2005). Provenance of LGM glacial till (sand fraction) across the Ross embayment, Antarctica. Quaternary Science Reviews, 24(12-13), 1499-1520. https://doi.org/10.1016/j.quascirev.2004.10.017

Lindholm, R. (2012). A practical approach to sedimentology. Springer Science \& Business Media.

Lythe, M. B., \& Vaughan, D. G. (2001). BEDMAP: A new ice thickness and subglacial topographic model of Antarctica. Journal of Geophysical Research, 106(B6), $11335-11351$

MacAyeal, D. R. (1984). Thermohaline circulation below the Ross Ice Shelf: A consequence of tidally induced vertical mixing and basal melting. Journal of Geophysical Research: Oceans, 89(C1), 597-606.

McBride, E. F. (1963). A classification of common sandstones. Journal of Sedimentary 
References

Research, 33(3), 664-669.

Michael J. Hambrey, Barrett, P. J., \& Powell, R. D. (2002). Late Oligocene and early Miocene glacimarine sedimentation in the SW Ross Sea, Antarctica: the record from offshore drilling. Geological Society, London, Special Publications, 203(1), $105-128$.

Miller, K. G., Wright, J. D., Browning, J. V, Kulpecz, A., Kominz, M., Naish, T. R., Cramer, B. S., Rosenthal, Y., Peltier, W. R., \& Sosdian, S. (2012). High tide of the warm Pliocene: Implications of global sea level for Antarctic deglaciation. Geology, 40(5), 407-410.

Moncrieff, A. C. M. M. (1989). Classification of poorly-sorted sedimentary rocks. Sedimentary Geology, 65(1-2), 191-194. https://doi.org/10.1016/00370738(89)90015-8

Naish, T., Powell, R., Levy, R., Wilson, G., Scherer, R., Talarico, F., Krissek, L., Niessen, F., Pompilio, M., Wilson, T., Carter, L., DeConto, R., Huybers, P., McKay, R., Pollard, D., Ross, J., Winter, D., Barrett, P., Browne, G., ... others. (2009). Obliquity-paced Pliocene West Antarctic ice sheet oscillations. Nature, 458(7236), 322-328. https://doi.org/10.1038/nature07867

Ng, F., \& Conway, H. (2004). Fast-flow signature in the stagnated Kamb Ice Stream, West Antarctica. Geology, 32(6), 481-484. https://doi.org/10.1130/G20317.1

Nicholls, R. J., Marinova, N., Lowe, J. A., Brown, S., Vellinga, P., De Gusmao, D., Hinkel, J., \& Tol, R. S. J. (2011). Sea-level rise and its possible impacts given a 'beyond $4 \circ \mathrm{C}$ world ' in the twenty-first century. Philosophical Transactions of the Royal Society A: Mathematical, Physical and Engineering Sciences, 369, 161-181. https://doi.org/10.1098/rsta.2010.0291

Passchier, S., Browne, G., Field, B., Fielding, C. R., Krissek, L. A., Panter, K., \& Pekar, S. F. (2011). Early and middle miocene antarctic glacial history from the sedimentary facies distribution in the AND-2A drill hole, Ross sea, Antarctica. Bulletin of the Geological Society of America, 123(11-12), 2352-2365. https://doi.org/10.1130/B30334.1

Peters, L. E., Anandakrishnan, S., Alley, R. B., Winberry, J. P., Voigt, D. E., Smith, A. M., \& Morse, D. L. (2006). Subglacial sediments as a control on the onset and location 
of two Siple Coast ice streams, West Antarctica. Journal of Geophysical Research: Solid Earth, 111(B1).

Powell, R. D. (1990). Glacimarine processes at grounding-line fans and their growth to ice-contact deltas. Geological Society, London, Special Publications, 53(1), 53-73. https://doi.org/10.1144/GSL.SP.1990.053.01.03

Price, S. F., Bindschadler, R. A., Hulbe, C. L., \& Joughin, I. R. (2001). Post-stagnation behavior in the upstream regions of Ice Stream C, West Antarctica. Journal of Glaciology, 47(157), 283-294. https://doi.org/10.3189/172756501781832232

Priscu, J. C., Downes, M. T., Priscu, L. R., Palmisano, A. C., \& Sullivan, C. W. (1990). Dynamics of ammonium oxidizer activity and nitrous oxide (N20) within and beneath Antarctic sea ice. Marine Ecology Progress Series, 62, 37-46.

Reilly, B. T., Stoner, J. S., \& Wiest, J. (2017). Sed CT: MATLAB ${ }^{T M}$ tools for standardized and quantitative processing of sediment core computed tomography (CT) data collected using a medical CT scanner. Geochemistry, Geophysics, Geosystems, 18(8), 3231-3240.

Retzlaff, R., \& Bentley, C. R. (1993). Timing of stagnation of ice stream C, West Antarctica, from short- pulse radar studies of buried surface crevasses. Journal of Glaciology, 39(133), 553-561. https://doi.org/10.1017/\$0022143000016440

Rooney, S T, Blankenship, D. D., Alley, R. B., \& Bentley, C. R. (1987). Till beneath ice stream B: 2. Structure and continuity. Journal of Geophysical Research: Solid Earth, 92(B9), 8913-8920.

Rooney, S T, Blankenship, D. D., Alley, R. B., \& Bentley, C. R. (1991). Seismic reflection profiling of a sediment-filled graben beneath ice stream B, West Antarctica. International Symposium on Antarctic Earth Sciences. 5, 261-265.

Rooney, Sean T, Blankenship, D. D., Alley, R. B., \& Bentley, C. R. (1988). SeismicReflection Profiling of a Widespread Till Beneath Ice Stream B, West Antarctica. Annals of Glaciology, 11, 210.

Rosenheim, B. E., Day, M. B., Domack, E., Schrum, H., Benthien, A., \& Hayes, J. M. (2008). Antarctic sediment chronology by programmed-temperature pyrolysis: 
References

Methodology and data treatment. Geochemistry, Geophysics, Geosystems, 9(4), 1-16. https://doi.org/10.1029/2007GC001816

Roser, B. P., \& Pyne, A. R. (1989). Antarctic Cenozoic History from the CIROS-1 drillhole, McMurdo Sound: Wholerock geochemistry (DSIR Bulletin, Vol. 245).

Sackett, W. M., Poag, C. W., \& Eadie, B. J. (1974). Kerogen recycling in the Ross sea, Antarctica. Science, 185(4156), 1045-1047.

Scherer, R. P. (1991). Quaternary and Tertiary microfossils from beneath Ice Stream B: Evidence for a dynamic West Antarctic Ice Sheet history. Global and Planetary Change, 4(4), 395-412. https://doi.org/10.1016/0921-8181(91)90005-H

Scherer, R. P., Aldahan, A., Tulaczyk, S., Possnert, G., Engelhardt, H., \& Kamb, B. (1998). Pleistocene collapse of the West Antarctic ice sheet. Science, 281(5373), 82-85. https://doi.org/10.1126/science.281.5373.82

Scherer, R. P., Powell, R. D., Coenen, J. J., Hodson, T. O., Puttkammer, R., \& Tulaczyk, S. M. (2015). Geological and paleontological results from the WISSARD (Whillans Ice Stream Subglacial Access Research Drilling) Project. AGU Fall Meeting Abstracts, 2015, C11C--0769.

Schoof, C. (2007). Ice sheet grounding line dynamics: Steady states, stability, and hysteresis. Journal of Geophysical Research: Earth Surface, 112(F3), 1-19. https://doi.org/10.1029/2006JF000664

Smith, J. A., Graham, A. G. C. C., Post, A. L., Hillenbrand, C.-D. D., Bart, P. J., \& Powell, R. D. (2019). The marine geological imprint of Antarctic ice shelves. Nature Communications, 10(1), 1-16. https://doi.org/10.1038/s41467-019-13496-5

Smith, M. W., Carrivick, J. L., \& Quincey, D. J. (2016). Structure from motion photogrammetry in physical geography. Progress in Physical Geography, 40(2), 247-275.

Stocker, T. (2014). Climate change 2013: the physical science basis: Working Group I contribution to the Fifth assessment report of the Intergovernmental Panel on Climate Change. Cambridge university press.

Stow, D. A. V. V, Hernández-Molina, F. J., Llave, E., Sayago-Gil, M., Díaz-del Río, V., Branson, A., del $R \backslash \backslash \backslash$ io, V., \& Branson, A. (2009). Bedform-velocity matrix: The 
estimation of bottom current velocity from bedform observations. Geology, 37(4), 327-330. https://doi.org/10.1130/G25259A.1

Studinger, M., Bell, R. E., Blankenship, D. D., Finn, C. A., Arko, R. A., Morse, D. L., \& Joughin, I. (2001). Subglacial sediments: A regional geological template for ice flow in West Antarctica. Geophysical Research Letters, 28(18), 3493-3496.

Subt, C, Yoon, H. I., Yoo, K. C., Lee, J. I., Leventer, A., Domack, E. W., \& Rosenheim, B. E. (2017). Sub-ice shelf sediment geochronology utilizing novel radiocarbon methodology for highly detrital sediments. Geochemistry, Geophysics, Geosystems, 18(4), 1404-1418.

Subt, Cristina, Fangman, K. A., Wellner, J. S., \& Rosenheim, B. E. (2016). Sediment chronology in Antarctic deglacial sediments: Reconciling organic carbon 14C ages to carbonate 14C ages using Ramped PyrOx. The Holocene, 26(2), 265-273.

Tol, R. S. J., Bohn, M., Downing, T. E., Guillerminet, M.-L., Hizsnyik, E., Kasperson, R., Lonsdale, K., Nicholls, R. J., Olsthoorn, A. A., Pfeifle, G., Poumadere, M., Toth, F. L., Vafeidis, A. T., Werff, P. E. Van Der, \& Yetkiner, I. H. (2006). Adaptation to Five Metres of Sea Level Rise Adaptation to Five Metres of Sea Level Rise. Journal of Risk Research, 9(5), 467-482. https://doi.org/10.1080/13669870600717632

Tulaczyk, S., Kamb, B., \& Engelhardt, H. F. (2001). Estimates of effective stress beneath a modern West Antarctic ice stream from till preconsolidation and void ratio. Boreas, 30(2), 101-114.

Tulaczyk, S., Kamb, B., Scherer, R. P., \& Engelhardt, H. F. (1998). Sedimentary processes at the base of a West Antarctic ice stream; constraints from textural and compositional properties of subglacial debris. Journal of Sedimentary Research, 68(3), 487-496. https://doi.org/10.2110/jsr.68.487

Van Der Wel, N., Christoffersen, P., \& Bougamont, M. (2013). The influence of subglacial hydrology on the flow of Kamb Ice Stream, West Antarctica. Journal of Geophysical Research: Earth Surface, 118(1), 97-110.

https://doi.org/10.1029/2012JF002570

van Scheltinga, R. C. T., Coco, G., Kleinhans, M. G., \& Friedrich, H. (2020). Observations 
References

of dune interactions from DEMs using through-water Structure from Motion. Geomorphology, 359, 107126.

Venturelli, R. A., Siegfried, M. R., Roush, K. A., Li, W., Burnett, J., Zook, R., Fricker, H. A., Priscu, J. C., Leventer, A., \& Rosenheim, B. E. (2020). Mid-Holocene grounding line retreat and readvance at Whillans Ice Stream, West Antarctica. Geophysical Research Letters, 47(15), e2020GL088476.

Vogel, S. W. (2004). The Basal Regime of the West-Antarctic Ice Sheet Interaction of Subglacial Geology with Ice Dynamics [University of California Santa Cruz]. http://www.es.ucsc.edu/ svogel/web-thesis.pdf

Webb, P. N., Ronan, T. E., Lipps, J. H., \& DeLaca, T. E. (1979). Miocene glaciomarine sediments from beneath the Southern Ross Ice Shelf, Antarctica. Science, 203(4379), 435-437. https://doi.org/10.1126/science.203.4379.435

Weertman, J. (1974). Stability of the junction of an ice sheet and an ice shelf. Journal of Glaciology, 13(67), 3-11.

Westoby, M. J., Brasington, J., Glasser, N. F., Hambrey, M. J., \& Reynolds, J. M. (2012). 'Structure-from-Motion'photogrammetry: A low-cost, effective tool for geoscience applications. Geomorphology, 179, 300-314.

Whillans, I. M., \& Van Der Veen, C. J. (1993). New and improved determinations of velocity of Ice Streams B and C, West Antarctica. Journal of Glaciology, 39(133), 483-590. https://doi.org/10.3189/s0022143000016373

Wilch, T. I., McIntosh, W. C., \& Dunbar, N. W. (1999). Late Quaternary volcanic activity in Marie Byrd Land: Potential 40Ar/39Ar-dated time horizons in West Antarctic ice and marine cores. Bulletin of the Geological Society of America, 111(10), 15631580. https://doi.org/10.1130/0016-7606(1999)111<1563:LQVAIM>2.3.CO;2

Woodget, A. S., Carbonneau, P. E., Visser, F., \& Maddock, I. P. (2015). Quantifying submerged fluvial topography using hyperspatial resolution UAS imagery and structure from motion photogrammetry. Earth Surface Processes and Landforms, $40(1), 47-64$.

Young, G. M., \& Nesbitt, H. W. (1998). Processes controlling the distribution of Ti and Al in weathering profiles, siliciclastic sediments and sedimentary rocks. Journal of Sedimentary Research, 68(3), 448-455. https://doi.org/10.2110/jsr.68.448 
References 
Appendices

\section{Appendices}

\section{A. Icefin Structure-from-Motion products}

The combined size of the orthomosaics and DEMs is too large to include in the thesis document. The files can be found at:

C: \Users\calkinth.STAFF\OneDrive - Victoria University of Wellington - STAFF\Appendix A - SfM products

Or access granted by emailing Gabrielle Holmes (gabrielle.holmes@vuw.ac.nz). 


\section{B. Geothermal measurements}

\begin{tabular}{|c|c|c|c|c|c|c|c|c|c|c|c|c|c|c|c|c|c|c|c|c|c|c|c|c|c|c|c|c|}
\hline \multirow{2}{*}{ Sample ID } & \multirow{2}{*}{$\begin{array}{c}\frac{K}{W /(m \cdot k)} \\
\end{array}$} & \multirow{2}{*}{$\begin{array}{l}\text { rho } \\
\mathrm{m} \cdot \mathrm{kWN}\end{array}$} & \multirow{2}{*}{\multicolumn{2}{|c|}{$\begin{array}{cc}\mathrm{C} & \mathrm{D} \\
\mathrm{IJ} /\left(\mathrm{m}^{3} \cdot \mathrm{K}\right) \mathrm{mm}^{2} / \mathrm{s}\end{array}$}} & \multirow{2}{*}{ Err } & \multirow{2}{*}{\multicolumn{3}{|c|}{$\begin{array}{l}\text { Temp(0) PowerCurrent } \\
{ }^{\circ} \mathrm{C} \quad \text { W/m amps }\end{array}$}} & \multirow{2}{*}{\multicolumn{3}{|c|}{$\begin{array}{l}\text { Temp } 1 \text { Temp 2 Temp 3 } \\
{ }^{\circ} \mathrm{C} C{ }^{\circ} \mathrm{C} C\end{array}$}} & \multirow{3}{*}{$\begin{array}{c}\text { Temp 4 } \\
{ }^{\circ} \mathrm{C} \\
15.437\end{array}$} & \multirow{3}{*}{\begin{tabular}{|l|} 
Temp 5 \\
${ }^{\circ} \mathrm{C}$ \\
15487
\end{tabular}} & & & & & & & & & & & & & & & \\
\hline & & & & & & & & & & & & & & ${ }^{\circ} \mathrm{C}$ & ${ }^{\circ} \mathrm{C}$ & ${ }^{\circ} \mathrm{C}$ & ${ }^{\circ} \mathrm{C}$ & ${ }^{\circ} \mathrm{C}$ & ${ }^{\circ} \mathrm{C}$ & ${ }^{\circ} \mathrm{C}$ & ${ }^{\circ} \mathrm{C}$ & ${ }^{\circ} \mathrm{C}$ & ${ }^{\circ} \mathrm{C}$ & ${ }^{\circ} \mathrm{C}$ & ${ }^{\circ} \mathrm{C}$ & ${ }^{\circ} \mathrm{C}$ & ${ }^{\circ} \mathrm{C}$ & ${ }^{\circ} \mathrm{C}$ \\
\hline & & & & & 0 & & & & & & & & & & 15629 & 1571 & 15802 & 15894 & 15987 & 16081 & 16.176 & 16270 & 16366 & 16.458 & 16.549 & 16639 & 6725 & 6.811 \\
\hline & 0.433 & & & 224 & & & 21.660 & & 16.020 & 16.029 & .080 & 16.186 & 16.329 & & & 16.862 & & & & & & & & & & & & \\
\hline & 1.367 & & & 50 & & & 910 & & 94 & & 132 & & & & & & & & & & & & & & & & & \\
\hline & 1.358 & & & 76 & 26 & 94 & 940 & 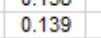 & 42 & 967 & 031 & 113 & 202 & 291 & 377 & .459 & 37 & 10 & 101 & $f$ & & 70 & 227 & 32 & 33 & & 30 & .176 \\
\hline & & & & & & & & & & 23 & 023 & & & & & & & & & & & & & & & & & 299 \\
\hline & 1.469 & & & 09 & 24 & & .940 & 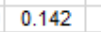 & & 16 & 392 & 84 & 079 & 16.171 & 261 & 16.344 & 24 & 99 & 16.569 & 36 & 16.700 & 31 & 16.818 & 72 & & 74 & 22 & 17.067 \\
\hline KIS1-08 & 1.273 & 36 & 34 & 90 & 029 & 15.65 & 20.860 & 0.142 & 652 & 15.685 & 15.762 & 360 & 15.962 & 16.065 & 164 & 16.258 & 347 & 16.432 & 16.510 & 585 & 16.658 & 16.726 & 16.790 & 51 & 909 & 966 & 20 & 17.071 \\
\hline & 1.569 & & & & & & 20.780 & & & & & 15.768 & & 15.980 & & 16.165 & & & & & & & & 16.698 & & & & 16.887 \\
\hline & 1.55 & & & & & 29 & 710 & & & & 512 & & & & & & & & & & & & & & & & & \\
\hline & 1.7 & & & & & & & & & & & & & & & & & & & & & & & & & & & \\
\hline & 1.8 & & & & 7 & & & & & & & & & & & & & & & & & & & & & & & \\
\hline & 1.7 & & & & 68 & & & & & & & & & & & & & & & & & & & & & & & \\
\hline & & & & & & & & & & & & & & & & & & & & & & & & & & & & $\begin{array}{l}40 \\
17\end{array}$ \\
\hline & 0 & & & & 10 & & 0 & & & & & & & & & & & & & & & & & & & & & 96 \\
\hline 149 & 0.44 & & 000 & 21 & 0.0063 & 86 & 280 & & 859 & 66 & 3 & 11 & 43 & 98 & 65 & 38 & 11 & & 50 & & & & & 7 & & & & 3.461 \\
\hline 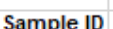 & K & & c & & Err & & & & & & & & & & & & & & & & & & & & & & & \\
\hline & & & & & & & & & ${ }^{\circ} \mathrm{C}$ & ${ }^{\circ}{ }^{\circ} \mathrm{C}$ & ${ }^{\circ} \mathrm{C}$ & & ${ }^{\circ} \mathrm{C}$ & & & ${ }^{\circ} \mathrm{C}$ & & & & & & & & & & & & \\
\hline & 0.5 & 1680 & 3660 & 3 & 0,0032 & 15.39 & & & 6.89 & 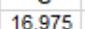 & 17.051 & & & & & & & & & & & & & & & & & \\
\hline & & & & & & & & & & & & & & & & & & & & & & & & & & & & \\
\hline & & & & & 024 & & & & & & & & & & & & & & & & & & & & & & & \\
\hline & & & & & 026 & & & & & & & & & & & & & & & & & & & & & & & \\
\hline & & & & & 028 & & & & & & 17 & & & & & & & & & & & & & & & & & \\
\hline & & & & & & & & & & & & & & & & & & & & & & & & & & & & \\
\hline & & & & & & & & & & & & & & & & & & & & & & & & & & & & \\
\hline & & & & & & & & & & & & & & & & & & & & & & & & & & & & \\
\hline & & & & & & & & & & & & & & & & & & & & & & & & & & & & \\
\hline & & & & & & & & & & & & & & & & & & & & & & & & & & & & \\
\hline & & & & & ( & & & & & & & & & & & & & & & & & & & & & & & \\
\hline & & & & & & & & & & & & & & & & & & & & & & & & & & & & \\
\hline & & & & & & & & & & & & & & & & & & & & & & & & & & & & \\
\hline & & & & & 0 & & & & & & & & & & & & & & & & & & & & & & & \\
\hline DB1491 & 143 & & 2.000 & 21 & 0.0063 & 86 & 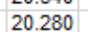 & & 4 & & 5 & & 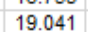 & & 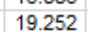 & & & & & & & & & & & & & 68 \\
\hline & & & & & & & & & & & & & & & & & & & & & & & & & & & & \\
\hline & w & & $c$ & & & & & & & 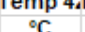 & ${ }_{0}^{\circ}$ & & . & & & & & & & & & & & & & & & \\
\hline & w & & & & & & & & & & & & 17. & & & & & & & & & & & & & & & \\
\hline & & & & & & & & & & & & & & & & & & & & & & & & & & & & \\
\hline & & & & & & & & & & & & & & & & & & & & & & & & & & & & \\
\hline & & & & & & & & & & & & & & & & & & & & & & & & & & & & \\
\hline & & & & & & & & & & & & & & & & & & & & & & & & & & & & \\
\hline & & & & & & & 20. & & & & & & & & & & & & & & & & & & & & & \\
\hline & & & & & & & & & & & & & & & & & & & & & & & & & & & & \\
\hline & & & & & & & & & & & & & & & & & & & & & & & & & & & & \\
\hline & & & & & & & & & & & & & & & & & & & & & & & & & & & & \\
\hline & & & & & & & & & & & & & & & & & & & & & & & & & & & & \\
\hline & & & & & & & & & & & & & & & & & & & & & & & & & & & & \\
\hline & & & 27 & & 8 & 15. & 20 & 0.1 & & & 6 & & 15. & & 15 & & & & & & & & & & & 665 & 51 & \\
\hline & & & & & & & & & & & & & & & & & & & & & & & & & & & & \\
\hline & 0.5 & & 3.8 & & 0.00 & & & & & & & & & & & & & & & & & & & & & & & \\
\hline & 0.4 & 2.2 & 2.000 & 221 & 0063 & 5.86 & & & 285 & & 7 & & 8.986 & 8.921 & 860 & & .750 & & & 8.610 & 8.570 & 18.5 & 8.497 & $8.4 \mathrm{H}$ & 8.434 & 405 & 8.378 & 8.353 \\
\hline
\end{tabular}




\section{Grain size results}

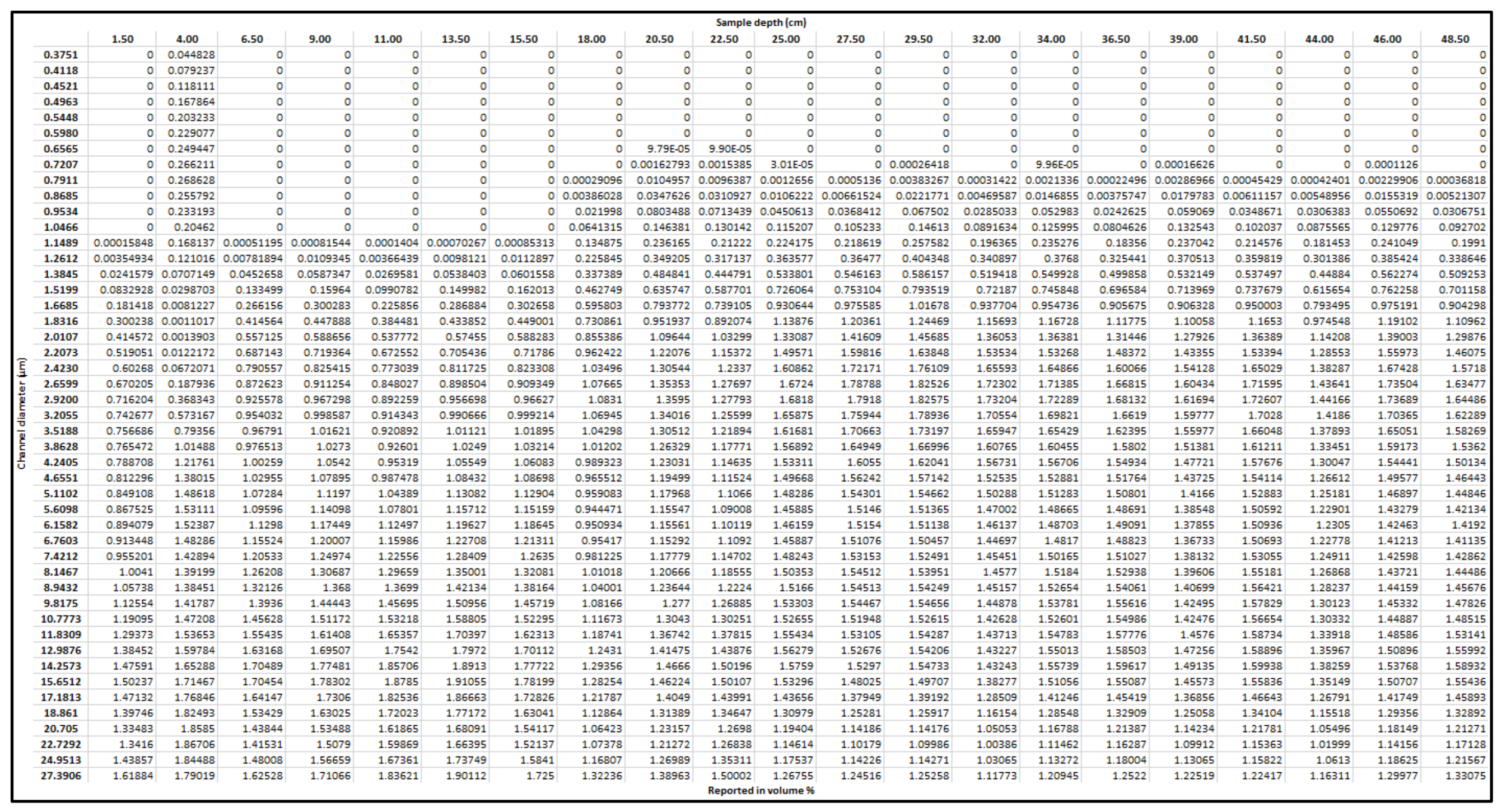




\begin{tabular}{|c|c|c|c|c|c|c|c|c|c|c|c|c|c|c|c|c|c|c|c|c|c|c|}
\hline \multicolumn{23}{|c|}{ Sample depth $(\mathrm{cm})$} \\
\hline & & 1.50 & 4.00 & 6.50 & 9.00 & 11.00 & 13.50 & 15.50 & 18.00 & 20.50 & 22.50 & 25.00 & 27.50 & 29.50 & 32.00 & 34.00 & 36.50 & 39.00 & 41.50 & 44.00 & 46.00 & 48.50 \\
\hline & 30.0685 & 1.81757 & 1.73579 & 1.78448 & 1.8734 & 2.00752 & 2.07763 & 1.87571 & 1.47706 & 1.51667 & 1.6448 & 1.36841 & 1.35653 & 1.37059 & 1.21654 & 1.2937 & 1.3272 & 1.32958 & 1.30273 & 1.27386 & 1.42444 & 1.4562 \\
\hline & 33.0081 & 1.98412 & 1.69362 & 1.9136 & 2.00914 & 2.12475 & 2.21192 & 1.99385 & 1.58764 & 1.60914 & 1.73943 & 1.4378 & 1.43519 & 1.44811 & 1.28998 & 1.34942 & 1.3722 & 1.40385 & 1.3582 & 1.35267 & 1.5143 & 1.54589 \\
\hline & 36.2352 & 2.05223 & 1.69261 & 1.95604 & 2.05348 & 2.12225 & 2.23261 & 2.02178 & 1.61187 & 1.61983 & 1.73834 & 1.43548 & 1.44266 & 1.44348 & 1.30124 & 1.34115 & 1.355 & 1.40759 & 1.35136 & 1.36008 & 1.52547 & 1.55474 \\
\hline & 39.7777 & 2.04564 & 1.7281 & 1.94543 & 2.03013 & 2.02226 & 2.1627 & 1.99044 & 1.59045 & 1.5788 & 1.68313 & 1.39549 & 1.41639 & 1.39001 & 1.28027 & 1.30189 & 1.3106 & 1.37114 & 1.30976 & 1.32904 & 1.49242 & 1.51723 \\
\hline & 43.6665 & 1.98012 & 1.7766 & 1.90411 & 1.9578 & 1.85507 & 2.02964 & 1.92131 & 1.54316 & 1.5017 & 1.59529 & 1.34003 & 1.3788 & 1.31521 & 1.2448 & 1.25254 & 1.25905 & 1.3158 & 1.25157 & 1.28089 & 1.43885 & 1.45846 \\
\hline & 47.9356 & 1.91478 & 1.81027 & 1.89051 & 1.89383 & 1.6857 & 1.89988 & 1.86986 & 1.52538 & 1.43923 & 1.53045 & 1.32224 & 1.38405 & 1.27349 & 1.23963 & 1.2407 & 1.24454 & 1.29053 & 1.22319 & 1.26736 & 1.41896 & 1.43347 \\
\hline & 52.6220 & 1.88196 & 1.78978 & 1.92574 & 1.86739 & 1.55515 & 1.81395 & 1.8602 & 1.56015 & 1.41956 & 1.51569 & 1.36393 & 1.45054 & 1.28699 & 1.27953 & 1.28315 & 1.28116 & 1.31439 & 1.24454 & 1.30912 & 1.45263 & 1.46327 \\
\hline & 57.7666 & 1.87699 & 1.70509 & 1.98926 & 1.86921 & 1.4666 & 1.77001 & 1.87722 & 1.63525 & 1.43819 & 1.5408 & 1.45256 & 1.56101 & 1.34191 & 1.34895 & 1.3648 & 1.35319 & 1.3734 & 1.30497 & 1.3927 & 1.523 & 1.53151 \\
\hline & 63.4141 & 1.90734 & 1.56029 & 2.06438 & 1.89544 & 1.42684 & 1.76721 & 1.91457 & 1.7615 & 1.51708 & 1.63036 & 1.58452 & 1.70471 & 1.43113 & 1.44338 & 1.4788 & 1.45706 & 1.4626 & 1.4043 & 1.51458 & 1.62281 & 1.63058 \\
\hline & 69.6138 & 1.9288 & 1.37917 & 2.0888 & 1.89527 & 1.39727 & 1.75491 & 1.92182 & 1.89567 & 1.62627 & 1.75564 & 1.70682 & 1.8221 & 1.50528 & 1.52004 & 1.57597 & 1.5495 & 1.53583 & 1.49985 & 1.62466 & 1.70107 & 1.70916 \\
\hline & 76.4196 & 1.94313 & 1.20484 & 2.0544 & 1.86305 & 1.37125 & 1.72103 & 1.89844 & 2.04962 & 1.78571 & 1.94877 & 1.81224 & 1.90227 & 1.55865 & 1.5825 & 1.65219 & 1.63216 & 1.59241 & 1.59103 & 1.72068 & 1.75725 & 1.76611 \\
\hline & 83.8907 & 1.93724 & 1.07066 & 1.95415 & 1.7877 & 1.33177 & 1.64848 & 1.83837 & 2.21 & 1.98753 & 2.2116 & 1.88059 & 1.9265 & 1.5799 & 1.62509 & 1.69415 & 1.69336 & 1.62382 & 1.66415 & 1.78995 & 1.78426 & 1.79387 \\
\hline & 92.0923 & 1.91908 & 1.0038 & 1.81357 & 1.68595 & 1.28102 & 1.54951 & 1.76076 & 2.37731 & 2.23102 & 2.54637 & 1.91585 & 1.9042 & 1.58014 & 1.65872 & 1.71008 & 1.73795 & 1.6421 & 1.72338 & 1.84222 & 1.7963 & 1.80662 \\
\hline & 101.096 & 1.90662 & 1.01115 & 1.67251 & 1.58893 & 1.23449 & 1.45284 & 1.69544 & 2.55449 & 2.51194 & 2.93999 & 1.93534 & 1.86109 & 1.58132 & 1.69811 & 1.71783 & 1.77699 & 1.66755 & 1.77966 & 1.89657 & 1.81424 & 1.82408 \\
\hline & 110.979 & 1.89533 & 1.08159 & 1.54871 & 1.50956 & 1.19616 & 1.37192 & 1.64971 & 2.7093 & 2.78443 & 3.31749 & 1.93856 & 1.80584 & 1.5856 & 1.73228 & 1.71592 & 1.80095 & 1.69769 & 1.82296 & 1.94757 & 1.83146 & 1.83791 \\
\hline & 121.829 & 1.90296 & 1.20649 & 1.47127 & 1.47647 & 1.18983 & 1.33249 & 1.64601 & 2.83947 & 3.02667 & 3.62388 & 1.95301 & 1.76978 & 1.61167 & 1.77032 & 1.72762 & 1.82642 & 1.75006 & 1.86733 & 2.01282 & 1.85755 & 1.85674 \\
\hline & 133.74 & 1.92862 & 1.36879 & 1.4442 & 1.49453 & 1.22611 & 1.33671 & 1.68161 & 2.9254 & 3.19493 & 3.78636 & 1.98985 & 1.76475 & 1.65674 & 1.81042 & 1.76367 & 1.85944 & 1.8246 & 1.91236 & 2.09194 & 1.88482 & 1.87257 \\
\hline & 146.815 & 1.98512 & 1.57005 & 1.47289 & 1.57067 & 1.32101 & 38791 & 1.75791 & 2.97895 & 3.27748 & 3.7861 & 2.06964 & 1.80595 & 1.72262 & 1.8715 & 1.84708 & 1.92204 & 1.93315 & 1.97309 & 2.19915 & 1.92045 & 1.8963 \\
\hline & 161.168 & 2.07107 & 1.80142 & 1.54614 & 1.69086 & 1.4725 & 1.47301 & 1.85754 & 3.00999 & 3.26555 & 3.62934 & 2.18846 & 1.88544 & 1.79258 & 1.96392 & 1.97998 & 2.01993 & 2.06964 & 2.04781 & 2.33077 & 1.9622 & 1.93048 \\
\hline \multirow{27}{*}{ 表 } & 176.925 & 2.16259 & 2.04043 & 1.63206 & 1.8168 & 1.65028 & 1.56138 & 1.94414 & 3.01506 & 3.14872 & 3.33238 & 2.30619 & 1.96329 & 1.83152 & 2.07414 & 2.12862 & 2.12842 & 2.20076 & 2.10935 & 2.45445 & 1.98862 & 1.95847 \\
\hline & 194.222 & 2.21857 & 2.23826 & 1.68707 & 1.89655 & 1.79892 & 1.61439 & 1.97505 & 2.978 & 2.91865 & 2.91222 & 2.35597 & 1.97942 & 1.80212 & 2.16107 & 2.22695 & 2.19587 & 2.2705 & 2.1136 & 2.51431 & 1.96249 & 1.94796 \\
\hline & 213.21 & 2.1862 & 2.33006 & 1.66317 & 1.87629 & 1.84963 & 1.59241 & 1.9105 & 2.86402 & 2.56796 & 2.37779 & 2.26103 & 1.8698 & 1.67372 & 2.15875 & 2.1918 & 2.15323 & 2.21177 & 2.00523 & 2.44279 & 1.83782 & 1.85138 \\
\hline & 234.054 & 2.04419 & 2.2788 & 1.5439 & 1.74144 & 1.76556 & 1.48757 & 1.7499 & 2.65668 & 2.12122 & 1.76113 & 1.99322 & 1.61823 & 1.45985 & 2.0232 & 1.98368 & 1.96539 & 1.99794 & 1.76759 & 2.21453 & 1.60277 & 1.65229 \\
\hline & 256.936 & 1.81985 & 2.09628 & 1.35683 & 1.52807 & 1.56855 & 1.3314 & 1.53483 & 2.37042 & 1.63879 & 1.13463 & 1.59824 & 1.27711 & 1.21864 & 1.76264 & 1.63938 & 1.65692 & 1.66735 & 1.44325 & 1.87003 & 1.29925 & 1.38699 \\
\hline & 282.056 & 1.58913 & 1.8537 & 1.16877 & 1.31413 & 1.34146 & 1.18822 & 1.33892 & 2.06116 & 1.21701 & 0.636216 & 1.19296 & 0.955988 & 1.02481 & 1.45298 & 1.27296 & 1.31714 & 1.32416 & 1.11884 & 1.51443 & 1.01977 & 1.13266 \\
\hline & 309.631 & 1.43422 & 1.64106 & 1.04818 & 1.17613 & 18113 & 12136 & 1.22938 & 1.79533 & 0.93023 & 0.355938 & 0.89729 & 0.752948 & 0.939828 & 1.19705 & 1.00751 & 1.04965 & 1.08031 & 0.890027 & 1.25757 & 851714 & 0.972563 \\
\hline & 339.902 & 1.40555 & 1.52413 & 1.03556 & 1.15609 & 1.15414 & 1.16789 & 1.24153 & 1.61892 & 0.806137 & 0.2842 & 0.769635 & 0.708061 & 0.980279 & 1.06998 & 0.910016 & 0.917553 & 1.00021 & 0.79863 & 1.16096 & 0.837551 & 0.941932 \\
\hline & 373.132 & 1.50377 & 1.51974 & 1.13362 & 1.25237 & 1.27869 & 1.32693 & 1.36917 & 1.53025 & 0.816862 & 0.370829 & 0.802719 & 0.809173 & 1.13042 & 1.0927 & 0.981958 & 0.925483 & 1.09061 & 0.843676 & 1.22432 & 0.972239 & 1.03353 \\
\hline & 409.611 & 1.67449 & 1.59328 & 1.30122 & 1.41536 & 51579 & 1.552 & 1.56286 & 1.47991 & 0.892126 & 0.559028 & 0.940327 & 0.995053 & 1.33565 & 1.23282 & 1.16778 & 1.02863 & 1.30222 & 0.986851 & .38913 & 1.19978 & 1.19496 \\
\hline & 449.657 & 1.82129 & 1.67484 & 1.46314 & 1.55992 & 1.77104 & 75807 & 1.73973 & 1.39002 & 0.93235 & 0.728031 & 1.0809 & 1.15378 & 1.51042 & 1.40905 & 1.35617 & 1.14281 & 1.52859 & 1.14976 & 1.54876 & 1.41177 & 1.33182 \\
\hline & 493.617 & 1.84524 & 1.69155 & 1.53511 & 1.59485 & 1.91766 & 85327 & 1.81567 & 1.18864 & 0.845955 & 0.731957 & 1.11061 & 1.17169 & 1.58322 & 1.51438 & 1.41828 & 1.17713 & 1.63686 & 1.2531 & 1.58629 & 1.49119 & 1.35954 \\
\hline & 541.876 & 1.70868 & 1.61151 & 1.4819 & 1.48111 & 1.87848 & 1.78969 & 1.74696 & 0.859914 & 0.614147 & 0.51095 & 0.978365 & 1.01894 & 1.54774 & 1.47376 & 1.29087 & 1.08961 & 1.54888 & 1.27822 & 1.44642 & 1.38371 & 1.27862 \\
\hline & 594.852 & 1.46414 & 1.46452 & 1.34222 & 1.25774 & 67729 & 58899 & 1.54846 & 0.463789 & 0.321149 & 0.230343 & 0.733517 & 0.774837 & 41881 & 1.28874 & 1.01778 & 0.918363 & 1.287 & .22946 & 1.1713 & .12728 & 1.12225 \\
\hline & 653.008 & 1.21743 & 1.3149 & 1.19888 & 01362 & 1.42097 & 32515 & 1.27505 & 0.164812 & 0.104825 & 0.0488439 & 0.491695 & 0.569952 & 1.24938 & 1.03228 & 0.721997 & 747577 & 0.960992 & 1.15386 & .868765 & 823905 & 0.968725 \\
\hline & 716.849 & 1.05937 & 1.21587 & 1.1294 & 0.831718 & 1.2336 & 1.07942 & 0.984332 & 0.0288907 & 0.0168787 & 0.0042496 & 0.339278 & 0.48559 & 1.04774 & 0.796391 & 0.513446 & 0.642456 & 0.691704 & 1.03913 & 0.638555 & 0.566091 & 0.82873 \\
\hline & 786.932 & 1.02579 & 1.17097 & 1.18231 & 0.770293 & 1.20672 & 0.907309 & 0.714865 & 0.00192249 & 0.00088051 & 0 & 0.292304 & 0.537333 & 0.714783 & 0.634563 & 0.428001 & 0.613747 & 0.543359 & 0.754908 & 0.527658 & 0.394899 & 0.593018 \\
\hline & 863.866 & 1.07407 & 1.13213 & 1.32356 & 0.810955 & 1.32667 & 0.802598 & 0.476985 & 0 & 0 & 0 & 0.3167 & 0.683183 & 0.356287 & 0.545927 & 0.438035 & 0.621147 & 0.504908 & 0.39597 & 0.511609 & 0.29137 & 0.315686 \\
\hline & 948.322 & 1.12029 & .02655 & 1.47791 & 0.916 & 1.525 & 34297 & 58701 & 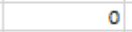 & 0 & 0 & 0.286786 & 654962 & 0.0837359 & 402192 & 0.382616 & 8228 & 0.414869 & 0961357 & 544241 & 0.190814 & 0.0779741 \\
\hline & 1041.03 & 1.05508 & 0.799877 & 1.50376 & 17 & 62387 & 49661 & .00157 & 0 & 0 & 0 & 0.1772 & 0.411464 & 0.00895281 & 0.218444 & 0.23506 & 0.275764 & 0.248626 & 0.0106299 & 0.551682 & 0.0933378 & 0.0089 \\
\hline & 1142.81 & 0.746247 & 0.465851 & 1.14569 & 0.798001 & 1.28621 & 0.454519 & 0.0194996 & 0 & 0 & 0 & 0.0464339 & 0.108189 & 0 & 0.0537452 & 0.0617041 & 0.0676021 & 0.0651069 & 0 & 0.421882 & 0.02172 & 0 \\
\hline & 1254.54 & 0.359082 & 0.178731 & 0.595681 & 0.441977 & 0.687835 & 0.224485 & 0.00157279 & 0 & 0 & 0 & 0.0052018 & 0.0121819 & $a^{2}+2$ & 0.0058473 & 0.0070162 & 0.00716652 & 0.00741965 & $\theta^{2}+2$ & 0.220185 & 0.00218099 & 9 \\
\hline & 1377.19 & 0.0804022 & 0.033439 & 41113 & 0.109323 & 0.165794 & 0516426 & 0 & 0 & 0 & 0 & $a^{2}+2$ & 0 & 0 & $a^{2}+$ & 0 & 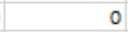 & 0 & 0 & 1836 & ; & D \\
\hline & 1511.83 & 0.00773212 & 0.0024182 & 0.0146408 & 0.0120689 & 0.0174405 & 0052482 & 0 & 0 & 0 & 0 & 0 & 0 & 0 & 0 & 0 & 0 & 0 & 0 & 0.00545132 & 0 & \\
\hline & 1659.63 & 0 & 0 & 0 & 0 & 0 & 0 & 0 & 0 & 0 & 0 & 0 & $a^{2}+$ & 0 & 0 & 0 & 0 & 0 & 0 & 0 & 0 & D \\
\hline & 1821.88 & 0 & 0 & 0 & 0 & 0 & 0 & 0 & 0 & 0 & 0 & 0 & 0 & 0 & 0 & 0 & 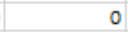 & 0 & 0 & 0 & $a^{2}+2$ & ) \\
\hline & 2000 & 0 & 0 & 0 & 0 & 0 & 0 & 0 & 0 & 0 & 0 & 0 & 0 & 0 & 0 & 0 & 0 & 0 & 0 & 0 & 0 & 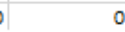 \\
\hline
\end{tabular}




\section{X-ray fluorescence results}

Standards tested prior to testing KIS-GZ samples + KIS-GZ tests for reproducibility

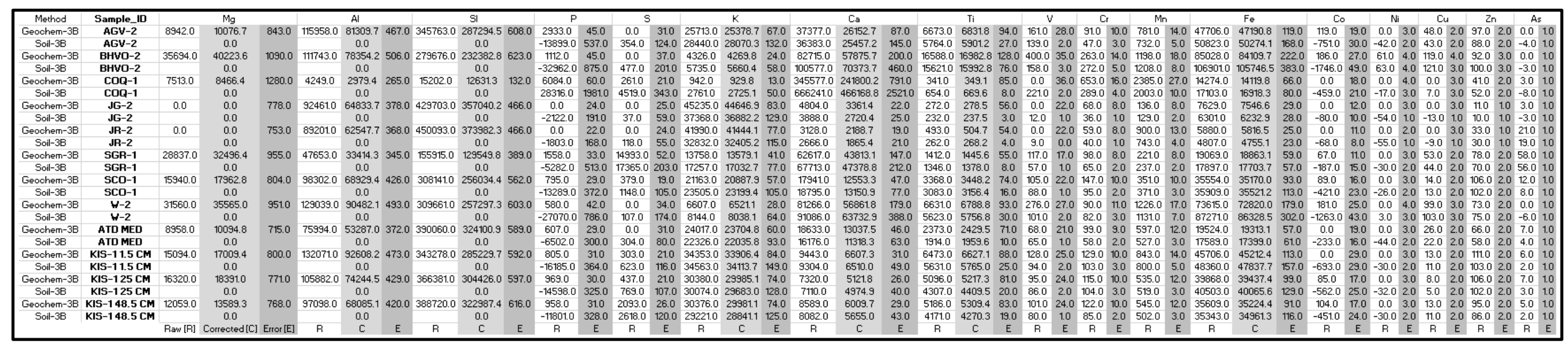

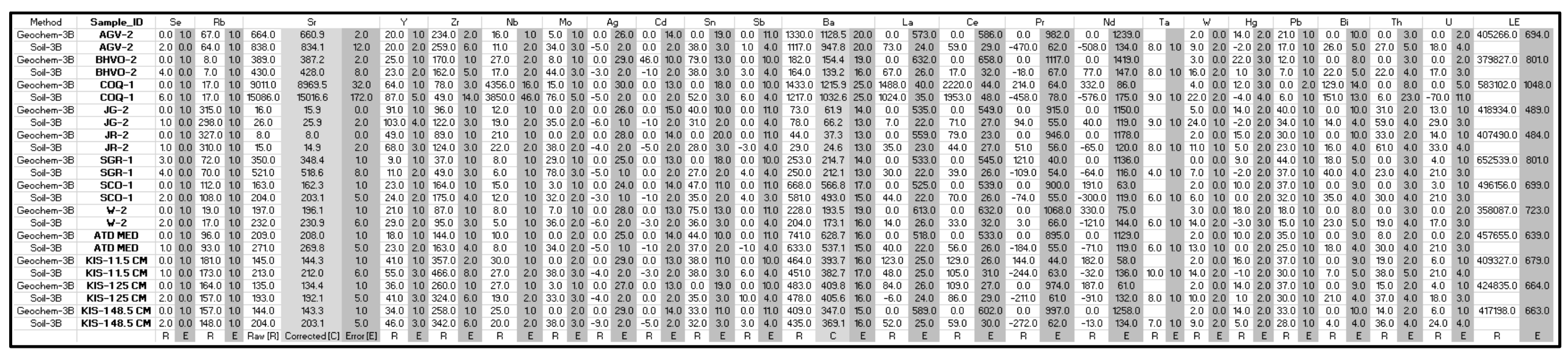




\section{KIS-GZ samples for analysis (part one)}

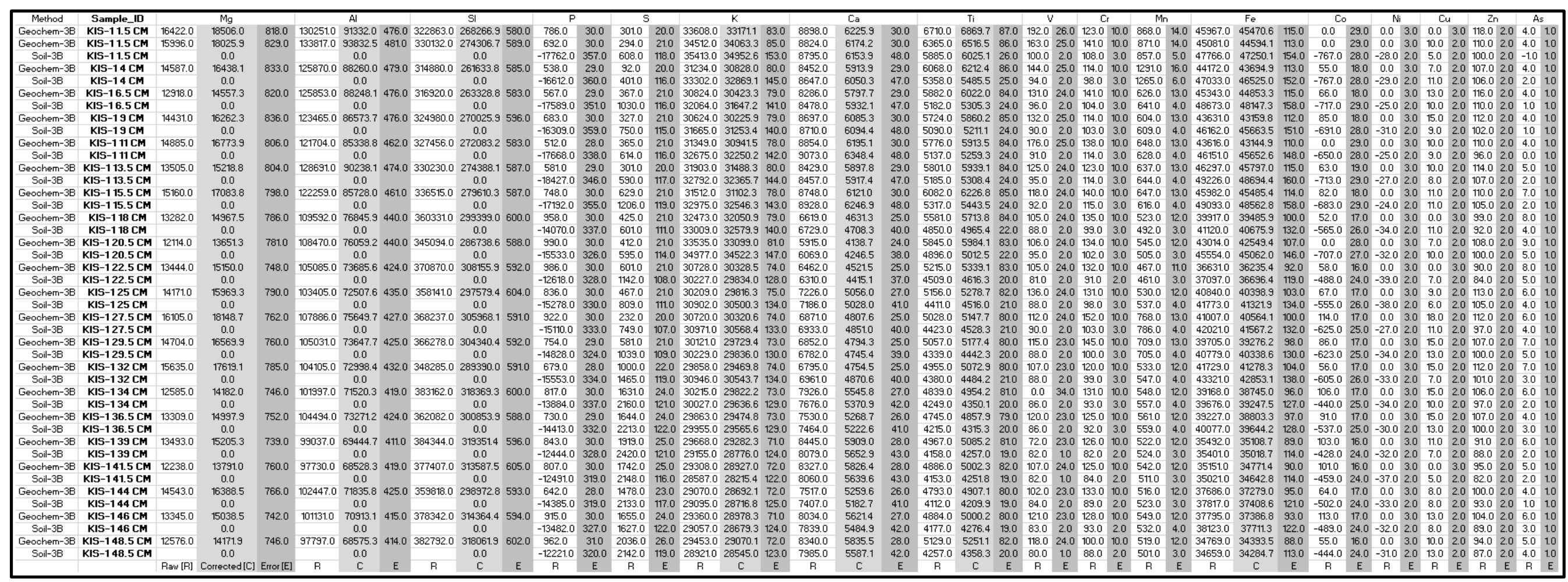




\section{KIS-GZ samples for analysis (part two)}

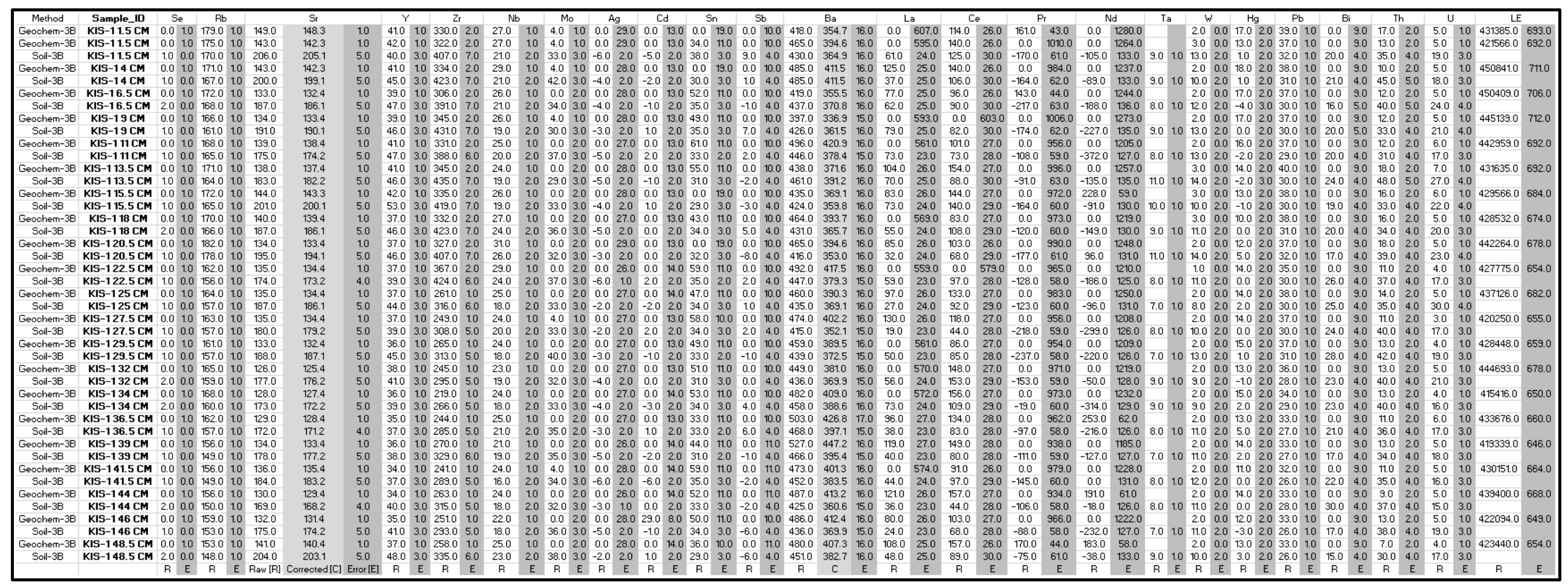




\section{Standards tested after testing KIS-GZ samples}

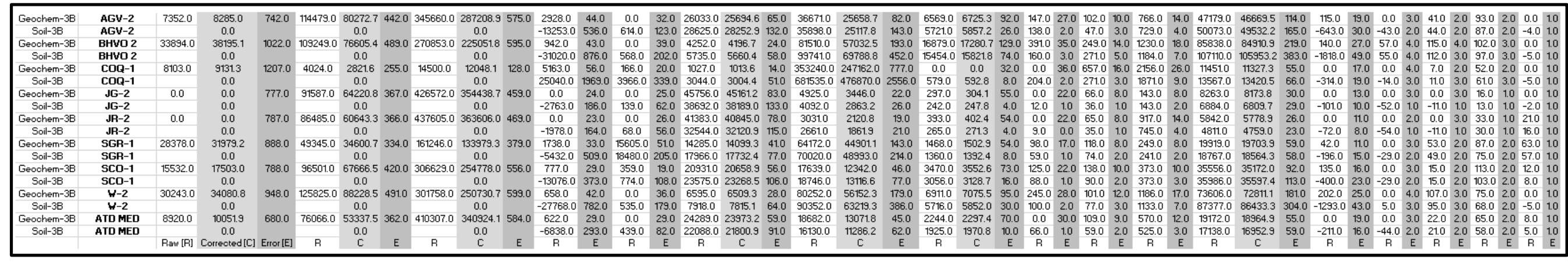

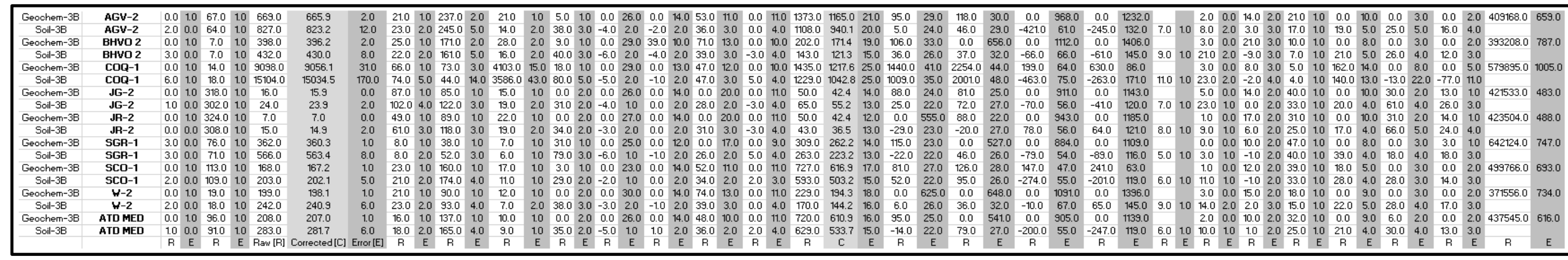

